\title{
AVALIAÇÃO DA RESISTÊNCIA FLEXIONAL, DO MÓDULO DE ELASTICIDADE E DO TIPO DE FRATURA DE UMA RESINA ACRÍLICA PARA RESTAURAÇÕES PROVISÓRIAS \\ - EFEITO DE DIVERSOS REFORÇOS
}

Dissertação apresentada à Faculdade de Odontologia de Bauru da Universidade de São Paulo, como parte dos requisitos para a obtenção do título de Mestre em Odontologia

- Área de Reabilitação Oral.

(Edição Revisada)

BAURU - SP 


\section{AVALIAÇÃO DA RESISTÊNCIA FLEXIONAL, DO MÓDULO DE ELASTICIDADE E DO TIPO DE FRATURA DE UMA RESINA ACRÍLICA PARA RESTAURAÇÕES PROVISÓRIAS \\ - EFEITO DE DIVERSOS REFORÇOS}

Dissertação apresentada à Faculdade de Odontologia de Bauru da Universidade de São Paulo, como parte dos requisitos para a obtenção do título de Mestre em Odontologia

- Área de Reabilitação Oral.

(Edição Revisada)

Orientador: Prof. Dr. Paulo Martins Ferreira

BAURU - SP

2003 


\section{LUIZ GUSTAVO CAVALCANTI BASTOS}

19 de janeiro de $1976 \quad$ Nascimento

Salvador -BA

Filiação

Eduardo José da Silva Bastos

Terezinha Cavalcanti Bastos

$1995-2000$

Curso de Odontologia - Faculdade de Odontologia da Universidade Federal da Bahia.

$2000-2001$

Professor Substituto do Departamento de Odontologia Restauradora da Faculdade de 7Odontologia da Universidade Federal da Bahia.

$2001-2003$

Curso de Pós-Graduação em Reabilitação Oral em nível de Mestrado, na Faculdade de Odontologia de Bauru-USP.

Associações

ABO - Associação Brasileira de Odontologia Secção Bahia

SBPqO - Sociedade Brasileira de Pesquisa Odontológica 


\section{Dedicatória}

A Deus, permanente luz do meu caminho.

Aos meus pais, Eduardo e Teresinha, exemplos de carinho e renúncia a favor dos filhos, que foram e ainda o são peça chave de minha formação. Acreditaram, contribuíram e compartilharam com a idealização de meus sonhos, sem permitir que nada me faltasse.

Aos meus irmãos, Dudu e Carol, companheiros de perseverança e busca por realizações pessoais. O fato de serem meus irmãos já basta para os meus motivos de orgulho e alegria.

Aos meus tios Abilio e Regina, à minha prima Nana e à minha avó Adélia. A presença de vocês foi constante em meus pensamentos. A disponibilidade e o afeto de vocês por mim, meus irmãos e meus pais, me alimenta de um sentimento de gratidão imensurável.

Fazemos juntos, parte de um todo, e é a vocês que dedico este trabalho. 
"Devo ser tão firme e resoluto quanto me for possivel em meus atos (...) seguir como os viajantes que, quando se vêem perdidos numa floresta, não devem ficar errando de um lado para outro, nem ficar, tampouco, no mesmo lugar, e sim andar em direção tão reta quanto possivel, acompanhando o mesmo rumo, sem jamais desviar-se, por motivos fúteis, da direção tomada."

René Descartes 


\section{Agradecimento Especial}

Ao Prof. Dr. Paulo Martins Ferreira, um entusiasta nato, que soube reger com sabedoria e discernimento o seu orientado. A honestidade com que sempre me conduziu a palavra, aliada à extrema disponibilidade, tornaram a execução deste trabalho limpa e sem enganos. Meu aprendizado se estendeu a valores outros que a pura ciência. Agradeço com veemência a sua orientação e amizade. 


\section{Agradecimento Especial}

Aos amigos Rafa, Jeff e Renato, por amenizarem o fenômeno "saudade de casa". Conviver com vocês é um exercício afável de vida. A vocês, minha profunda gratidão e amizade.

À família Martins Ferreira, Mariane, Felipão e Gabriel, pela acolhida, amizade e carinho que recebi de vocês. Meus sinceros agradecimentos.

À minha família em Petrolina-PE, pela referência de uma vida simples e consistente. 


\section{Agradecimentos}

Ao Prof.Dr.José Henrique Rubo, pela transmissão de conhecimentos e convivio. Pelo exemplo que é de uma pessoa serena e disciplinada.

Ao Prof.Dr.Luiz Fernando Pegoraro, exemplo de sensatez, pela condução de seus ensinamentos e princípios. Ao Prof.Dr.Accácio Lins do Valle e ao Prof.Dr. Gerson Bonfante, coordenador do curso de mestrado em Reabilitação

Oral, pela disponibilidade e valiosas orientações.

Ao Prof.Dr. Paulo César Rodrigues Conti e ao Prof. Dr.

Carlos Araújo, pela forma empolgante com que conduzem seus conhecimentos.

Ao Prof.Dr. Wellington Bonachella, pelas orientações sempre pertinentes e em defesa de nosso desenvolvimento.

Aos Professores do Departamento de Prótese, Salvador, Renato e Lucimar por tudo que me ensinaram, A todos, meu muito obrigado! 
Ao Prof.Dr. Vinicius Porto, orgulho da comunidade baiana, pela amizade, estima e exemplo.

À Stellinha Mendes, pela amizade e tempo despendido juntos na degustação, aos finais de semana, da culinária nordestina. Pela sempre disposição em ajudar um baiano longe de sua casa.

Aos colegas de mestrado Luciana, Tatiany, Oswaldo, Paulo, Mauro, Mariana e Leylha, pela companhia quase diária, pela amizade e permuta cultural e científica.

Aos colegas de Doutorado, Barnabé, Carlinhos, Nelsinho, Stefânia e Anuar, em especial ao Juliano e ao Rudys, pelas circunstâncias compartilhadas e ajuda constante.

Ao Celso, Léo, Diego, Fernanda, Marinelle pela amizade $e$ pelos momentos compartilhados extra-faculdade. 
A todos os colegas de mestrado, pelos momentos felizes que compartilhamos.

À Dani Diniz e familia, pelo apoio despendido durante boa parte do tempo de execução deste projeto.

Aos ex-estagiários, e hoje colegas de mestrado, Jonas, Érico, Estevan, Samara, Lucas, Valdey e Evelyn, pela disponibilidade em sempre nos auxiliar e pelo convivio.

À Thania, sempre solicita, pela amizade e bom-humor contagiante.

Aos funcionários do Departamento, Edna, Cláudia, Débora, Riva, Marcelo, Luzia e Valquiria, pelo profissionalismo e gentileza em todos os momentos.

Ao Prof. Dr. José Roberto Pereira Lauris, pela paciência em instruir a análise estatística deste trabalho. 
Aos amigos Gildo e Jace, grandes incentivadores de minha vida profissional, obrigado por despertarem em mim a consciência da vida acadêmica

À amiga professora Cicely, por me conduzir com sua sempre boa vontade à carreira docente. Seus ensinamentos serão eternos.

Aos amigos Adriana e Vagner Mendes, pelo tempo compartilhado junto nos afazeres domésticos, nas refeições e nas horas de trabalho, hoje, eu que agradeço pela sua companhia enquanto esteve aqui.

Aos amigos da Bahia, Léo Cruz, André Pinheiro, Ana Telles, Fred Penalva, Eugênio Leite, Jorge Pain, Ianderley, Denise e Daniela Higashi, Kátia Aleluia, Lyz Cerqueira, Marcos D’Oliveira, Juliana Azevedo, Safira Andrade. É sempre bom revê-los.

Aos amigos Vitor e Larissa, pelos reencontros agradáveis $e$ “amparo” nas idas a São Paulo. 
À Juliana e Renata, pela ajuda e sempre disponibilidade.

Aos funcionários da Pós-Graduação da FOB, pela atenção e sempre disponibilidade, em particular a Ana, Cleuza, Aurélio e

\section{Giane.}

Aos Professores e Funcionários do Departamento de Materiais Dentários, em particular à Sandra, por disponibilizar o laboratório para execução deste trabalho.

Aos funcionários da biblioteca pela solicitude e profissionalismo.

À Faculdade de Odontologia de Bauru - USP, representada por sua Diretora Profa.Dra. Maria Fidela de Lima Navarro, e à sua Comissão de Pós-Graduação, representada pelo Prof.Dr. José Carlos Pereira. 
Ao $\mathbf{C N p Q}$, pelo apoio financeiro tornando exeqüivel este trabalho.

A todas as pessoas que de algumas maneira, direta ou indiretamente, contribuiram com esta conquista.

Meus sinceros agradecimentos. 


\section{SUMÁRIO}

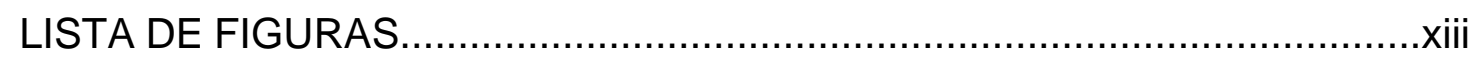

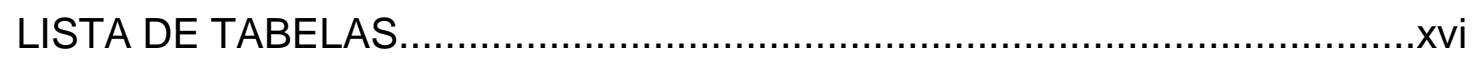

LISTA DE ABREVIATURAS E SÍMBOLOS ............................................viii

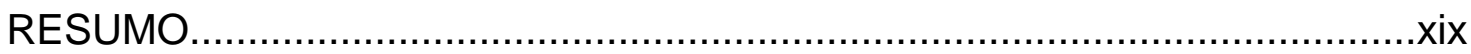

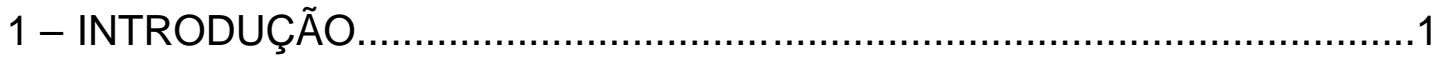



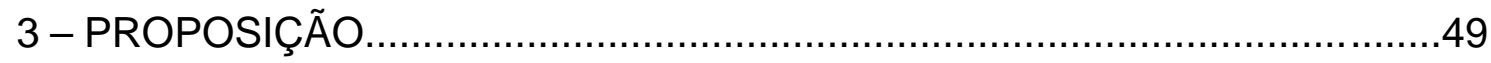



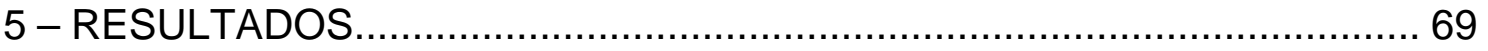

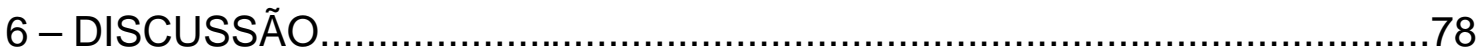

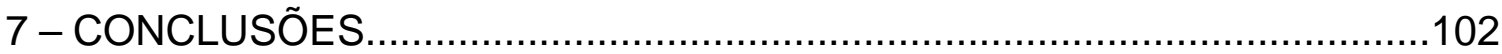

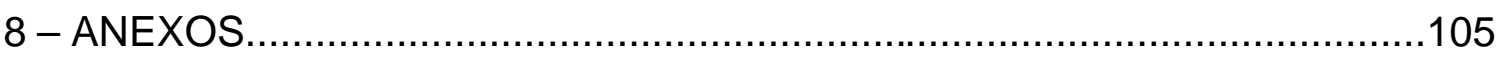

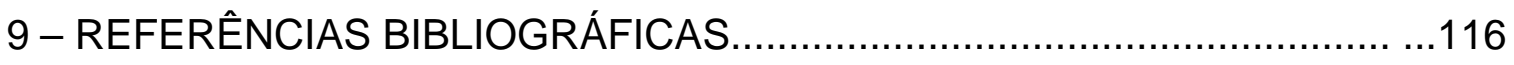

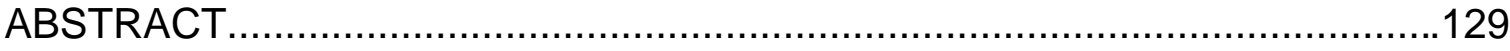




\section{LISTA DE FIGURAS}

FIGURA 1: llustração da matriz metálica para confecção dos corpos de prova com a localização dos guias 53

FIGURA 2: Detalhe do relacionamento dos guias quando a matriz se encontra fechada, evidenciando suas dimensões .53

FIGURA 3: Secção transversal da matriz quando fechada, mostrando o posicionamento dos guias.

FIGURA 4: Secção transversal mostrando os espaços formados pelos guias quando a matriz se encontra fechada. Um espaço de $0,4 \mathrm{~mm}$ foi mantido para apreensão das fibras, enquanto que o espaço na forma de uma circunferência de $0,8 \mathrm{~mm}$ de diâmetro foi desejado para a fixação do fio de aço 0,7 e do fio de amarrilho trançado

FIGURA 5: llustração das três partes, sendo uma posicionada centralmente às outras duas, da matriz metálica para a confecção dos espécimes em resina, com e sem reforço. 55

FIGURA 6: Vista lateral das três partes desarticuladas da matriz metálica utilizada para a confecção dos espécimes, com e sem reforço 55

FIGURA 7: Metade da matriz preenchida com resina. 60

FIGURA 8: Metade da matriz preenchida com resina e reforço metálico posicionado sobre os guias. 60 
FIGURA 9: Metade da matriz preenchida com resina e um exemplar de fibra posicionado sobre os guias. 60

FIGURA 10: Matriz totalmente preenchida com resina. No grupo controle, os espécimes foram diretamente preenchidos desta maneira, sem a necessidade de vazar inicialmente a primeira metade da matriz 60

FIGURA 11: Pequena prensa mantendo a matriz fechada 60

FIGURA 12: Remoção dos espécimes do interior da parte central da matriz. 60

FIGURA 13: llustração do espécime contendo no seu interior um reforço em forma de fita. 61

FIGURA 14: llustração do espécime reforçado com fio metálico. 61

FIGURA 15: Detalhe da fibra de vidro unidirecional Fibrante ${ }^{\circledR}$ 62

FIGURA 16: Detalhe da fibra de poli(etileno) trançada Connect ${ }^{\circledR}$. 62

FIGURA 17: Detalhe da fibra de vidro trançada Interlig ${ }^{\circledR}$ 62

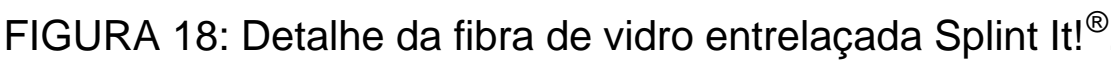
62

FIGURA 19: Detalhe da fibra cerâmica flexível trançada GlasSpan. 62

FIGURA 20: Ilustração do teste de carga de três pontos e medidas das hastes e distância do vão estabelecida pela norma ISO 10477 63 
FIGURA 21: Ensaio de flexão através do teste de carga de três pontos com auxílio de artefato metálico confeccionado seguindo a norma ISO 10477 .64

FIGURA 22:Espécime de resina defletido em função do ensaio de flexão. Observação da posição da vareta central induzindo uma carga no meio do espécime, eqüidistante das duas hastes de apoio 64

FIGURA 23: Representação gráfica dos valores médios, em $\mathrm{MPa}$, da Resistência Flexional para cada grupo. Grupos unidos por barras horizontais não apresentam diferenças estatisticamente significantes....71

FIGURA 24: Representação gráfica dos valores médios, em $\mathrm{MPa}$, do Módulo de Elasticidade para cada grupo. Grupos unidos por barras horizontais não apresentam diferenças estatisticamente significantes....74

FIGURA 25: Fratura ausente .76



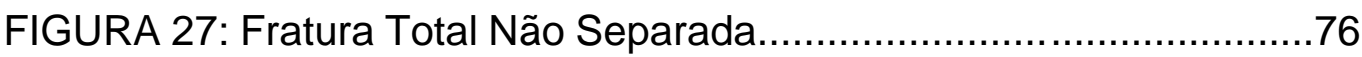

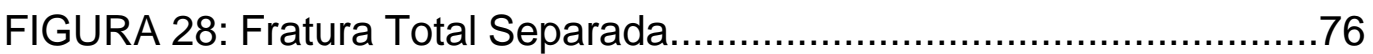




\section{LISTA DE TABELAS}

TABELA 1: Informação dos grupos e descrição dos reforços utilizados..59

TABELA 2: Classificação das fraturas sofridas pelos espécimes .67

TABELA 3: Valores individuais de cada espécime, desvio padrão (D.P.) e médias da Resistência Flexional, em MPa, de cada grupo. 70

TABELA 4: Análise de variância (ANOVA) dos resultados da resistência flexional dos espécimes

TABELA 5: Comparações individuais obtidas através do Teste de Tukey, com nível de significância de 5,0 \% .72

TABELA 6: Valores individuais de cada espécime (Esp.), desvio padrão (D.P.) e médias do módulo de elasticidade (Méd.), em MPa, de cada grupo (Grup.). .73

TABELA 7: Análise de variância (ANOVA) dos resultados do módulo de elasticidade dos espécimes. .74

TABELA 8: Comparações individuais obtidas através do Teste de Tukey, com nível de significância de 5,0 \% .75

TABELA 9: Ocorrência, em porcentagem (\%), dos tipos de fratura em cada grupo 
TABELA 10: Resumo dos resultados da resistência flexional e do módulo de elasticidade, em função do tipo da resina e do reforço utilizado, obtido

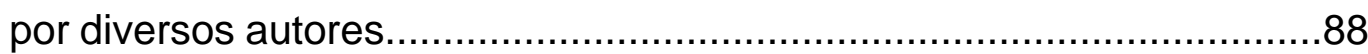




\section{LISTA DE ABREVIATURAS E SÍMBOLOS}

$\begin{array}{ll}{ }^{\circ} \mathrm{C} & \text { Graus Celsius } \\ \mathrm{Kgf} & \text { Quilograma força } \\ \mathrm{N} & \text { Newton } \\ \mathrm{MPa} & \text { Megapascal } \\ \text { ìm } & \text { Micrômetro } \\ p & \text { Nível de significância } \\ \mathrm{mm} & \text { Milímetro } \\ \mathrm{mm} / \mathrm{min} . & \text { Milímetro por minuto } \\ \% & \text { Por Cento } \\ \text { Bis-GMA } & \text { Resina bis glicol metacrilato } \\ \text { EMA } & \text { Monômero etilmetacrilato } \\ \text { MMA } & \text { Monômero metilmetacrilato } \\ \text { PEMA } & \text { Poli(etilmetacrilato) } \\ \text { PMMA } & \text { Poli(metilmetacrilato) } \\ \text { PVMA } & \text { Poli(vinilmetacrilato) } \\ \text { PVEMA } & \text { Poli(etilvinilmetacrilato) } \\ \text { UDMA } & \text { Uretano dimetacrilato }\end{array}$




\section{RESUMO}

A importância das restaurações provisórias no tratamento reabilitador oral é inquestionável. Os materiais utilizados para a execução destas restaurações, entretanto, são críticos com relação à resistência e longevidade, principalmente, quando estas são executadas em tratamentos prolongados e/ou em espaços desdentados extensos. A proposta deste trabalho foi determinar o efeito de diversos reforços sobre a resistência flexional, o módulo de elasticidade e o tipo de fratura apresentados por espécimes confeccionados em uma resina poli(metilmetacrilato) (PMMA), quando submetidos a um teste de carga de três pontos. Sete tipos de reforços constituíram os grupos experimentais com dez espécimes cada: um fio de aço com 0,7 mm de diâmetro; um fio de amarrilho trançado; uma fibra de vidro trançada Interlig ${ }^{\circledR}$ (Angelus $^{\circledR}$ ); uma fibra de vidro entrelaçada Splint-It! ${ }^{\circledR}$ (JenericPentron ${ }^{\circledR}$ ); uma fibra de vidro unidirecional Fibrante ${ }^{\circledR}$ (Angelus ${ }^{\circledR}$ ); uma fibra de poli(etileno) Connect $^{\circledR}\left(\right.$ Kerr $\left.^{\circledR}\right)$ e uma fibra cerâmica flexível GlasSpan ${ }^{\circledR}\left(\right.$ GlasSpan $\left.^{\circledR}\right)$. O grupo controle, também com dez amostras, foi composto de espécimes não reforçados. A confecção dos espécimes, o ensaio mecânico e cálculo da resistência flexional e do módulo de elasticidade foram realizados seguindo norma ISO 10477 modificada. A análise dos resultados (ANOVA, $p<0,05$ ), para ambas as propriedades, mostrou haver diferença estatística entre os grupos. O teste de Tukey encontrou que os grupos reforçados com fio de aço com $0,7 \mathrm{~mm}$; fibra Interlig $^{\circledR} \mathrm{e}$ fibra Connect $^{\circledR}$ aumentaram significantemente a resistência flexional, e que os 
grupos reforçados com fio de aço com 0,7 mm; fibra Interlig ${ }^{\circledR}$; fibra Splint-lt ${ }^{\circledR}$; fibra Connect $^{\circledR}$ e fibra GlasSpan ${ }^{\circledR}$, aumentaram o módulo de elasticidade, em relação ao grupo controle. A análise das fraturas concorreu com a elaboração de um novo sistema de classificação dividindo-as em quatro tipos: Ausente, Parcial, Total Não Separada e Total Separada. As fraturas dos espécimes reforçados foram consideradas mais favoráveis ocorrendo, predominantemente, os tipos Ausente e Parcial.

Palavras-chave: Resinas acrílicas, poli(metilmetacrilato), fibras para reforço 


\section{1 - INTRODUÇÃO}

O tratamento reabilitador oral necessita de uma fase provisória, freqüentemente, de longa duração ${ }^{17,50}$. Nesta fase são empregadas restaurações provisórias com a finalidade de proteger o complexo dentina-polpa dos dentes preparados; manter e avaliar os tecidos periodontais; evitar a movimentação dos dentes pilares; auxiliar na estabilização de dentes com mobilidade; fornecer uma estética adequada e promover conforto durante a função fonética e mastigatória ${ }^{17,24,25,26,28,31,36,41,42,46,62,72,73,74}$. O clínico deve, portanto, entender esta fase como sendo uma oportunidade de se elaborar um modelo e antever o sucesso da restauração definitiva ${ }^{25}$.

O uso das próteses provisórias durante períodos mais longos é justificado por ser a reabilitação oral um tratamento muitas vezes multidisciplinar consistindo de diversas etapas: preparo dental; procedimentos de impressão; registro e montagem maxilo-mandibular; fabricação laboratorial e prova da prótese definitiva ${ }^{26,73}$. Estas restaurações provisórias confeccionadas de forma direta ou indireta são empregadas, da mesma maneira, durante os tratamentos complementares, tais como, ortodônticos, endodônticos e periodontais e, por isso, podem ser exigidas por períodos mais prolongados, em alguns casos, por meses e até anos ${ }^{28,36,42,46}$. Em algumas circunstâncias, por exemplo, um plano de tratamento protético definitivo somente deve ser formulado após o completo tratamento periodontal que inclui desde terapias periodontais preliminares, consistindo de raspagem, curetagem, instrução e motivação em higiene oral até terapias cirúrgicas mais avançadas ${ }^{46}$. 
Quanto maior o período de tempo de utilização dessas restaurações, maior a durabilidade requerida. Próteses provisórias com resistência e adaptação marginal inadequadas podem levar a recidiva de cáries, sensibilidade dental, inflamação gengival, movimentação do dente preparado ${ }^{73}$, além de constantes fraturas. A falha da restauração provisória através da perda da integridade marginal e/ou fratura, logo, se traduz em um inconveniente clínico imensurável, podendo comprometer o êxito da prótese definitiva ${ }^{19,31,41,46,50,62}$.

A resina poli(metilmetacrilato) ${ }^{*}$ (PMMA) tem sido geralmente eleita para a confecção das restaurações provisórias. Quando estas são exigidas por um longo tempo e se estendem por vários dentes, com longos vãos, a resistência e a estabilidade das próteses realizadas com este material, entretanto, se tornam críticas $^{14,17,31,36,42,43,50,72}$.

A alta incidência de fraturas e a necessidade constante de reparos das próteses provisórias em resina PMMA têm impulsionado o desenvolvimento de materiais e técnicas que possibilitam a melhora de suas propriedades mecânicas, dentre elas, a resistência flexional e o módulo de elasticidade, traduzidos pela resistência à fratura e rigidez, respectivamente, deste material ${ }^{24,28,72}$.

A resistência e a rigidez adequadas das próteses provisórias confeccionadas em resinas PMMA podem ser alcançadas através de modificações na composição

\footnotetext{
* A nomenclatura de poli(metilmetacrilato) e poli(etileno) será mantida em todo o texto deste trabalho seguindo as regras atuais da International Union of Pure and Applied Chemistry que declara: "Um polímero de cadeia de extensão inespecífica é denominado com o prefixo 'poli' seguido do nome da menor unidade repetida entre parênteses ou aspas, como apropriado. $O$ nome genérico para um polímero linear simples é, assim, poli(radical bivalente ${ }^{4}$.
} 
da resina, técnicas de polimerização mais eficientes e uso de reforços em seu interior.

A utilização de reforços em resinas PMMA é descrita desde a década de 60, quando GRANT; GREENER ${ }^{20}$ comprovaram aumento da resistência destas resinas com a inclusão em seu interior de fibras de alumínio denominadas "sapphire whiskers". A partir deste fato, inúmeros tipos e desenhos de reforços metálicos foram propostos. Há relatos de estruturas fundidas, fios de vários diâmetros, malhas trançadas e até bandas ortodônticas utilizadas com a finalidade de se reforçar a resina $P M M A^{18,25,26,46}$. Esses materiais, porém, devem ser utilizados com bastante critério pois seu aspecto é anti-estético e, rotineiramente, provocam um sobrecontorno da restauração para que possam ser totalmente envolvidos pela resina $^{36,46,50,62}$.

Com o desenvolvimento dos compostos reforçados com fibras utilizados na engenharia aeronáutica e, mais tarde, na indústria automobilística, naval e bélica, materiais baseados em fibras de aramida $\left(\operatorname{Kevlar}^{\circledR}\right)$ e carbono foram introduzidos na Odontologia com a finalidade de reforçar próteses confeccionadas em resinas acrílicas $^{6,50}$. Embora tenha sido comprovado o efeito dessas fibras sobre a resistência da resina PMMA, a cor negra das fibras de carbono e a dificuldade se manusear as fibras de aramida acarretaram a restrição de seu uso $36,46,50,62$.

Atualmente, as fibras de vidro e as de poli(etileno) têm sido alvos de vários estudos. Estas fibras surgiram com o propósito de reforçar as bases de próteses totais realizadas em $\mathrm{PMMA}^{30}$. O seu desenvolvimento e crescente uso têm incitado o 
seu emprego também nas restaurações provisórias extensas em tratamentos protéticos mais prolongados ${ }^{26,41,50,62}$.

A capacidade destes reforços baseados em fibras de vidro e de poli(etileno) de melhorar as propriedades mecânicas da resina parece ser dependente, principalmente, da orientação e do arranjo das fibras e da união destas com a resina. Alguns fatores como o tratamento superficial das fibras de vidro com silano e das fibras de poli(etileno) com plasma, a possibilidade de arranjos variados destas fibras e a sua translucidez propiciando uma situação mais estética, têm sido associados com o progresso destes materiais ${ }^{26,50}$. Pesquisas têm sido realizadas para se determinar as variáveis que comprometem ou influenciam positivamente as próteses provisórias usando estas fibras, com o propósito principal de se desenvolver tanto materiais quanto técnicas que permitam uma maior longevidade dessas restaurações. 


\section{REVISÃO DE LITERATURA}

As propriedades físicas e mecânicas de resinas acrílicas à base de PMMA, já em 1949, despertaram o interesse de HARMAN ${ }^{22}$. O autor estudou, o efeito da temperatura, do tempo de polimerização e do tempo de espera antes do ensaio, na resistência flexional de uma resina PMMA termo-polimerizável.

Observou, em seus resultados, que essas variáveis foram relevantes na resistência flexional dessa resina. Um maior pico de temperatura, maior tempo do ciclo de polimerização e maior tempo de espera para o teste, resultaram em amostras mais resistentes.

CAUL; SCHOONOVER ${ }^{10}$, também em 1949, escreveram sobre a importância das propriedades físico-mecânicas das resinas acrílicas utilizadas na Odontologia. A fragilidade desse material seria uma característica associada à técnica de polimerização e à possível retenção de monômero residual. Para os autores, qualquer melhora na sua resistência seria obtida com a aplicação de elementos que poderiam influenciar positivamente a cura dessas resinas. Avaliaram algumas propriedades de uma resina acrílica PMMA termo-ativada, após a polimerização por dois ciclos diferentes: $75^{\circ} \mathrm{C}$ por duas horas e trinta minutos; ou $100^{\circ} \mathrm{C}$ por 45 minutos. A polimerização em água fervente resultou em uma maior resistência flexional das amostras. 
Em 1952, CAUL; STANFORD; SERIO11, investigaram as propriedades físicas e mecânicas de algumas marcas de resinas acrílicas PMMA auto-polimerizáveis, comercializadas na época como materiais indicados para bases de próteses totais. Os autores descrevem algumas vantagens destas resinas sobre as termo-ativadas, tais como simplicidade e rapidez de técnica. Para o estudo, confeccionaram espécimes medindo $65 \times 10 \times 2,5 \mathrm{~mm}$, de acordo com a especificação $\mathrm{n}^{\circ} 12$ da American Dental Association (ADA), de 1940, para avaliação da resistência flexional dessas resinas.

Os resultados da resistência obtidos pelas resinas, com exceção de uma, permaneceram abaixo do valor mínimo necessário requerido pela norma. Os autores discutiram que essa diminuição é causada pela presença de monômero residual resultado de uma polimerização incompleta. Sugeriram, contudo, que essas resinas quimicamente ativadas sejam polimerizadas por um ciclo em água a $100^{\circ} \mathrm{C}$ por trinta minutos para que obtenham maior resistência e respeitem os requisitos da referida norma.

STANFORD; BURNS; PAFFENBARGER ${ }^{51}$, em 1955, sustentaram que uma das primeiras utilizações da resina PMMA auto-polimerizável foi servir de material para reparo de bases de próteses totais. Defenderam que as resinas quimicamenteativadas apresentam facilidades, como por exemplo, a simplicidade de técnica em relação às termo-polimerizáveis. Os autores elaboraram um estudo com o propósito de comparar algumas propriedades físico-mecânicas, incluindo a resistência 
flexional, de algumas resinas PMMA auto e termo-polimerizáveis utilizadas para confecção de bases de dentaduras.

Com base em seus resultados, concluíram que as resinas polimerizadas sob maior calor produziram espécimes com maiores valores de resistência flexional.

McCRORIE; ANDERSON ${ }^{37}$, em 1960, fizeram um estudo com a finalidade de avaliar o efeito do reparo sobre a resistência flexional de resinas acrílicas disponíveis em seu país, a Inglaterra. Utilizaram resinas à base de PMMA auto-polimerizáveis e uma termo-polimerizável como controle comparativo. Encontraram em seus resultados que a resina termo-ativada quando reparada com a resina quimicamente ativada obtém somente $57 \%$ da sua resistência original. De acordo com os autores, este resultado é explicado pelo fato de que as resinas auto-polimerizáveis, como conseqüência da retenção de monômero residual, apresentam somente $80 \%$ da resistência daquelas polimerizadas sob calor.

GRANT; GREENER ${ }^{20}$ foram autores de um dos primeiros relatos da utilização de algum tipo de reforço em resinas acrílicas baseadas em PMMA no universo Odontológico. Realizaram, em 1967, um estudo avaliando a resistência flexional e o módulo de elasticidade de resinas acrílicas PMMA auto e termo-polimerizáveis quando reforçadas com fibras à base de alumínio denominadas "sapphire whiskers". Utilizaram espécimes medindo $65 \times 10 \times 2 \mathrm{~mm}$, sendo que o ensaio mecânico foi obtido através de um teste de carga de três pontos. 
Os autores evidenciaram em seus resultados um considerável aumento da resistência flexional e do módulo de elasticidade das resinas acrílicas que continham uma pequena concentração dessas fibras. Os autores relataram ainda a importância do uso de silano nas propriedades mecânicas dos compostos reforçados. Descreveram que a aplicação de silano sobre o reforço aumenta sua atividade superficial permitindo uma melhor transferência, da matriz de PMMA para as fibras, das tensões originadas durante o ensaio.

HARRISON; HUGGETT; HANDLEY ${ }^{23}$, em 1979, pesquisaram a dureza superficial e o módulo de elasticidade na tentativa de relacionar essas propriedades com a resistência ao desgaste de vinte e três marcas comerciais de resina acrílicas auto e termo-polimerizáveis.

Os resultados mostraram que a dureza foi positivamente correlacionada com a resistência ao desgaste, enquanto que o módulo de elasticidade não obteve correlação com essa propriedade.

Em 1984, CARROLL; FRAUNHOFER ${ }^{9}$, estudaram o efeito do uso de fios metálicos, de diversos diâmetros, unidirecionais ou trançados, com e sem dobras circulares em suas extremidades, na resistência flexional de espécimes em resina acrílica PMMA auto-polimerizável. Os fios mediam 0,41; 0,64;0,91; e 1,30 mm de diâmetro. Confeccionaram barras medindo $45 \times 10 \times 2 \mathrm{~mm}$ em resina através da técnica da saturação e posicionaram os diversos fios no seu terço inferior. De acordo com os autores essa localização dos fios permite uma maior resistência às forças de 
tração pelo espécime. O ensaio ocorreu através de um teste de carga de três pontos para registro da resistência flexional das amostras.

Os resultados demonstraram que o uso de fios de diâmetros tão pequenos quanto $0,41 \mathrm{~mm}$, este com dobra na extremidade, aumenta significantemente a resistência da resina. O maior valor médio de resistência foi encontrado quando se utilizou o fio com maior diâmetro. Nenhuma vantagem foi observada na confecção de dobras nas extremidades dos fios. Observaram, por fim, que o uso dos fios trançados aumentou a resistência, tendo sido entretanto, um aumento clinicamente questionável.

YAZDANIE; MAHOOD ${ }^{73}$, em 1985, investigaram a resistência flexional e o módulo de elasticidade de espécimes em resina acrílica PMMA termo-polimerizável, quando reforçados com fibra de carbono em diversas concentrações em peso.

Os autores concluíram que as amostras reforçadas com essas fibras são mais resistentes e rígidas que aquelas não reforçadas. As fibras com conformação unidirecional e contínua resultaram em espécimes mais resistentes. Há, além disso, uma relação positiva entre a concentração de fibras, a resistência flexional e a rigidez, porém, maiores concentrações podem dificultar a inserção dessas fibras à mistura da resina.

DONOVAN; HURST; CAMPAGNI ${ }^{14}$, também em 1985, descreveram a importância das resinas quimicamente ativadas na confecção de próteses provisórias que são mantidas em função, algumas vezes, por um longo tempo. 
Resistência adequada, densidade e dureza são requisitos propostos pelos autores como sendo as causas da longevidade dessas restaurações.

Baseados nesse comentário, os autores pesquisaram algumas propriedades físico-mecânicas, dentre elas a resistência flexional, de uma resina acrílica PMMA auto-polimerizável quando processada sob as seguintes condições de polimerização: ambiente seco; imersa em água; sob pressão; e sob pressão associado à imersão em água.

As amostras polimerizadas em ambiente seco ou imersas em água não apresentaram diferenças significantes nos valores de resistência flexional. Os espécimes polimerizados sob pressão, entretanto, exibiram as maiores médias de resistência flexional.

EKSTRAND; RUYTER; WELLENDORF ${ }^{15}$, em 1987, investigaram as propriedades flexionais de uma resina acrílica PMMA associada a diferentes concentrações de três tipos de fibras de carbono. Estudaram, além disso, a adesão dessas fibras à matriz resinosa e a influência da imersão em água sobre essas propriedades. Os autores elegeram a resina PMMA por ser um material utilizado extensivamente na Odontologia apesar de sua baixa resistência relativa à flexão quando sob influência de umidade.

Concluíram que o módulo de elasticidade aumenta proporcionalmente à concentração dessas fibras. As fibras unidirecionais produziram os maiores valores das propriedades flexionais, porém, somente neste grupo, a imersão em água foi negativamente relevante. Os autores relataram a dificuldade de se testar os 
polímeros dentais em laboratório, já que este ambiente não simula a complexidade do meio oral. Defenderam, portanto, a implementação desses testes sob condições observadas na boca, como a umidade e a temperatura.

Ainda em 1987, GEGAUFF; PRYOR ${ }^{18}$, escreveram que a resistência das resinas utilizadas para restaurações provisórias fixas é particularmente crítica quando se utiliza esse material em próteses nas regiões anteriores onde a fratura causa embaraço e inconveniência ao paciente.

Os autores propuseram um estudo em que avaliaram a resistência à fratura de seis resinas utilizadas para próteses provisórias: duas à base de PMMA, uma à base de epimina, um compósito Bis-GMA, uma baseada em PEMA, além de um outro acrilato. Utilizaram um ensaio próprio para registro da resistência à fratura coesiva dos espécimes em que este era pré-trincado e testado por forças de tração. Avaliaram também a influência da polimerização sob pressão nesta resistência.

Os autores não encontraram efeito significante quanto ao uso de pressão durante a polimerização. Os dados indicaram que os materiais à base de PMMA e epimina tiveram, significantemente, as maiores médias de resistência.

BRADEN et $\mathrm{al}^{8}$, em 1988, defenderam o uso de fibras de poli(etileno) tratadas com plasma ao invés das fibras de carbono para resolução da baixa resistência ao impacto das resinas PMMA quando comparadas aos metais. O tratamento com plasma, segundo os autores, consiste em um método de se aumentar a energia de 
superfície dessas fibras através de um tratamento elétrico com plasma utilizando o gás oxigênio ou hélio como carreadores.

Os autores investigaram a resistência flexional e o módulo de elasticidade de resinas acrílicas PMMA termo e auto-polimerizáveis com a inclusão de fibras de poli(etileno) em suas diversas formas: sem tratamento, tratadas com plasma, unidirecionais e trançadas. Testaram, além disso, a adesão dessas fibras, em sua forma unidirecional, à resina auto-polimerizável. Como grupo comparativo nos ensaios mecânicos utilizaram resinas reforçadas com fibras de carbono.

No teste de adesão entre as fibras e a resina foi evidente que o tratamento superficial com plasma aumentou significantemente a união entre os dois materiais. Foi conclusivo também que o tratamento com plasma aumenta a resistência flexional dos espécimes, porém, tendo sido somente significante quando se utilizou um número conveniente de camadas de fibras trançadas. Os autores, por fim, expuseram as vantagens estéticas de se utilizar as fibras de poli(etileno), quase transparentes, comparadas às fibras escuras de carbono.

GUTTERIDGE $^{21}$, ainda em 1988, estudou a efetividade das fibras de poli(etileno) quando misturadas à resina PMMA na resistência ao impacto de três marcas comerciais deste material. Para esse estudo utilizou uma resina convencional PMMA termo-polimerizável e duas resinas à base de metacrilatos modificados, de alta resistência ao impacto, tendo sido somente a primeira reforçada com tais fibras. Avaliou ainda a influência de diferentes concentrações em peso dessas fibras incluindo $0,5 \%, 1 \%, 2 \%, 3 \%$ e $4 \%$ na resistência dos espécimes. 
Em seus resultados, as resinas denominadas "de alta resistência ao impacto" mantiveram os maiores valores de resistência comparados aos grupos não reforçados. As amostras reforçadas demonstraram um aumento da resistência ao impacto em relação ao grupo controle não reforçado, e uma equivalência aos valores obtidos com os materiais de alta resistência. A concentração que resultou em melhores médias foi a de $3 \%$ em peso.

Em 1989, WANG et $\mathrm{al}^{72}$, comentaram sobre a importância das restaurações provisórias em um tratamento reabilitador protético. Relataram que as resinas baseadas em PMMA freqüentemente utilizadas para a confecção de tais restaurações, entretanto, não possuem todas as propriedades desejáveis para esse fim.

Apoiados nessa afirmativa, os autores fizeram um extenso estudo comparando as características de tipos distintos de resinas utilizadas para confecção de próteses provisórias. Utilizaram duas resinas à base de PMMA autopolimerizável, um compósito ativado quimicamente, um compósito foto-polimerizado, uma resina PVMA e uma à base de PEMA. Avaliaram diversas propriedades químicas e físico-mecânicas, dentre elas a resistência flexional de espécimes íntegros ou reparados.

Diante de seus resultados, os autores concluíram que nenhuma resina provou ser superior às outras nas propriedades testadas nesse estudo. Com relação à resistência flexional dos espécimes íntegros, não houve diferença estatística entre as resinas utilizadas apesar das resinas constituídas de polímeros de EMA não 
terem sido testadas por suas características borrachóides. Na resistência flexional após o reparo, os dois polímeros à base de PMMA e o compósito foto-ativado não tiveram diferenças significantes, porém, somente uma destas resinas à base de PMMA não teve diminuição significante em relação ao corpo de prova íntegro, demonstrando um melhor comportamento mecânico.

HENRY; BISHOP; PURT ${ }^{26}$, em 1990, destacaram que os materiais indicados para a confecção de próteses provisórias estão sempre sujeitos à fadiga e à fratura particularmente em regiões com espessuras menores e sob efeito de maiores cargas oclusais. Citaram que o método usual de se reforçar essas próteses com fios e malhas metálicas resultam normalmente em sobrecontorno da restauração dificultando a sua utilização. Ao contrário, defendem o uso de fibras baseadas em polímeros de alto peso molecular como fator de diminuição ao risco de fraturas e falhas de tais restaurações em resina, principalmente quando utilizadas por períodos de tempo mais longos.

Os autores executaram testes de resistência à tração e de resistência flexional em alguns materiais utilizados para confecção de próteses provisórias, incluindo uma resina PMMA auto-polimerizável, contendo em seu interior fibras de poli(etileno). Em ambos os ensaios foi testado o tratamento dessas fibras com silano.

A inclusão de fibras de poli(etileno) silanizadas do tipo longa e unidirecional resultou em espécimes mais resistentes à tração e à flexão. O uso de fibras não silanizadas, porém, diminuiu essas propriedades. Os autores afirmaram que a 
silanização provoca uma adesão química entre as fibras e a matriz resinosa reduzindo o micro-deslizamento entre essas duas e, portanto, minimizando a propagação de micro-trincas que futuramente podem acarretar numa fratura de todo o conjunto.

BERRONG; WEED; YOUNG ${ }^{7}$, em 1990, comentaram que as resinas PMMA têm sido aplicadas com sucesso em várias áreas da Odontologia. São materiais de fácil manipulação, porém, com algumas propriedades mecânicas limitadas. Sustentaram que as áreas críticas de próteses realizadas com essas resinas, como por exemplo as regiões de pouca espessura, devem ser reforçadas prevenindo fraturas.

Os autores elaboraram um estudo para avaliar o efeito de diversas concentrações, em peso, de fibras à base de aramida na resistência ao impacto de espécimes confeccionados em resina acrílica PMMA termo-polimerizável.

Nos espécimes com fibras nas concentrações de $1 \%$ e $2 \%$ as fraturas foram em "galho verde" mantendo os dois fragmentos unidos. Todas as amostras reforçadas foram significantemente mais resistentes que o grupo controle não reforçado, sendo que, quanto maior a concentração da fibra, maior foi a resistência ao impacto. Tal material composto de fibras sintéticas de aramida, segundo os autores, tem sido indicada para restaurações dentárias onde a resistência é essencial. Essas fibras têm maiores valores de módulo de elasticidade e resistência à tração que o aço, e por isso têm sido empregadas na fabricação de vestimentas à prova de bala, pneus automotivos, mastros de embarcações e partes de aeronaves. 
KOUMJIAN; NIMMO ${ }^{31}$, em 1990, avaliaram a resistência flexional de sete marcas comerciais de resinas utilizadas para restaurações provisórias, observando os efeitos da imersão em água, o tempo de espera para o ensaio e o reparo.

A resistência à flexão de cinco das sete marcas de resina testadas não apresentou diferenças significantes entre si após sete dias de espera em ambiente seco ou imersas em água. Todos os materiais tiveram sua resistência significantemente diminuída após o reparo. Os autores concluíram, ao final, que não há nenhuma vantagem de se realizar o reparo nessas resinas utilizadas em restaurações provisórias, dentre elas o PMMA, já que a diminuição da resistência apresentada não justifica o tempo gasto nesse procedimento.

LARSON et $\mathrm{al}^{36}$, em 1991, citaram que as restaurações provisórias geralmente são realizadas de forma direta ou indireta usando uma resina acrílica auto-polimerizável. Essas resinas, entretanto, apresentam algumas desvantagens tais como a absorção de água em função do tempo e inadequada resistência às cargas oclusais. Explicaram que a fratura dessas próteses, por sua vez, está relacionada com o início e a propagação de uma ou mais micro-trincas, por isso, diversos métodos têm sido usados para que as resinas auto-polimerizáveis resistam à propagação dessas trincas. Os métodos incluem o aumento da espessura da resina em áreas críticas da prótese mais susceptíveis às forças oclusais, o uso de resinas com ligações cruzadas, reforços com fibras de vidro, fibras de "nylon", fibras de alumínio e policarbonatos, além de reforços metálicos. 
Os autores realizaram um trabalho para avaliar o efeito de fibras de carbono sobre o módulo de elasticidade de três resinas para restaurações provisórias, uma PMMA, uma PEMA e uma PVEMA, após a imersão em água a $37^{\circ} \mathrm{C}$ durante 30 e 60 dias.

Encontraram em seus resultados que a resina PMMA reforçada com fibras de carbono exibiu um aumento significante do módulo de elasticidade quando comparada com as outras resinas. A imersão em água, além disso, não teve efeito relevante sobre os valores da propriedade estudada.

PARANHOS et $\mathrm{al}^{44}$, em 1992, executaram um trabalho com a proposta de verificar as alterações na resistência à flexão de resinas acrílicas que sofreram um processo de envelhecimento artificial em laboratório. Nesse estudo, os autores utilizaram espécimes em resina acrílica PMMA auto e termo-polimerizável, tendo sido avaliada também a resistência das amostras após um reparo simulado.

Encontraram através de seus resultados, dentre outras conclusões, que a resina termo-polimerizável resultou em amostras mais resistentes e que o reparo diminuiu a resistência à flexão nos corpos de prova, porém, essa resistência foi maior quando se reembasou com o material do mesmo tipo. Ambos os tipos de resinas, entretanto, tiveram sua resistência diminuída pelo processo de envelhecimento.

DIXON; BREEDING ${ }^{13}$, em 1992, ressaltaram o uso crescente de vários tipos de fibras utilizadas para reforço de resinas baseadas em PMMA. Disseram, contudo, 
que as fibras de carbono e as de aramida, apesar de sua eficiência comprovada sobre as propriedades mecânicas da resina PMMA, não podem ser usadas em áreas estéticas, a primeira por sua coloração negra e a outra por sua coloração amarelada.

Os autores investigaram a resistência flexional de três resinas acrílicas utilizadas para a confecção de bases de próteses totais quando reforçadas com fibras de poli(etileno). Usaram uma resina de alta resistência ao impacto, uma resina termo-ativada de polimerização rápida e uma resina foto-polimerizável.

Encontraram em seus resultados que a incorporação das fibras de poli(etileno) aumentou significantemente a resistência flexional somente da resina foto-polimerizável.

Em 1992, VALLITTU; LASSILA ${ }^{67}$, declararam que a resina PMMA, material comumente utilizado na confecção de bases de próteses totais, é freqüentemente reforçada com diferentes tipos de fios metálicos e com fibras de carbono. O uso das fibras de carbono, entretanto, é limitado esteticamente pela sua coloração negra. Argumentaram que por essa razão se deve eleger reforços que forneçam uma estética mais apropriada, como as fibras de vidro e as de aramida.

Os autores, em um estudo, usaram fios metálicos semicirculares, fios metálicos achatados e trançados, fios metálicos cilíndricos de 1,0 mm de diâmetro e uma malha metálica, todos esses, lisos ou jateados com óxido de alumínio, além disso, utilizaram fibras de vidro contínuas e trançadas, fibras trançadas de carbono e fibras trançadas de aramida, com e sem tratamento superficial com silano. Testaram 
a eficiência de todos esses reforços na resistência flexional de uma resina PMMA através de um teste de carga de três pontos.

Observaram que todos os fios metálicos aumentaram significantemente a resistência à flexão dos espécimes, porém, não houve diferença estatística entre os lisos e os que foram jateados. A malha metálica, contrariamente, não apresentou boas propriedades mecânicas. Com relação às fibras, todas elas reforçaram os espécimes em resina com exceção das fibras de vidro não silanizadas que, ao contrário, diminuíram levemente sua resistência à flexão. As fibras posicionadas de maneira perpendicular ou diagonal à carga não resultaram em diferença nesta resistência.

Por fim, concluíram que nenhuma das fibras estudadas teve um efeito tão favorável na resistência à flexão quanto os fios metálicos.

LADIZESKY; $\mathrm{CHOW}^{32}$, também em 1992, relataram que as fibras de poli(etileno) utilizadas como reforços de resinas PMMA oferecem um leque de propriedades de particular interesse à área de prótese odontológica, tais como alta rigidez e resistência, biocompatibilidade, aparência translúcida e absorção de água desprezível.

Os autores, fundamentados nessas informações, desenvolveram um estudo que avaliou, dentre outras propriedades, a resistência flexional e o módulo de elasticidade de espécimes em resinas à base de PMMA e de Bis-GMA próprias para a confecção de bases de próteses totais, quando reforçadas com fibras de 
poli(etileno), com e sem tratamento superficial com plasma. Analisaram ainda o efeito da imersão em água a $37^{\circ} \mathrm{C}$ sobre essas propriedades.

Notaram que a inclusão das fibras de poli(etileno) produziram um aumento entre $60 \%$ e $100 \%$ da resistência flexional das amostras em resina comparado às não reforçadas. O tratamento com plasma, por sua vez, foi relacionado com uma pequena melhora dessa propriedade. Nos espécimes reforçados, além disso, as fibras não permitiram que estes perdessem a sua integridade após a fratura, mantendo as duas partes fraturadas unidas entre si. A imersão em água a $37^{\circ} \mathrm{C}$ durante três meses teve somente um pequeno efeito na diminuição dessa resistência. Os valores do módulo de elasticidade dos grupos reforçados foram $700 \%$ a $1200 \%$ maiores comparados aos grupos não reforçados, sendo que o tratamento com plasma esteve associado apenas a um pequeno aumento, em relação ao grupo não tratado.

LADIZESKY et aß", em 1993, pesquisaram a resistência flexional, o módulo de elasticidade e a resistência ao impacto de uma resina PMMA termo-polimerizável utilizada para bases de dentaduras, quando reforçadas com fibras de poli(etileno). Avaliaram também a influência do tempo de imersão em água nessas propriedades.

Observaram em seus resultados que a incorporação de fibras não exerceu efeitos significantes sobre a resistência flexional e o módulo de elasticidade, embora um pequeno aumento de tais propriedades tenha sido evidenciado quando foram utilizadas três camadas dessas fibras. O uso deste reforço na forma de fita trançada, 
por sua vez, foi associado com um aumento substancial na resistência ao impacto. A imersão durante três meses em água a $37^{\circ} \mathrm{C}$ não afetou nenhuma das propriedades.

Os autores discutiram que a inserção das fibras próxima ao eixo neutro de deflexão, isto é, no meio do espécime, pode ter acarretado uma diminuição da influência desses reforços na resistência flexional e na rigidez.

Ainda em 1993, LADIZESKY et al ${ }^{35}$, analisaram o módulo de elasticidade, a resistência flexional e a absorção de energia ao impacto de uma resina à base de PMMA termo-polimerizável quando reforçada com fibras de poli(etileno) pré-cortadas em 6 mm de comprimento, na concentração em torno de $30 \%$ em volume.

Em seus resultados, encontraram que a incorporação de $37 \%$ em volume de fibras aumentou significantemente a rigidez e a resistência ao impacto da resina acrílica em questão. Em adição, a absorção de água, as alterações dimensionais durante a imersão em água e a contração de polimerização foram estatisticamente menores que aqueles espécimes que não foram reforçados com tais fibras. Os autores finalizaram dizendo que esse novo material não é oneroso e pode se inserido facilmente em próteses em PMMA.

VALLITTU ${ }^{57}$, também em 1993, argumentou que a resistência à flexão das próteses em resina reforçadas com fibras é dependente da adesão entre a matriz da resina acrílica e a fibra utilizada, e que essa adesão poderia ser melhorada por meio de tratamento dessas fibras com compostos de silano. 
O autor pesquisou o efeito do uso de duas fórmulas de silano diferentes, A174 e AP133, na adesão entre diferentes tipos de fibras e uma resina à base de PMMA, através de um teste de resistência flexional. Testou as fibras de vidro, carbono e aramida. Evidenciou que somente o composto A174 aumentou significantemente a adesão entre a resina e as fibras de vidro e aramida, porém nenhum dos dois tipos de silano teve efeito relevante na união entre as fibras de carbono e a resina.

OSMAN; OWEN ${ }^{43}$, em 1993, comentaram sobre a importância da resistência à fratura de restaurações provisórias. Em função disso, os autores compararam a resistência flexional de espécimes confeccionados com os seguintes materiais utilizados em próteses provisórias: duas marcas de resinas à base de PMMA, uma baseada em Bis-GMA quimicamente ativada, outra em epimina e a última em PEMA.

Em seus resultados observaram que os melhores valores de resistência à fratura, estatisticamente significante, foram encontrados nos espécimes confeccionados com o polímero PEMA. A resistência obtida com o PMMA e com compósito não teve diferença estatística, enquanto que os realizados $\infty m$ a resina epimina foram significantemente menores.

Ao final, elegeram o teste de carga de três pontos, pois simula a situação clínica onde uma combinação de tensões de compressão, tração e de cisalhamento age sobre a prótese parcial fixa provisória. A resistência flexional, entretanto, seria somente um dos diversos fatores que devem ser observados na seleção de um material para confecção de provisórios. 
POWELL et $\mathrm{al}^{46}$, em 1994, explanaram que as próteses provisórias devem ter, entre outras características, resistência mecânica aos esforços mastigatórios, já que em algumas circunstâncias são utilizadas por alguns meses durante o tratamento protético reabilitador. Elaboraram um estudo utilizando próteses fixas provisórias reforçadas com fio de aço e fibras de aramida denominadas Kevlar 49. Avaliaram a rigidez inicial, a carga na fratura inicial e a unidade de tenacidade, esta última descrita pelos autores como a energia armazenada pela viga da prótese após ter sofrido uma deflexão de 1,0 mm. Confeccionaram próteses provisórias em PMMA reforçadas com um fio de $0,9 \mathrm{~mm}$ de diâmetro ou com Kevlar 49, além de um grupo sem reforço.

Observaram em seus resultados, que as próteses provisórias em que os reforços estavam numa configuração em "V", acompanhando a inclinação da própria prótese e com isso se mantendo o mais inferiormente possível, exibiram maior rigidez, tendo sido o grupo reforçado com o fio 0,9 significantemente maior. Não houve diferença estatística entre o valor da carga gerada na primeira fratura.

Justificaram esse resultado baseando-se na "Lei de flexão das vigas". De acordo com os autores, a referida lei declara que quando uma viga está sob ação de uma carga compressiva no centro e eqüidistante entre dois pontos de suporte, a força aplicada induz tensão de compressão na região superior e tensão de tração na região inferior. Os reforços utilizados nas resinas e polímeros odontológicos são mais eficientes quando posicionados fora do eixo neutro no interior da prótese, o mais inferiormente possível em relação ao centro no sentido vertical. Freqüentemente a fratura se inicia no lado de tração, por isso, nesse estudo, quando 
o reforço foi posicionado na região mais inferior, a resistência à fratura do espécimeprótese foi significantemente maior que naquele em que o reforço foi posicionado mais próximo da superfície oclusal.

Foi dito por VALLITTU; LASSILA; LAPPALAINEN ${ }^{68}$, em 1994, que as fibras para reforço deveriam ser utilizadas com o propósito de se aumentar a resistência flexional e o módulo de elasticidade dos materiais poliméricos. Os autores defenderam que uma ótima adesão entre as fibras e a matriz do polímero é essencial para o aumento da resistência mecânica. Essa adesão, por sua vez, pode ser conseguida e aumentada através do uso de um composto de silano.

A fim de se compreender o efeito da quantidade de fibras sobre a resistência dos polímeros utilizados na Odontologia, os autores estudaram a resistência flexional de espécimes em resina acrílica PMMA termo-polimerizável quando reforçados com fibras de vidro, fibras de aramida e fibras de carbono. As fibras foram inseridas no centro do espécime, no sentido vertical, utilizando três concentrações em peso a depender do tipo de reforço. Os autores, em seus resultados, observaram que a incorporação de qualquer uma dessas fibras na resina acrílica aumentou estatisticamente sua resistência à flexão, sendo que este aumento foi proporcional à concentração das mesmas. Não foram encontradas diferenças significantes entre os tipos de reforços. Evidenciaram, porém, a presença de bolhas na interface fibra-resina onde se localizou a fratura. Os autores justificam a presença dessas bolhas em decorrência da contração de polimerização do monômero 
metilmetacrilato no qual as fibras foram imersas antes de sua incorporação à massa da resina acrílica, que é de cerca de $21 \%$ contra $8 \%$ do polímero PMMA.

VALLITTU ${ }^{58}$, ainda em 1994, dando continuidade ao trabalho anterior, pesquisou a possibilidade da imersão das fibras em monômero, previamente à sua inclusão no interior da resina, causar uma diminuição da resistência flexional como resultado da diferença de contração de polimerização entre esta resina oriunda de uma mistura mais fluida que está em íntimo contato com as fibras e a resina que compõe o restante do provisório, proporcionada segundo o fabricante. As fibras foram silanizadas e tratadas antes da confecção do corpo de prova de duas formas: imersão no monômero ou numa mistura de polímero/monômero.

Concluíram que diminuindo a contração de polimerização da resina que está em contato com as fibras aumenta-se a resistência à flexão do corpo de prova. Essa contração pode ser amenizada pela imersão das fibras numa mistura de polímero/monômero, com proporção em peso variando de 3:8 a 10:8, antes da polimerização do espécime. Por fim, observaram que essa imersão fornece uma camada mais espessa de resina acrílica na superfície da fibra de vidro, comparada àquela fornecida pela imersão somente no monômero.

LADIZESKY; CHOW; CHENG ${ }^{33}$, em 1994, citaram que a resina à base de PMMA apresenta alguns defeitos relacionados, principalmente, com o seu comportamento mecânico. O uso de fibras pode melhorar a função dessa resina, porém, as fibras de carbono e de aramida, por exemplo, são antiestéticas e de difícil 
polimento. As fibras de poli(etileno) de alto peso molecular, de outra forma, são uma escolha promissora no campo dos reforços utilizados nas resinas PMMA. São fibras biocompatíveis, transparentes, insolúveis em água e provêem uma alta rigidez e resistência.

Em um estudo com essas fibras, pesquisaram as propriedades mecânicas de duas resinas acrílicas PMMA termo-polimerizáveis reforçadas com até dez camadas de fibras de poli(etileno) trançadas, representando acima de $40 \%$ em volume. Esse estudo incluiu o efeito da imersão em água e do tratamento com plasma da superfície da fibra. As propriedades analisadas foram: a resistência flexional, o módulo de elasticidade, além da absorção de energia ao impacto

Os autores evidenciaram que a incorporação de uma alta concentração dessas fibras aumenta significantemente a rigidez e a resistência ao impacto. Houve, contrariamente, somente um pequeno aumento na sua resistência flexional. A imersão em água não foi significante, assim como o posicionamento e o tratamento com plasma das fibras.

De acordo com GEGAUFF; WILKERSON ${ }^{19}$, em 1995, muitas dessas resinas utilizadas para confecção de restaurações provisórias são frágeis e susceptíveis à fratura durante a função. A experiência clínica, segundo os autores, indica que esta fratura ocorre como resultado da propagação de trincas provenientes de uma falha superficial.

Os autores estudaram a resistência à fratura de espécimes confeccionados em resinas utilizadas para próteses provisórias, quando em meio seco e imersos em 
água. Avaliaram as resinas PMMA e PEMA, auto-polimerizáveis, além das resinas UDMA e PVEMA, foto-polimerizáveis. Executaram um teste específico para registro da resistência à fratura, no qual os espécimes são pré-trincados com o auxílio de uma lâmina de bisturi.

Em seus resultados, puderam observar que a imersão em água foi irrelevante na resistência testada, para todas as resinas. A resina UDMA obteve a maior resistência, seguida da resina PMMA. As outras duas resinas foram, estatisticamente, menos resistentes.

Em 1995, VALLITTU; VOJTKOVA; LASSILA ${ }^{71}$, pesquisaram a resistência ao impacto de espécimes em resina acrílica PMMA termo-polimerizável quando reforçados com fios metálicos de $1,0 \mathrm{~mm}$ de diâmetro ou com diferentes concentrações em peso de fibras de vidro unidirecionais e contínuas.

As médias de resistência ao impacto dos grupos reforçados foram consideravelmente maiores que aquelas encontradas nos grupos sem reforço. Houve somente uma modesta diferença na resistência entre a utilização de fio e fibras, tendo estas últimas, originado melhores resultados.

VALLITTU ${ }^{59}$, em 1995, elaborou um estudo para estabelecer a relação entre o tempo de polimerização e a resistência flexional de espécimes em resina acrílica PMMA termo-polimerizável reforçadas com fibras de vidro unidirecionais e silanizadas. Comparou a resistência flexional após processos de polimerização de 45 minutos, 2,6 , e 12 horas a $80^{\circ} \mathrm{C}$, além de processos de 6 e 12 horas, em que 
nos 30 minutos finais os espécimes permaneciam imersos em água fervente. Averiguou, além disso, as causas e efeitos dos espaços vazios internos nos corpos de prova reforçados.

Dentro do mesmo grupo, com e sem reforço, não foi encontrada diferença estatística na resistência em relação ao tempo de polimerização dos corpos de prova. Observou também que não houve relação da presença de bolhas de ar encontradas entre as fibras e a resistência flexional das amostras, fortalecendo a hipótese, segundo o autor, de que a resistência flexional é influenciada principalmente pelo contato entre a superfície das fibras e a matriz resinosa, e não pelo contato entre as fibras.

De acordo com HAZELTON et $\mathrm{al}^{25}$, em 1995, a resina acrílica PMMA tem sido o material de maior escolha para a realização de próteses provisórias. Vários materiais e técnicas de reforço deste material têm sido sugeridos. Segundo os autores, o reforço com estruturas metálicas fundidas é possível, porém necessita de um maior tempo e custo adicional despendidos com procedimentos laboratoriais.

Os autores investigaram algumas variáveis experimentais para dois tipos de desenhos de próteses provisórias em PMMA auto-polimerizável: uma reforçada com fio ortodôntico $0,8 \mathrm{~mm}$ de diâmetro e outra com uma fita metálica utilizada para confecção de bandas ortodônticas. Avaliaram a carga quando foi perdido o selamento marginal do cimento nos pilares mesial e distal, além de registrarem a rigidez e a carga no momento da fratura destas próteses. 
Observaram que as próteses reforçadas com as matrizes metálicas foram estatisticamente mais rígidas e necessitaram uma maior carga para perder o selamento marginal nos pilares. Nenhuma diferença significante foi notada na resistência à fratura entre as próteses com e sem reforço, entretanto, os autores relataram que os reforços mantiveram as duas peças fraturadas contíguas. Clinicamente esse comportamento reduziria o risco da perda, ingestão ou aspiração da prótese provisória.

Em 1996, RAMOS; RUNYAN; CHRISTENSEN ${ }^{47}$, escreveram que as resinas utilizadas na execução de próteses provisórias têm como característica inerente, a fragilidade e que qualquer método de reforçar esses materiais adicionando-Ihes resistência é bem-vindo.

Os autores, contribuindo com o estudo sobre o uso de fibras para reforços, avaliaram o efeito da utilização de fibras entrelaçadas de poli(etileno) tratadas com plasma, na resistência flexional de espécimes confeccionados em resina acrílica para restaurações provisórias, PMMA auto-polimerizável. Os autores explicaram que esse tratamento com plasma consiste em aumentar a energia de superfície pela modificação química superficial das fibras implicando em uma maior reatividade química e compatibilidade com outros materiais. Os corpos de prova foram produzidos em forma de barras e as fibras foram inseridas no terço inferior do espécime. A polimerização da resina aconteceu sob pressão e calor.

Em seus resultados, os autores evidenciaram o aumento da resistência flexional dos corpos de prova reforçados com essas fibras. Justificaram o aumento 
da resistência em função da adesão química real conseguida através do tratamento com plasma, do interaprisionamento da resina às fibras, ou ambos. Finalizaram relatando a facilidade no uso destas fibras, apesar da preocupação de, ao manuseála, evitar o contato direto afim de que não ocorra a perda do seu tratamento superficial com plasma.

MIETTINEN; VALLITTU ${ }^{38}$, em 1996, explicaram que a resina PMMA absorve água lentamente durante um período de tempo e que essa embebição é devida principalmente pela polaridade de suas moléculas. A água absorvida, por sua vez, pode amaciar a resina, agindo como um plastificante e reduzindo seu módulo de elasticidade. Alta solubilidade, portanto, não é uma característica favorável aos materiais à base de PMMA utilizados para diversos fins na prótese odontológica.

Os autores, baseados nesse princípio, elaboraram um estudo com a finalidade de se investigar os efeitos do uso de reforços de fibra de vidro na absorção de água e na solubilidade de dois tipos de resina PMMA, uma auto e outra termo-polimerizável.

Os resultados encontrados sugeriram que o tipo de resina utilizada, auto ou termo-polimerizável, foi mais importante que a presença ou não de fibras nos espécimes. A resina auto-polimerizável obteve maiores valores de absorção d’água em decorrência, segundo os autores, da quantidade de monômero residual que acarretaram em bolhas de ar. Esses espaços vazios mantiveram regiões da fibra sem impregnação pela resina, aumentando a solubilidade. De qualquer forma, 
ambas as resinas, reforçadas ou não, estiveram de acordo com as especificações da norma ISO no que diz respeito à solubilidade à água .

Os materiais restauradores provisórios, segundo SAMADZADEH et $\mathrm{al}^{50}$, em 1997, geralmente exibem baixa resistência à fratura, especialmente em casos de próteses com vãos longos, de longa duração, localizadas em áreas de maior estresse mastigatório ou em pacientes que apresentam bruxismo. A resistência desses materiais, porém, tem sido aumentada com a utilização de fibras com diversas composições e desenhos.

Os autores avaliaram o efeito do uso de uma fibra trançada à base de poli(etileno) tratada com plasma na resistência à fratura de corpos de prova simulando próteses provisórias com vão de 22 mm, confeccionados em PMMA autopolimerizável e em um material restaurador provisório de polimerização dual.

Estudaram também o tipo de fratura: a) parcial, quando a região de conexão da prótese permaneceu intacta e uma porção vestibular ou lingual do pôntico fraturou separando-se da prótese; b) não separada, quando houve fratura de um ou ambos os conectores, porém, o conjunto permaneceu unido pela fibra que não se fraturou; e c) catastrófica, quando o pôntico sofreu uma fratura dividindo-o em várias partes que se separaram da prótese.

Verificaram, ao final, que o reforço de poli(etileno) aumentou significantemente a resistência à fratura das próteses confeccionadas no material de polimerização dual, ao contrário do que ocorreu com aquelas em resina acrílica PMMA, nas quais não houve diferença estatística desta resistência. Os autores 
enfatizam, todavia, que em ambos os grupos reforçados a fratura foi mais favorável, tendo sido do tipo parcial ou não separada.

VALLITTU ${ }^{60}$, em 1997, estudou a influência da inclusão de fibras trançadas de poli(etileno) de alto peso molecular, tratadas com gás de plasma, na resistência flexional de espécimes em resina acrílica PMMA auto-polimerizável. As fibras, em uma ou duas camadas, foram inseridas no terço inferior dos corpos e o ensaio realizado foi um teste compressivo de carga de três pontos.

Os resultados evidenciaram uma melhora, porém modesta, na resistência flexional dos espécimes. O autor concluiu que, baseado na análise microscópica eletrônica de varredura dos espécimes fraturados, essa fibra não provê uma adesão adequada à matriz da resina, justificando o pequeno aumento da sua resistência.

VALLITTU61, ainda em 1997, apresentou resultados preliminares de um estudo clínico que avaliou a utilização de fibras de vidro no reparo das bases de doze próteses totais e dez próteses parciais removíveis. A avaliação foi feita após 13 meses de uso, em média.

Muitas das próteses utilizadas nesse estudo já tinham história de fratura recorrente de sua base em PMMA. Utilizou para o reparo fibras de vidro unidirecionais e silanizadas.

Houve recorrência da mesma fratura somente em duas próteses. Em outras seis, as fraturas se localizaram em novas posições. Com base nestes resultados o autor suporta o uso dessas fibras no reparo de próteses removíveis, totais ou 
parciais, observando cuidadosamente as áreas de maior tensão em que elas devem ser inseridas. Finaliza relatando que os resultados são promissores, mas que uma avaliação mais longa é necessária.

VALLITTU; NARVA ${ }^{69}$, também em 1997, compararam a resistência ao impacto de uma resina acrílica PMMA auto-polimerizável quando reforçada com fibras de vidro ou com uma associação de fibras de vidro e fibras de aramida. Espécimes em forma de barras foram confeccionados e quando foi utilizado o reforço adicional, este foi posicionado no lado onde há maior tensão de tração no interior do corpo de prova, isto é, mais inferiormente.

A utilização de fibras de vidro silanizadas aumentou consideravelmente a resistência ao impacto do polímero auto-polimerizável. Observaram, entretanto, que o efeito da inclusão de fibras adicionais no lado de tensão, tanto de aramida quando de vidro, não foi relevante nessa resistência.

MIETTINEN; VALLITTU ${ }^{38}$, em 1997, explicaram que a resina acrílica PMMA tem sido utilizada como matriz polimérica para compostos reforçados com fibras. $\mathrm{O}$ uso desta resina, entretanto, apresenta alguns problemas, já que uma das dificuldades encontradas é a inadequada impregnação das fibras com a matriz de PMMA. Uma efetiva impregnação das fibras, segundo os autores, permite um contato mais íntimo entre as fibras e a matriz, resultando em um efeito relevante no aumento da resistência do composto. Um dos mecanismos para melhorar a adesão entre as fibras e o PMMA é através da aplicação sobre a fibra de uma solução fluida 
de PMMA-MMA ou a imersão da fibra em monômero MMA. Essas duas técnicas, porém, aumentam a quantidade de monômero residual e a sua liberação do composto resina-fibra.

Com a proposta de se estudar este problema, os autores fizeram uma pesquisa para determinar a liberação de monômero MMA residual, em água, de espécimes em resinas acrílicas PMMA auto e termo-polimerizáveis, com e sem a adição de reforço à base de fibras de vidro. Utilizaram barras com adição de fibras de vidro contínuas, unidirecionais e silanizadas, que foram molhadas com cerca de 10 gotas de monômero antes de sua incorporação à resina. As amostras em resina termo-ativada foram imersas em água fervente por 45 minutos, enquanto os espécimes em resina auto-polimerizável foram polimerizados sob pressão e temperatura de $45^{\circ} \mathrm{C}$ durante 10,30 e 60 minutos.

O ciclo de polimerização foi determinante no conteúdo de monômero residual que foi liberado. Um tempo menor de polimerização resultou em uma maior liberação desse monômero. Nos espécimes reforçados obtidos com a resina ativada quimicamente, a quantidade de monômero residual foi semelhante àqueles sem reforço, entretanto a liberação de monômero nas amostras termo-ativadas, com e sem reforço, foi significantemente menor que estas primeiras.

De acordo com VALLITTU ${ }^{65}$, em 1998, a utilização de fibras reforçando os polímeros odontológicos tem fornecido melhores resultados mecânicos que o uso de fios metálicos. $\mathrm{O}$ autor fez um estudo com a finalidade de se determinar a resistência à fratura de corpos de prova semelhantes a próteses provisórias de três unidades, 
sendo dois pilares e um pôntico, quando reforçados com fibras de vidro experimentais na forma unidirecional ou ao mesmo tempo associada à forma trançada. O autor utilizou uma mistura de pó da resina PMMA e líquido do monômero n-butilmetacrilato, e a distribuição das fibras foram de três formas: uma, duas ou três fibras unidirecionais. Foram também confeccionados espécimes contendo três fibras unidirecionais e uma trançada. As vantagens das fibras descritas nesse estudo seriam a pré-impregnação destas com um polímero que possibilita uma maior adesão da fibra à matriz dos polímeros existentes no mercado. Os corpos de prova foram submetidos a um teste compressivo de carga de três pontos.

Observou em seus resultados que a resistência à fratura das próteses foi aumentada significantemente pela adição das fibras, muito embora, o posicionamento destas, de acordo com o autor, não tenha sido o ideal, já que não foram posicionadas inteiramente na região onde se concentraram as tensões de tração, ou seja, na sua parte inferior. Por fim, o uso da fibra trançada próxima aos pilares reforçou as coroas provisórias sobre estes.

Em 1998, STIPHO ${ }^{52}$, mencionou os diversos tipos de fibras que são utilizados com a finalidade de melhorar as propriedades mecânicas das resinas à base de PMMA utilizadas em próteses provisórias. Descreveu que as fibras de aramida e carbono são reforços eficazes, porém não fornecem uma boa estética, assim como os fios e malhas metálicas, que normalmente exigem um sobrecontorno em regiões menos espessas da prótese. As fibras de poli(etileno) apesar de fornecerem 
características estéticas ao composto reforçado, não são práticas, exigindo cuidados na sua manipulação. Por outro lado, defendeu que as fibras de vidro apresentam o maior potencial como reforço das restaurações provisórias.

O autor procurou estudar o efeito de diversas concentrações de fibras de vidro na forma de pequenos feixes, nas propriedades mecânicas de uma resina auto-polimerizável à base de PMMA. Avaliou a resistência flexional, a deformação e o módulo de elasticidade dos espécimes em resina, variando a concentração em peso, de $1 \%, 2 \%, 5 \%, 10 \%$ e $15 \%$, de fibras na sua mistura.

Foi encontrado um aumento significante na resistência flexional nos grupos reforçados com as concentrações em peso de $1 \%$ e $2 \%$ de fibras, enquanto que maiores concentrações provocaram diminuição desta resistência, além disso a deformação alcançada no momento da fratura mostrou-se estatisticamente maior no grupo com a concentração de 1\%. O autor finalizou ratificando que altas concentrações de fibras de vidro incorporadas à mistura da resina resultam na perda de homogeneidade e aumento da porosidade, provocando uma diminuição de sua resistência.

IRELAND et $\mathrm{al}^{28}$, em 1998, comentaram sobre a importância de se compreender as propriedades mecânicas dos materiais restauradores temporários para se determinar a capacidade da restauração provisória em resistir às forças funcionais repetidas.

Contribuindo com o estudo dessas propriedades, os autores investigaram a resistência flexional e o módulo de elasticidade, em função do tempo de imersão em 
água, de corpos de prova obtidos com quatro resinas utilizadas em restaurações provisórias: uma resina à base de PMMA auto-polimerizável; uma mistura de resina pigmentada com outra incolor também à base de PMMA; uma resina UDMA; e uma resina com polimerização dual.

Em seus resultados, evidenciaram que a resina de polimerização do tipo "dual" exibiu os maiores valores do módulo de elasticidade e da resistência flexional após 24 horas de imersão em água, porém esta mesma resina obteve a maior diminuição destas propriedades em função do tempo de armazenamento.

STIPHO ${ }^{53}$, ainda em 1998, examinou os efeitos do uso de fibras de vidro précortadas em tamanhos curtos, com $2 \mathrm{~mm}$ de extensão, em diversas concentrações, na resistência e deflexão de espécimes em PMMA termo-polimerizável quando reparados com PMMA auto-polimerizável.

O autor, neste estudo, avaliou os espécimes através de um teste de carga de três pontos. Encontrou em seus resultados que todos os corpos de prova, reforçados ou não, demonstraram uma diminuição significante na carga de fratura e na deflexão máxima após o reparo. Os espécimes reparados por meio de uma quantidade menor de reforço, em peso, apresentaram um aumento significante na sua resistência à flexão. Todos os espécimes, entretanto, demonstraram diminuição do módulo de elasticidade após o reparo. O grupo contendo fibras na concentração de $1 \%$ após o reparo, teve resultados melhores que o grupo controle sem reforço e íntegro. Não foram encontradas diferenças estatísticas nas propriedades estudadas pela incorporação de fibras numa concentração acima de 5\%. 
VALLITTU; RUYTER; EKSTRAND ${ }^{70}$, em 1998, determinaram as propriedades flexionais de dois polímeros à base de PMMA, um auto e outro termo-polimerizável, quando reforçados com fibras de vidro contínuas ou com fibras de sílica, em função do tempo de armazenamento em água. Utilizaram espécimes que foram ensaiados através de um teste de carga de três pontos para registro do limite da resistência flexional, módulo de elasticidade e deformação no momento da fratura, após a imersão durante 2, 4, 12, 24 e 48 semanas em água destilada.

Em seus resultados, observaram que o armazenamento em água diminuiu significantemente a resistência flexional e o módulo de elasticidade nos espécimes sem reforço, evidenciando o efeito plastificante resultado da interação das moléculas de água com a estrutura do polímero. A resistência flexional também decresceu nos espécimes reforçados, tanto com as fibras de vidro quanto com as de sílica, tendo sofrido esta última uma maior diminuição. Os autores ainda citaram que a adesão entre as fibras e a matriz da resina diminuiu com a imersão, porém esta redução foi menor nos espécimes reforçados com as fibras de vidro. Explicaram que as regiões das fibras que não sofreram uma boa impregnação causaram porosidades que, provavelmente, aumentaram a absorção de água provocando a diminuição da resistência flexional. Por fim, justificaram que esta impregnação pela resina foi menor quando se utilizaram fibras de sílica.

VALLITTU ${ }^{65}$, também em 1998, fez um estudo motivado a determinar experimentalmente a resistência à tração e o módulo de elasticidade de compostos 
em resina acrílica PMMA auto-polimerizável reforçados com fibras de vidro unidirecionais. Espécimes medindo $16 \times 3 \times 2 \mathrm{~mm}$ foram confeccionados em um desenho em forma de alteres, próprio para testes de tração, adicionando fibras em diversas concentrações em peso, longitudinalmente e paralelas à força. Esses corpos de prova foram mantidos em água a $37^{\circ} \mathrm{C}$ durante quarenta dias.

Evidenciou que os espécimes reforçados com 14,8 \% em peso de fibras tiveram sua resistência à tração e módulo de elasticidade aumentados significantemente. Esses valores, entretanto, foram menores que os encontrados através de um cálculo teórico, considerando os materiais puros, secos e totalmente aderidos uns aos outros. O autor percebeu que essa diferença foi encontrada por uma diversidade de variáveis tais como: a imersão em água, a dificuldade de se obter uma interface resina-fibra com uma adesão mais forte e a característica multifásica do PMMA usado na Odontologia, justificando sua heterogeneidade. Explicou ainda que o PMMA é polimerizado a partir de uma mistura de pérolas prépolimerizadas de PMMA e o monômero líquido MMA, formando um polímero multifásico contendo uma matriz polimérica, pérolas de PMMA e uma rede polimérica interpenetrando estes dois componentes.

TANER et $\mathrm{aP}^{54}, 1999$, avaliaram e compararam a resistência ao impacto e à tração de uma resina à base de PMMA termo-ativado, a qual foi reforçada com diversas quantidades de fibras de poli(etileno) de alto peso molecular com concentrações variando entre $1 \%$ a $10 \%$ em peso, sem qualquer tratamento ou modificação química superficial destas fibras. 
Encontraram em seus resultados, uma relação linear existente entre a concentração de fibra e a resistência ao impacto, não existindo diferenças significativas somente quando as concentrações foram entre $1 \%$ e $2 \%$. A concentração de $10 \%$ em peso das fibras resultou nos maiores valores dessa resistência.

Sobre a resistência à tração, os autores observaram uma diminuição inicial nesta propriedade associada com a inclusão de fibras na mistura, tendo uma pequena recuperação quando a concentração alcançou 5\%. A adição de fibras além dessa concentração diminuiu drasticamente a sua resistência à tração. Os autores relataram que embora clinicamente o alongamento por tração muitas vezes não alcance o seu limite de resistência, os resultados não podem ser subestimados.

VALLITTU ${ }^{66}$, em 1999, relatou que a resistência flexional dos polímeros baseados em PMMA usados em próteses provisórias pode ser ligeiramente aumentada através do uso de reforços metálicos, entretanto, a influência destes reforços sobre a resistência à fadiga é questionável. As fibras de vidro, por sua vez, podem oferecer tanto características estéticas quanto melhores propriedades mecânicas, incluindo aumento da resistência à fadiga. Um dos requisitos para a eficiência dessas fibras é que mantenham uma ótima união com a matriz do polímero PMMA. A boa impregnação das fibras, portanto, concorre pelo aumento dessa adesão. Motivado por essa afirmativa, pesquisou as propriedades flexionais, resistência à flexão e módulo de elasticidade de polímeros à base de PMMA auto e termo-polimerizáveis utilizados para a confecção de bases de próteses totais e 
próteses provisórias, quando reforçados com um sistema de fibras de vidro préimpregnadas com um polímero poroso, na sua forma trançada e unidirecional. A impregnação presente na superfície deste sistema de fibras permite um molhamento pela mistura de polímero e monômero da resina a ser utilizada e subseqüente plastificação por dissolução de sua camada de polímero poroso.

Em seu estudo, utilizou normas da ISO tanto nos espécimes obtidos com resina para dentadura $(64,0 \times 10,0 \times 3,3 \mathrm{~mm})$, quanto naqueles com resina para provisório (25, 0 × 2,0 × 2,0 mm), sendo que neste último, fez uso de pressão e calor para a polimerização do polímero. Ambos os corpos de prova foram ensaiados através de um teste de carga de três pontos.

Observou em seus resultados, que o uso dos dois tipos de reforços aumentou significantemente a resistência flexional e o módulo de elasticidade dos polímeros estudados. A resistência encontrada com as fibras unidirecionais foi maior que a oferecida pelas fibras trançadas. A análise microscópica eletrônica, por fim, evidenciou que ambas as fibras foram bem impregnadas pela matriz do polímero utilizado.

UZUN; HERSEK; TINÇER ${ }^{56}$, em 1999, compararam o efeito de cinco tipos de reforços na resistência ao impacto, na resistência flexional, na deflexão e no módulo de elasticidade de espécimes confeccionados com uma resina à base de PMMA termo-polimerizável.

Os corpos de prova foram reforçados com fibras entrelaçadas à base de vidro, de carbono, de aramida (delgada e espessa) e de poli(etileno). 
Baseados em seus resultados, concluíram que os espécimes reforçados com fibras de poli(etileno) e de vidro foram consideravelmente mais resistentes ao impacto. O uso da fibra de poli(etileno) diminuiu a deflexão dos corpos de prova. No que diz respeito à resistência flexional, nenhuma das fibras melhorou estatisticamente esta propriedade em relação ao grupo controle. Finalizaram citando que as amostras reforçadas com fibras de poli(etileno), fibras de carbono e fibras espessas de aramida, registraram um aumento significantemente do seu módulo de elasticidade.

NOHRSTRÖM; VALLITTU; YLFURPO ${ }^{41}$, em 2000, defenderam que a qualidade das próteses parciais fixas provisórias é dependente de uma boa integridade marginal, adequada rigidez e resistência suficiente para resistir às cargas mastigatórias. A rigidez e a resistência são resultados do tipo de polímero e do possível tipo de reforço utilizado. Concordaram que os polímeros mais utilizados são baseados em PMMA ou em uma variação do mesmo. No que diz respeito aos reforços, explicaram que as fibras de poli(etileno) apresentam a desvantagem de não permitirem uma boa adesão entre a matriz polimérica e sua superfície. As fibras de vidro, ao contrário, por possibilitarem a sua silanização apresentam uma boa adesão com a matriz de PMMA, aumentando seu potencial como reforço destes materiais.

Os autores, sustentados por essas informações, estudaram a influência da posição e do número de fibras de vidro com arranjos unidirecionais ou entrelaçados, na resistência à fratura de próteses provisórias confeccionadas com uma mistura do 
polímero PEMA e o monômero n-butilmetacrilato. Avaliaram, além disso, o efeito da distância entre os pilares nessa resistência.

Pesquisaram sobre o uso das fibras posicionadas na superfície oclusal dos preparos dos pilares, na superfície inferior do pôntico, e quando em ambas as posições. Confeccionaram próteses com vãos de 10,0, 17,0, e 19,5 mm.

Os autores concluíram que a utilização de fibras posicionadas na parte inferior do pôntico associadas a um primeiro reforço localizado próximo à superfície oclusal dos pilares aumentou a resistência à fratura dos corpos de prova. A eficiência dos reforços foi mais evidente quando se utilizaram próteses com vãos mais extensos.

OGAWA; TANAKA; KOYANO ${ }^{42}$, em 2000, também amparados na proposição de que as restaurações provisórias estão susceptíveis à fratura, em função do tempo, principalmente quando apresentam vãos mais longos, sugeriram a pesquisa de um método para se aumentar a resistência destas restaurações.

Os autores fizeram um estudo com o propósito de examinar os efeitos do ambiente em que a resina acrílica é polimerizada, na sua resistência flexional e no seu módulo transverso. Os autores utilizaram espécimes medindo $25 \times 2 \times 2 \mathrm{~mm}$ confeccionados em PMMA auto-polimerizável utilizado para a confecção de próteses provisórias. A polimerização dos espécimes ocorreu em dois ambientes distintos: imersos n'água, à temperatura que variou entre $10^{\circ} \mathrm{C}$ e $80^{\circ} \mathrm{C}$; ou expostos ao ar, a 23ํㅡ. O tempo decorrido da polimerização sob estas condições controladas foi de 1 minuto e 50 segundos. 
Seus resultados demonstraram que a polimerização da resina em água com temperaturas maiores que a do ambiente a $23^{\circ} \mathrm{C}$ aumentou sua resistência mecânica. A imersão em água a $60^{\circ} \mathrm{C}$ e $80^{\circ} \mathrm{C}$ produziu uma resistência flexional e módulo de elasticidade duas vezes maiores que aqueles obtidos quando a polimerização aconteceu à temperatura ambiente. Os autores concluíram que este método, isto é, o uso de água quente na polimerização das resinas pode ser útil e melhorar as propriedades mecânicas nos provisórios utilizados clinicamente.

NAGAI et $\mathrm{al}^{40}$, em 2001, estudaram a eficiência de dois reforços na resistência de uma resina acrílica PMMA termo-polimerizável quando reparada com PMMA quimicamente ativado. Avaliaram o uso de fibras de vidro trançadas, além de um fio metálico, também trançado, na resistência flexional e no módulo de elasticidade de espécimes medindo $64,5 \times 10,5 \times 3 \mathrm{~mm}$. Verificaram também o efeito do tratamento superficial da resina termo-ativada com cloreto de metileno previamente ao reparo.

Observaram que o tratamento da superfície da resina com cloreto de metileno resultou em um aumento da resistência à flexão e do módulo de elasticidade dos espécimes reparados, com e sem reforços. Os maiores valores dessas propriedades foram encontrados naqueles espécimes em que o tratamento superficial foi associado ao reforço com fibras de vidro, tendo sido significantemente maiores que os valores encontrados nos espécimes íntegros. 
POLYZOIS et $\mathrm{al}^{45}$, em 2001, investigaram o efeito de reforços à base de fibras de vidro e de fios metálicos na deflexão, energia absorvida e resistência à flexão de espécimes confeccionados em resina acrílica PMMA termo-polimerizável quando reparados com resina PMMA quimicamente ativada. Utilizaram barras que foram submetidas a um teste de carga de três pontos. Os reforços foram os seguintes: uma camada de fibras de vidro entrelaçadas, seis camadas dessas mesmas fibras, um fio metálico de 1,5 mm de diâmetro e um fio metálico trançado achatado medindo $1,8 \mathrm{x}$ $0,8 \mathrm{~mm}$.

Evidenciaram que todos os grupos que sofreram o reparo exibiram diminuição das propriedades estudadas, com exceção das amostras reforçadas com o fio metálico com 1,5 mm de diâmetro, as quais exibiram valores de resistência à flexão estatisticamente maiores que os encontrados nos espécimes íntegros. Os que foram reparados e reforçados com as fibras de vidro exibiram melhores propriedades que aqueles reparados sem a utilização de reforços.

HASELTON; DIAZ-ARNOLD; VARGAS ${ }^{24}$, em 2002, investigaram a resistência flexional de treze marcas comerciais de materiais utilizados para confecção de próteses provisórias. Utilizaram resinas à base de MMA e bis-acrilatos e produziram espécimes medindo $25 \times 2 \times 2 \mathrm{~mm}$ que foram avaliados em um teste de carga de três pontos.

Os resultados mostraram que apesar das quatro resinas mais resistentes terem sido à base de bis-acrilatos, não houve correlação entre a resistência flexional e o tipo de resina utilizada. Os autores relataram, ao final, algumas características 
das resinas PMMA tradicionais, tais como baixo peso molecular, moléculas lineares, além de resistência flexional e rigidez diminuídas, ao contrário das resinas bisacrilatos que são materiais compostos com ligações cruzadas mais efetivas e com melhores propriedades mecânicas. 


\section{3 - PROPOSIÇÃO}

Diante da escassez de trabalhos que tenham avaliado, conjuntamente, o efeito de diversos tipos de reforços sobre as propriedades mecânicas de resinas PMMA autopolimerizáveis empregadas na confecção de próteses provisórias, este estudo laboratorial tem como propostas:

a) Avaliar o efeito de sete diferentes tipos de reforços, na resistência flexional e no módulo de elasticidade de uma resina PMMA autopolimerizável.

b) Analisar e classificar os tipos de fraturas apresentados pelos espécimes quando utilizados os reforços. 


\section{4 - MATERIAL E MÉTODOS}




\section{4 - MATERIAL E MÉTODOS}

A confecção e os ensaios mecânicos dos espécimes foram realizados seguindo, principalmente, os parâmetros determinados pela International Organization for Standardization (ISO), norma número 10477:1992/Amd.1:199827.

\section{Confecção da matriz metálica}

Com o auxílio de um torno eletrônico computadorizado* foi fabricada uma matriz metálica que pudesse ser utilizada tanto para a confecção das amostras sem reforço quanto para as reforçadas.

A matriz consiste de três partes, sendo que a parte central foi vazada formando uma cavidade medindo $35,0 \mathrm{~mm}$ de extensão, 2,0 $\mathrm{mm}$ de largura, e 2,0 $\mathrm{mm}$ de altura. As outras duas partes são iguais, sendo uma posicionada superiormente e outra inferiormente à parte central vazada. Cada uma dessas duas partes contém dois guias que foram localizados nas suas extremidades para permitir a fixação dos reforços e o seu posicionamento o mais centralmente possível no interior do espécime em resina, além de limitar o comprimento final dos corpos de prova em 25,0 mm. As partes da matriz e suas dimensões estão ilustradas nas Figuras 1 a 6.

\footnotetext{
* Gentilmente disponibilizado pela Ki-metais Ltda. Bauru-SP
} 


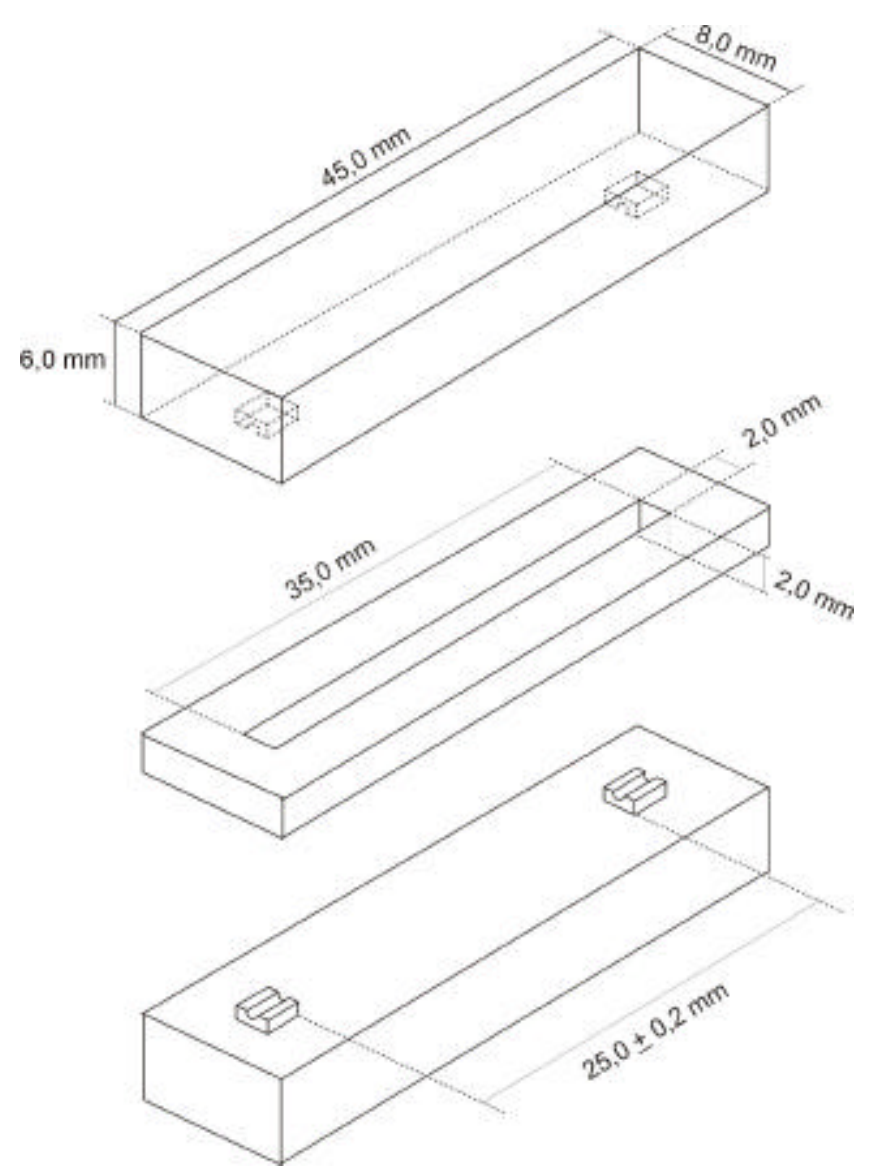

Figura 1 - llustração da matriz metálica para confecção dos corpos de prova com a localização dos guias.

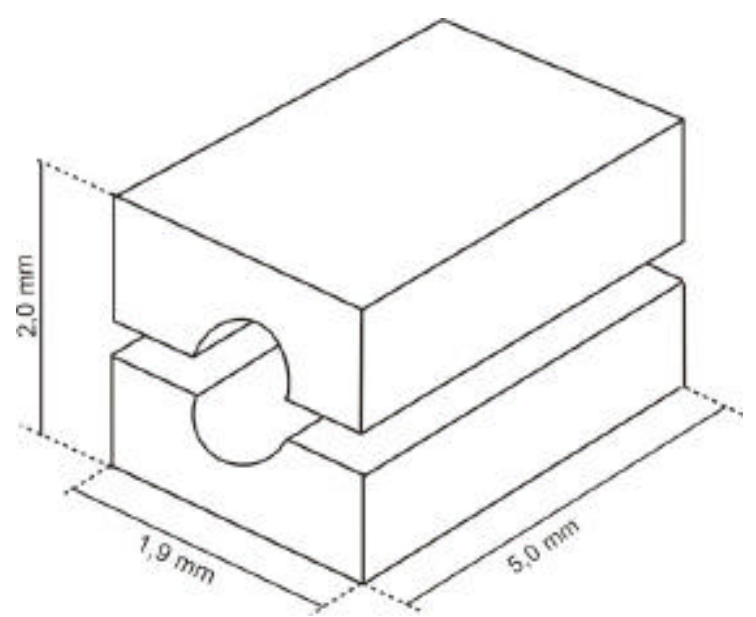

Figura 2 - Detalhe do relacionamento dos guias quando a matriz se encontra fechada, evidenciando suas dimensões 

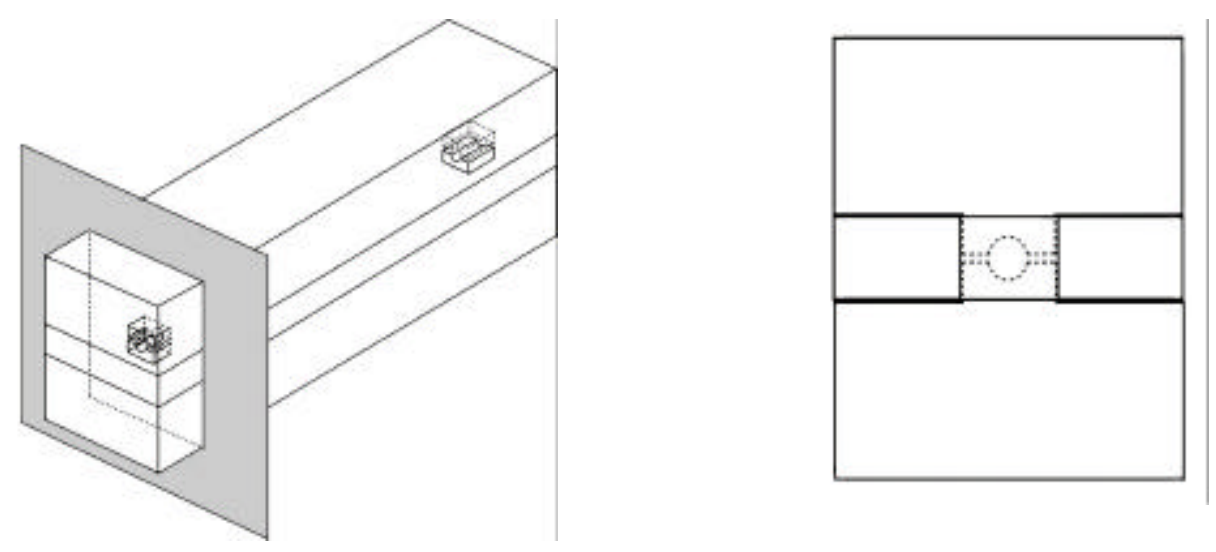

Figura 3 - Secção transversal da matriz quando fechada, mostrando o posicionamento dos guias



Figura 4 - Secção transversal mostrando os espaços formados pelos guias quando a matriz se encontra fechada. Um espaço de 0,4 $\mathrm{mm}$ foi mantido para apreensão das fibras, enquanto que o espaço na forma de uma circunferência com $0,8 \mathrm{~mm}$ de diâmetro foi desejado para a fixação do fio de aço com $0,7 \mathrm{~mm}$ e da amarria trançada 


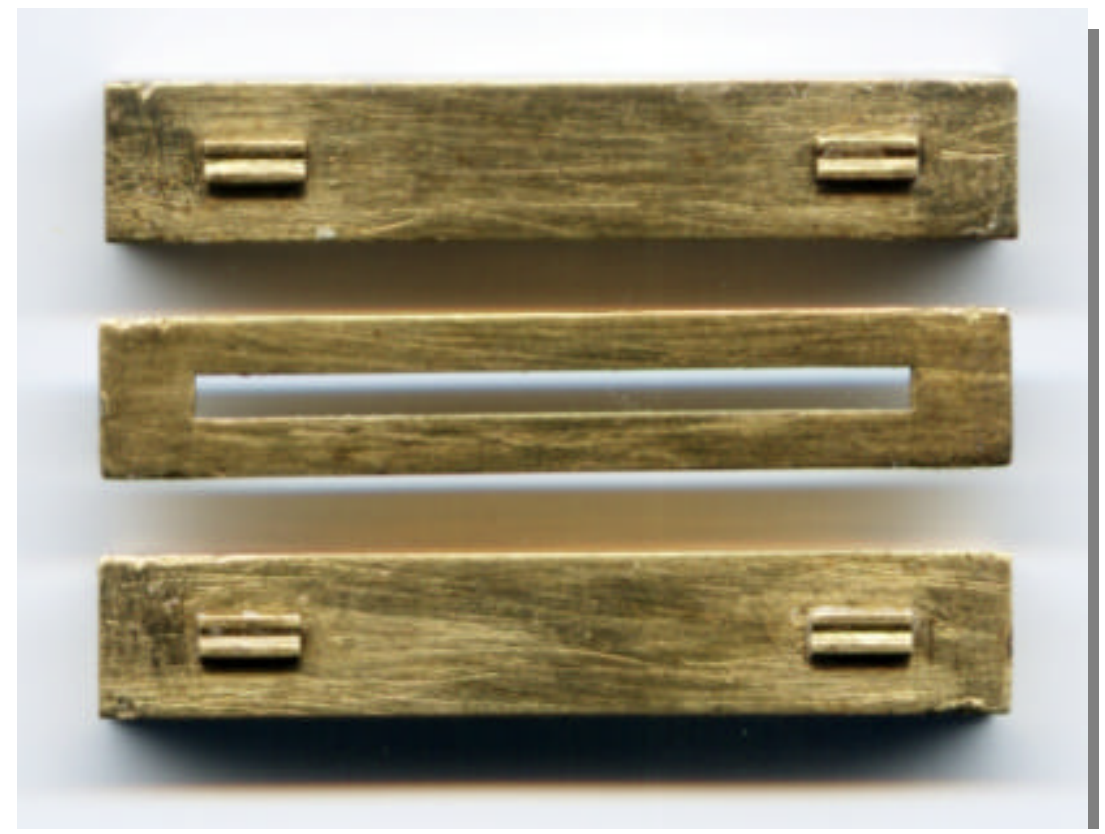

Figura 5 - Ilustração das três partes da matriz metálica, sendo uma posicionada centralmente às outras duas, para a confecção dos espécimes em resina, com e sem reforço.

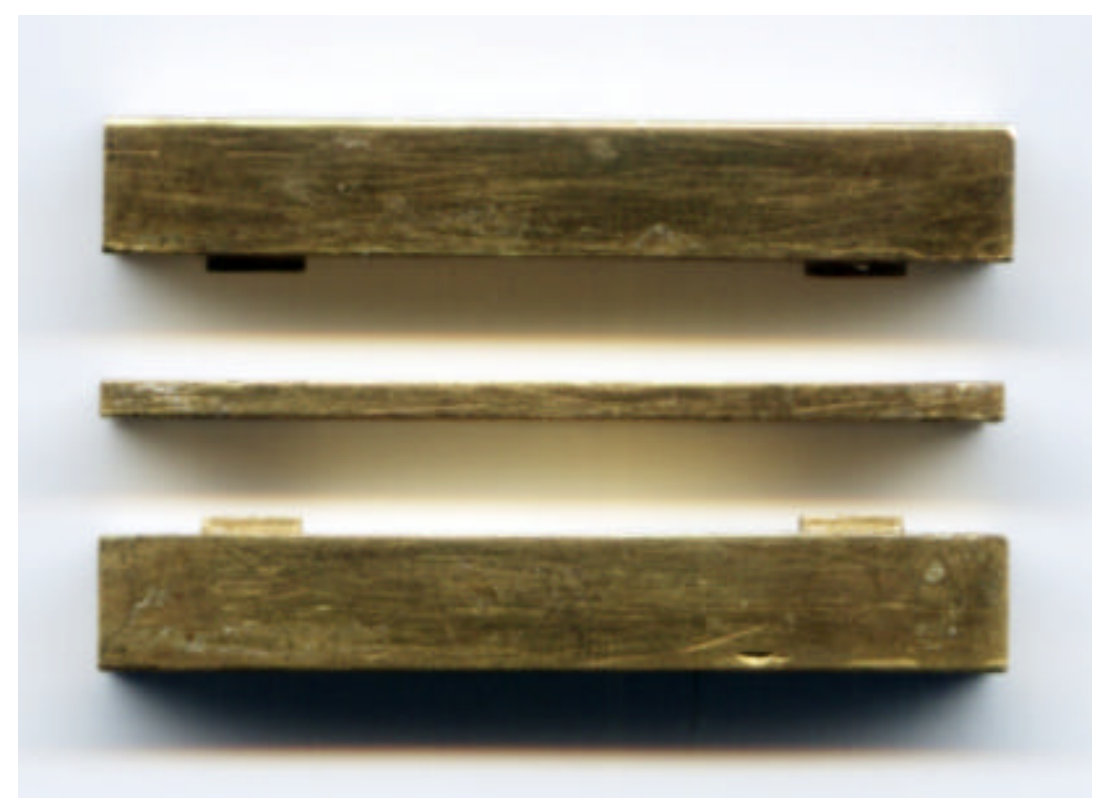

Figura 6 - Vista lateral das três partes desarticuladas da matriz metálica utilizada para a confecção dos espécimes, com e sem reforço 


\section{Confecção dos espécimes}

Todos os espécimes, com e sem reforço, foram preparados utilizando a resina Dencor $^{\circledR}$ (Artigos Odontológicos Clássico LTDA, São Paulo - SP), cor ํㅡ 66. A resina Dencor ${ }^{\circledR}$ é uma resina acrílica PMMA auto-polimerizável indicada, segundo os fabricantes, para a execução de restaurações, coroas e facetas, e empregada rotineiramente na confecção direta de próteses provisórias.

O presente estudo foi constituído por oito grupos de dez espécimes cada um. Um grupo controle não reforçado e sete grupos experimentais reforçados com dois tipos de fios metálicos e cinco tipos de fibras. A divisão dos grupos, além das identificações e características dos reforços utilizados estão mostrados na Tabela 1.

\section{Confecção dos espécimes sem reforço}

Para confecção dos corpos de prova sem reforço que representaram o Grupo CONTROLE, inicialmente foi aplicado um isolante (Cera Hoechst ${ }^{\circledR}-\mathrm{V}$ P.6456 diluída em $10 \%$ em benzina) sobre a matriz metálica com o auxílio de um pincel ํำ 1 . O excesso foi removido com lenços de papel e esperou-se até que a superfície da matriz estivesse seca.

O polímero (pó) da resina foi pesado em uma balança com precisão de 0,001 g (Sauter $^{\circledR}$, model K1200, Switzerland), enquanto o monômero (líquido) foi aspirado e medido com uma pipeta $\left(\right.$ Pyrobras $^{\circledR}$ ) com capacidade de 1,0 ml, graduada em intervalos de $0,1 \mathrm{ml}$, com o auxílio de um pipetador (Bel-art products ${ }^{\circledR}$, Spain) para pipetas com volume de 1 a $5 \mathrm{ml}$. 
Na mistura foram utilizados $1,50 \mathrm{~g}$ de polímero e $0,70 \mathrm{ml}$ de monômero, equivalente a proporção em volume de 3:1 indicada pelo fabricante, sendo que somente uma porção dessa mistura foi utilizada para a confecção do corpo-deprova. O líquido (monômero) foi despejado em um pote Dappen e sobre ele foi dispensado o pó (polímero). Usando-se uma espátula no 7, foram misturados lentamente por cerca de cinco segundos. Esperou-se a saturação do conjunto por cerca de dois minutos no interior do pote Dappen com uma placa de vidro medindo 5 $X 5 \mathrm{~cm}$ vedando-o superiormente.

A resina foi inserida na cavidade da parte central da matriz metálica posicionada sobre a parte inferior contendo os guias. A inclusão da resina se deu através de uma única etapa com o auxílio de uma espátula de inserção no 1 (Figura 10). As três partes da matriz foram pressionadas com ajuda de uma pequena prensa até que mantivessem o máximo de contato possível analisado visualmente. 0 excesso de resina extravasado pelas interfaces, entre as partes da matriz, foi removido com uma lâmina de bisturi no 15. A manipulação e a inserção da resina foram realizadas em laboratório com temperatura e umidade relativa do ar controladas, em $22^{\circ}$ C e $45 \%$, respectivamente.

A matriz metálica contendo a resina foi imersa em água em um recipiente plástico e permaneceu por vinte minutos no interior de uma estufa (Fanem, mod. 315 - SE, SP, Brasil) a 37ำ C durante 20 minutos. Após essa polimerização inicial o espécime foi removido cuidadosamente, acabado com um silicone abrasivo (KG Sorensen Ref. 9226 PM) e armazenado novamente em água a 37ํㅡ por 48 horas. 


\section{Confecção dos espécimes com reforço}

Os espécimes reforçados foram confeccionados de forma similar àqueles sem reforço. A resina foi igualmente proporcionada e misturada, entretanto, a inserção aconteceu em duas etapas descritas a seguir (Figuras 7 a 12). O reforço que seria utilizado foi imerso no respectivo monômero MMA da resina Dencor ${ }^{\circledR}$, durante cinco minutos, e ao mesmo tempo a resina era manipulada da mesma maneira como foi descrita anteriormente. O excesso de monômero foi removido das fibras ou dos fios com auxílio de lenços de papel. Após o tempo de espera para saturação da mistura da resina, a primeira camada foi inserida de modo que a metade, cerca de $1,0 \mathrm{~mm}$, da parte vazada da matriz fosse preenchida. Posicionou-se o reforço sobre os guias da parte inferior da matriz e em seguida completourse o restante da cavidade com uma segunda camada da mesma mistura da resina. A matriz foi fechada com ajuda de uma pequena prensa da mesma forma que nos espécimes sem reforços.

O excesso de resina foi removido e a matriz foi imersa em água a $37^{\circ} \mathrm{C}$ por vinte minutos. O espécime foi removido com cuidado e armazenado novamente em água a $37^{\circ} \mathrm{C}$ por 48 horas previamente ao ensaio. As figuras 13 e 14 ilustram os espécimes em resina com o reforço posicionado centralmente em seu interior denominado eixo neutro.

Os reforços utilizados estão descritos na Tabela 1 e nas Figuras 15 a 19 . Esses materiais são disponibilizados em diversas formas, por isso foram cortados em comprimentos adequados para que pudessem ser posicionados no interior da matriz. 
Tabela 1 - Informação dos grupos e descrição dos reforços utilizados

\begin{tabular}{|c|c|c|c|c|}
\hline Grupo $(\mathrm{N}=10)$ & Nome/Fabricante & Composição & Medidas & Referência \\
\hline CONTROLE & Sem reforço & - & - & - \\
\hline FIO 0,7 & $\begin{array}{l}\text { Fio metálico ortodôntico } \\
\qquad 0,7 \\
\text { Dental Morelli }{ }^{\circledR} \text { Ind. Bras. }\end{array}$ & Aço inoxidável & $\begin{array}{l}\text { Fio com } 5 \mathrm{~m} \text { de extensão e } \\
0,70 \mathrm{~mm} \text { de diâmetro }\end{array}$ & - \\
\hline AMARRILHO & $\begin{array}{c}\text { Fio metálico para } \\
\text { amarrilho } \\
\text { Dentaurum }^{\circledR} \text { - Germany }\end{array}$ & Aço inoxidável & $\begin{array}{c}\text { Rolo de fio com } 5 \mathrm{~m} \text { de } \\
\text { comprimento e } 0,24 \mathrm{~mm} \text { de } \\
\text { diâmetro }\end{array}$ & - \\
\hline CONNECT & $\begin{array}{c}\text { Connect }^{\circledR} \\
\text { KerrLab }^{\circledR} \text { - Orange, CA - } \\
\text { USA }\end{array}$ & $\begin{array}{c}\text { Fibras trançadas de } \\
\text { poli(etileno) tratadas } \\
\text { superficialmente com plasma } \\
\text { gasoso à frio }\end{array}$ & $\begin{array}{c}\text { Carretel de fita com } 915 \mathrm{~mm} \\
\text { de extensão e 2,0 mm de } \\
\text { largura }\end{array}$ & $\begin{array}{l}\text { № ref.: } 900-679 \\
\text { № lote: } 109320\end{array}$ \\
\hline GLASSPAN & $\begin{array}{c}\text { GlasSpan }^{(\circledast)} \text { - Tape } \\
\text { GlasSpan }^{\circledR}\end{array}$ & $\begin{array}{c}\text { Fibras cerâmicas trançadas } \\
\text { flexíveis }\end{array}$ & $\begin{array}{l}\text { Três fitas com } 90 \text { mm de } \\
\text { extensão e 2,0 mm de largura }\end{array}$ & $\begin{array}{l}\text { № ref.: } 0473 \\
\text { № lote.: nd }\end{array}$ \\
\hline SPLINT-IT & 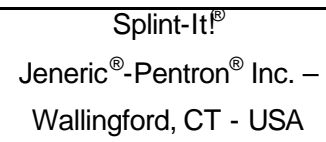 & $\begin{array}{c}\text { Fibras de vidro entrelaçadas } \\
\text { impregnadas com resina } \\
\text { composta }\end{array}$ & $\begin{array}{c}\text { Seis fitas com } 75 \mathrm{~mm} \text { de } \\
\text { extensão e 2,0 mm de largura }\end{array}$ & $\begin{array}{c}\text { № ref.: N23B } \\
\text { № lote: } 2130.1\end{array}$ \\
\hline INTERLIG & $\begin{array}{c}\text { Interlig }^{\circledR} \\
\text { Ângelus }^{\circledR} \text { - Odonto-lógika } \\
\text { Ind. Ltda - Londrina, PR } \\
\text { - Brasil }\end{array}$ & $\begin{array}{c}\text { Fibras de vidro trançadas } \\
\text { impregnadas com resina } \\
\text { composta }\end{array}$ & $\begin{array}{c}\text { Seis fitas com } 85 \mathrm{~mm} \text { de } \\
\text { extensão e 2,0 mm de largura }\end{array}$ & $\begin{array}{l}\text { № ref.: } 484 \\
\text { № lote: } 1183\end{array}$ \\
\hline FIBRANTE & $\begin{array}{c}\text { Fibrante }^{\circledast} \\
\text { Ângelus }^{\circledR} \text { - Odonto-lógika } \\
\text { Ind. Ltda - Londrina, PR } \\
\text { - Brasil }\end{array}$ & $\begin{array}{c}\text { Fibras de vidro unidirecionais } \\
\text { impregnadas com } \\
\text { glicoldimetacrilato }\end{array}$ & $\begin{array}{l}\text { Um feixe de fibras com } 500 \\
\text { mm de extensão }\end{array}$ & $\begin{array}{l}\text { № ref.: } 490 \\
\text { № lote: } 1010\end{array}$ \\
\hline
\end{tabular}




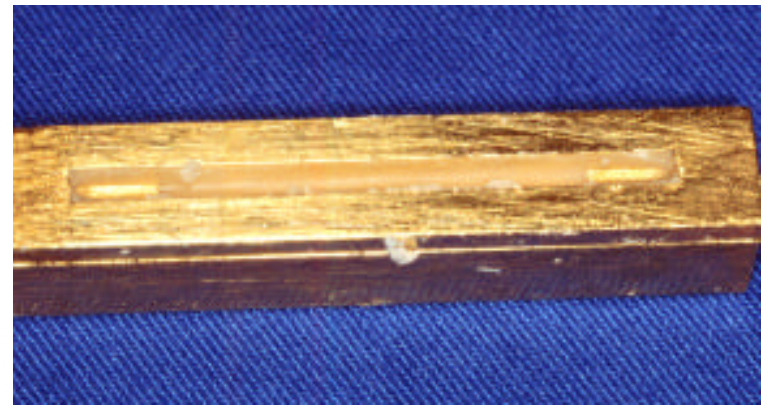

Figura 7 - Metade da matriz preenchida com resina

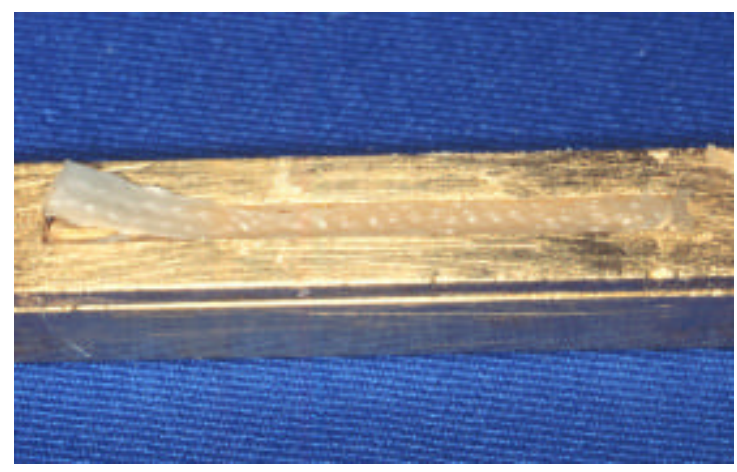

Figura 9 - Metade da matriz preenchida com resina e um exemplar de fibra posicionado sobre os guias

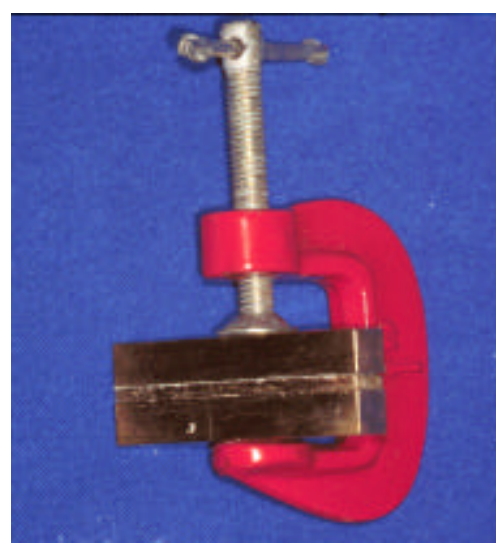

Figura 11 - Pequena prensa mantendo a matriz fechada

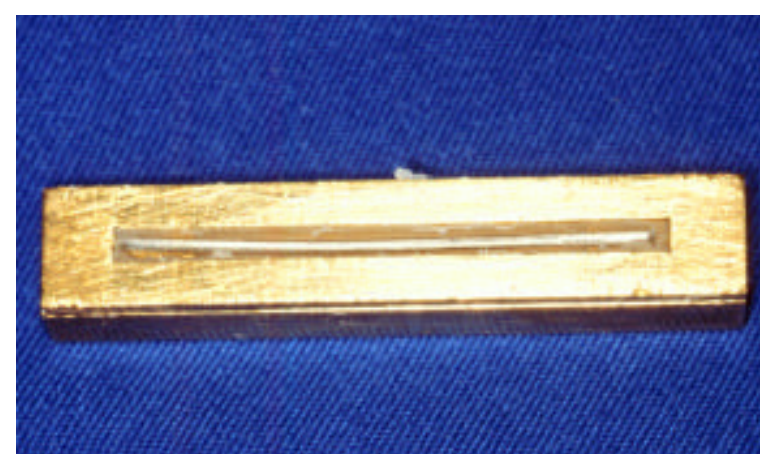

Figura 8 - Metade da matriz preenchida com resina e reforço metálico posicionado sobre os guias

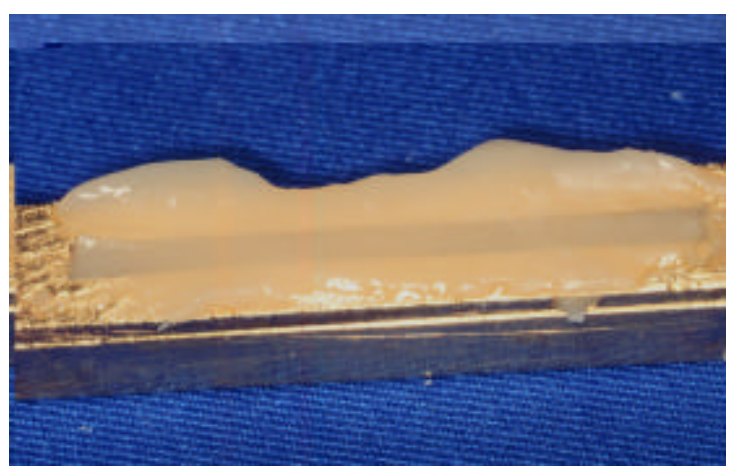

Figura 10 - Matriz totalmente preenchida com resina. No grupo controle, os espécimes foram diretamente preenchidos desta maneira, sem a necessidade de vazar inicialmente a primeira metade da matriz

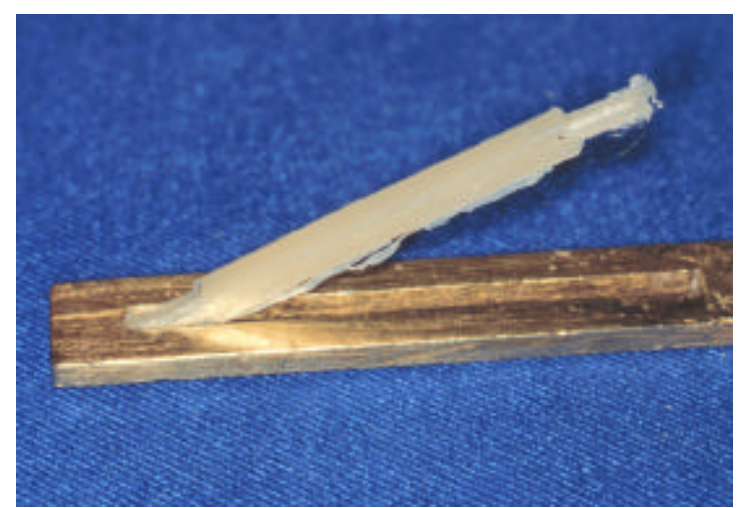

Figura 12 - Remoção dos espécimes do interior da parte central da matriz 
As superfícies lisas dos fios metálicos cilíndricos foram modificadas para que se tornassem ásperas. Uma abrasão foi provocada através de uma ponta abrasiva de carborundum com granulação média (Pontas Schelble Ltda. Petrópolis -RJ. Ref. 02) sob baixa rotação aplicada em toda superfície de cada fio.

Os fios ortodônticos para amarrilho foram também modificados. Cortourse cerca de $80 \mathrm{~mm}$ desse fio que foi dobrado ao meio e, com auxílio de dois alicates ortodônticos nำ156, apreendeu-se cada extremidade e com cerca de 20 voltas completas dadas com um dos alicates se obteve o fio na forma trançada.

Os reforços à base de fibras de vidro ou de poli(etileno) são disponibilizados em formas de longas fitas ou de rolos por isso foram cortados em comprimento. Somente a fibra Fibrante ${ }^{\circledR}$ foi pesada em uma balança de precisão (A\&D GR-202, Japan) para que tivesse $0,047 \mathrm{~g}$ ou cerca de $3,5 \%$, em peso, do espécime final. Por fim, todos os reforços utilizados em cada espécime tiveram um pouco menos que $35,0 \mathrm{~mm}$ de extensão para que pudessem ser posicionados no interior da matriz e fixados pelos guias.

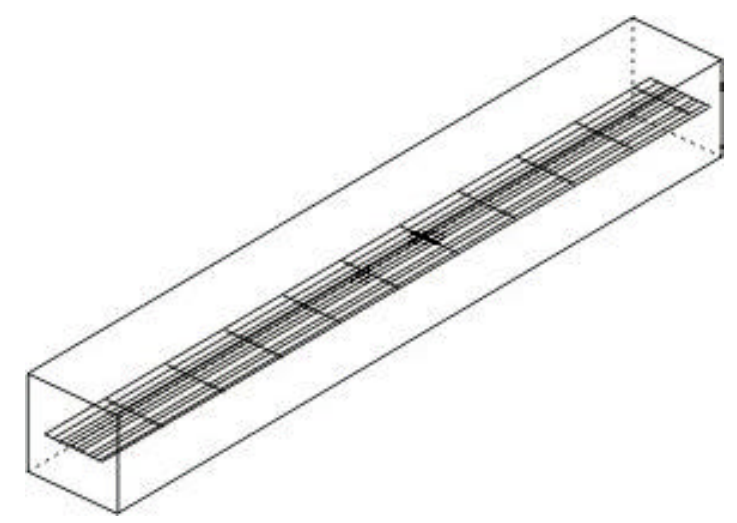

Figura 13 - llustração do espécime contendo no seu interior um reforço em forma de fita.

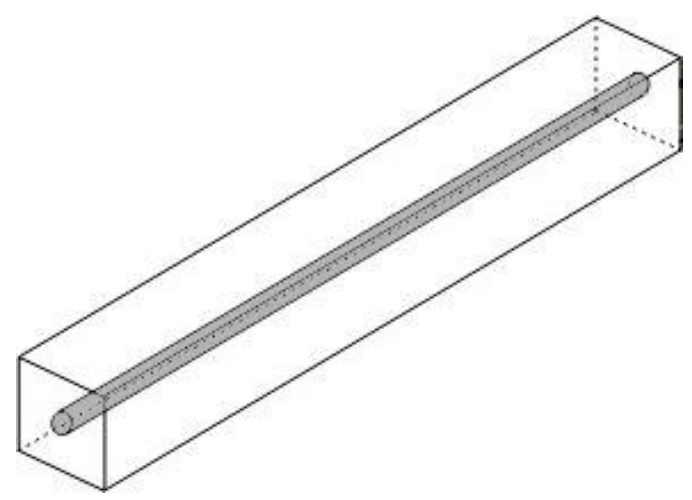

Figura 14 - Ilustração do espécime reforçado com fio metálico 


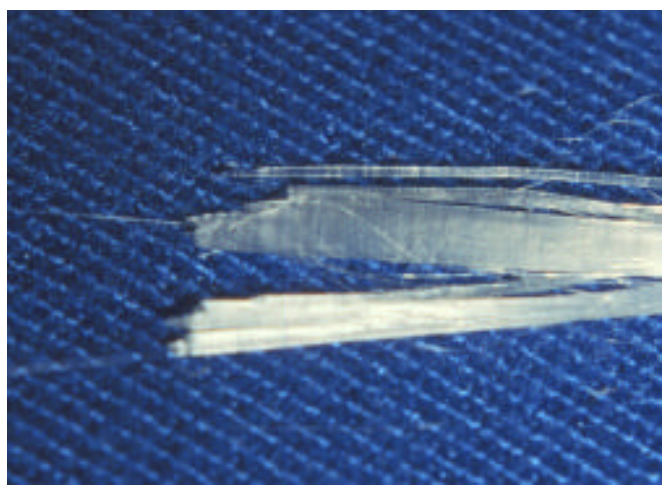

Figura 15 - Detalhe da fibra de vidro unidirecional Fibrante ${ }^{\circledR}$



Figura 17 - Detalhe da fibra de vidro trançada Interlig ${ }^{\circledR}$

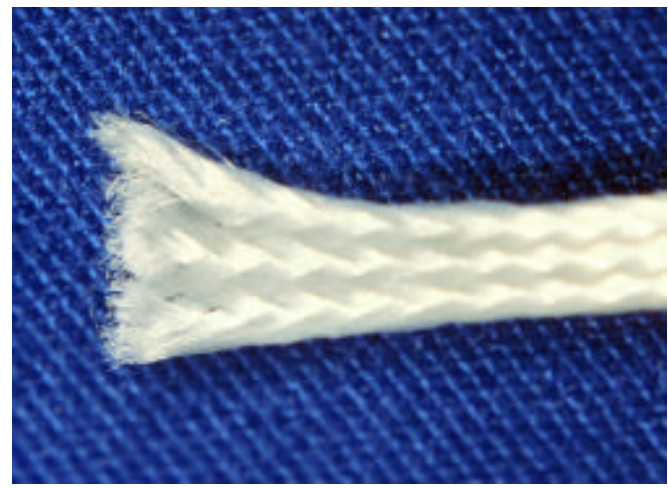

Figura 16 - Detalhe da fibra de poli(etileno) trançada Connect ${ }^{\circledR}$

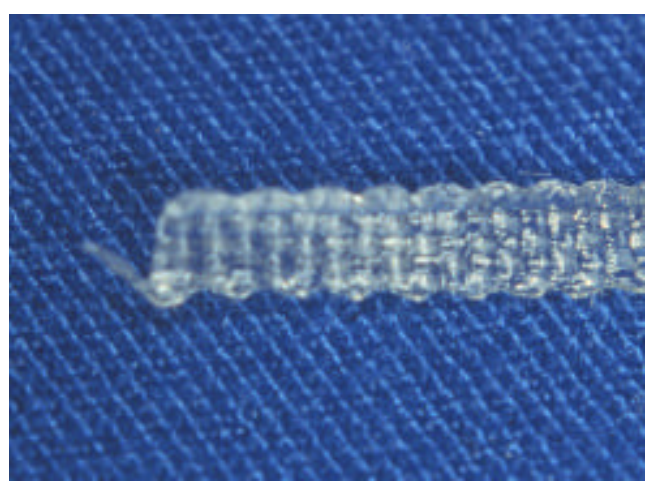

Figura 18 - Detalhe da fibra de vidro entrelaçada Splint It! ${ }^{\circledast}$

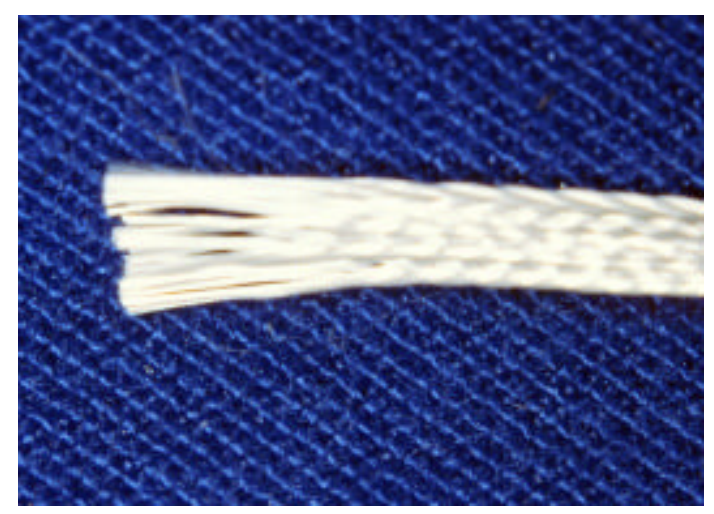

Figura 19 - Detalhe da fibra cerâmica flexível trançada GlasSpan ${ }^{\circledR}$ 


\section{Ensaio mecânico de flexão}

O ensaio mecânico para registro da resistência flexional e cálculo do módulo de elasticidade foi realizado através de um teste de carga de três pontos. Os testes foram executados através de uma máquina universal de ensaios Kratos ${ }^{\circledR}$ (KratosDinamômetros Ltda. São Paulo - SP) onde foram seguidos os parâmetros estabelecidos pela norma ISO no $10477^{27}$.

Foi confeccionada uma base metálica em aço temperado contendo duas varetas suspensas com 2,0 mm de diâmetro, dispostas paralelamente entre si e distantes entre centros $20 \mathrm{~mm}$, onde seriam apoiados os espécimes. Um outro artefato foi fabricado para ser rosqueado à célula de carga, da mesma forma em aço temperado e contendo também uma vareta com 2,0 mm diâmetro (Figura 20).

Durante os testes de compressão essa vareta foi posicionada no centro do espécime, paralelamente e eqüidistante das outras duas varetas localizadas na base metálica onde o corpo de prova estava apoiado.

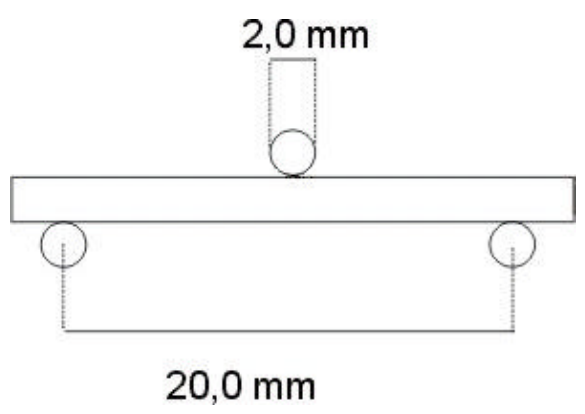

Figura 20 - llustração do teste de carga de três pontos e medidas das hastes e distância do vão estabelecidos pela norma ISO 10477 
O teste foi executado com o auxílio de uma célula de carga de 100 kgf, sendo que a máquina foi configurada para exercer uma pré-carga inicial de 0,050 kgf. A velocidade do cabeçote foi constante em 1,0 mm/ min (Figuras 21 e 22).

Os espécimes foram submetidos à carga compressiva até a fratura. Aqueles que não fraturaram foram permitidos à deformação até uma deflexão máxima de 5,0 $\mathrm{mm}$ registrado pela máquina de testes, a partir do qual o ensaio era interrompido. $\mathrm{O}$ valor de carga máximo, em kgf, obtido em cada amostra, fraturada ou não, foi

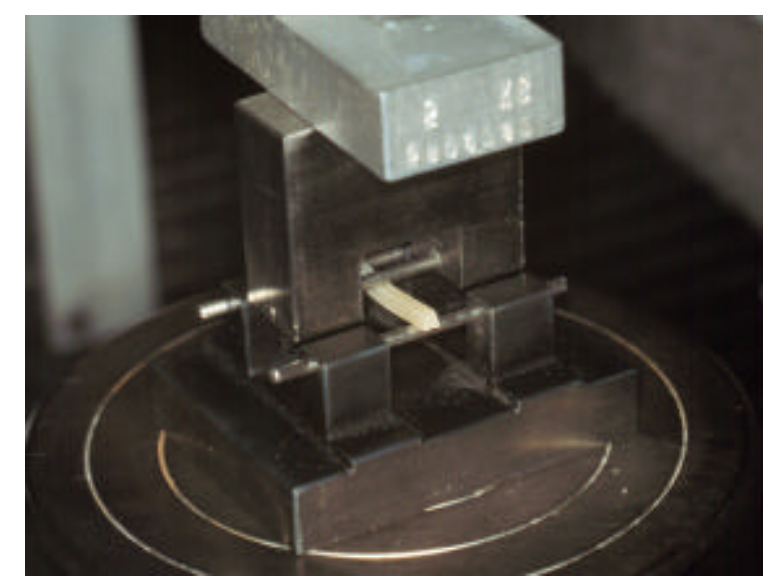

Figura 21 - Ensaio de flexão através do teste de carga de três pontos com auxílio de artefato metálico confeccionado seguindo a norma ISO 10477

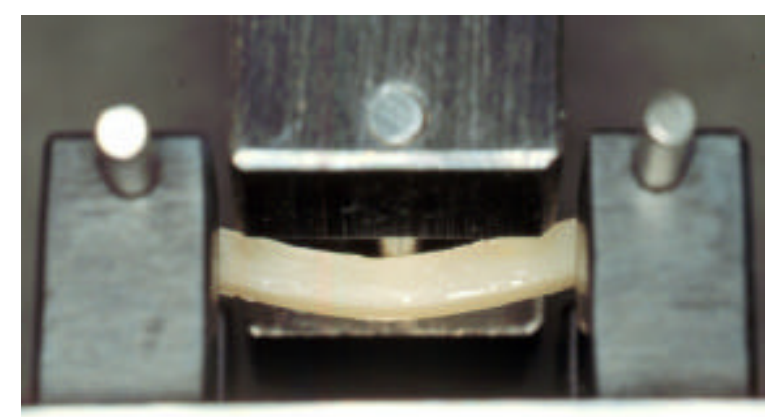

Figura 22 - Espécime de resina defletido em função do ensaio de flexão. Observação da posição da haste central induzindo uma carga no meio do espécime, eqüidistante das duas varetas de apoio. 
registrado e impresso juntamente com o seu respectivo gráfico, através de um programa de computador próprio da $\operatorname{Kratos}^{\circledR}$.

\section{Cálculo da resistência flexional}

Os valores, em MPa, da resistência flexional (ä) foram obtidos utilizando a seguinte fórmula:

$\ddot{a}=3 F I / 2 b h^{2}$; onde $\boldsymbol{F}$ é a carga máxima em Newton; I é a distância entre os suportes, isto é, $20 \mathrm{~mm}$; $\boldsymbol{b}$ é a largura dos espécimes; e $\boldsymbol{h}$ é altura dos espécimes. Para se obter o valor da carga máxima em Newton, suportado por cada corpo de prova, multiplicourse o valor em kgf registrado pela máquina $\operatorname{Kratos}^{\circledR}$ pelo valor aproximado da força de gravidade, ou seja 9,807.

\section{Cálculo do módulo de elasticidade}

Os valores do módulo de elasticidade (å), em Mpa, foram calculados pela seguinte fórmula:

$a ̊ ̊=I^{3} \times F_{1} / 4 f b h^{3}$; onde $I$ é a distância entre os suportes, isto é, $20 \mathrm{~mm}$; $\boldsymbol{b}$ é a largura dos espécimes; e $\boldsymbol{h}$ é altura dos espécimes; $\boldsymbol{F}_{\boldsymbol{1}}$ é a carga, em Newton, registrada em qualquer ponto do gráfico enquanto a deformação ainda é elástica; e $\boldsymbol{f}$ é a deflexão do espécime em milímetros quando registrada a força $F_{1}$. 
Os valores de $F_{1}$ e $f$ foram extraídos dos gráficos relativos aos ensaios dos espécimes de cada grupo. Elegeurse um ponto em cada gráfico onde a deformação do espécime ainda era elástica, isto é, a deformação ainda não era permanente, e verificourse o valor de carga referente. Para execução desse método os gráficos sofreram uma varredura digital através de um "scanner" (ColorPage - Vivid III V2, Genius, China), com uma definição de 200 dpi, para que pudessem ser ampliados, cada um, a $3.200 \%$ e melhor serem visualizados.

\section{Classificação das fraturas}

Cada corpo de prova após o ensaio foi avaliado com auxílio de uma lupa com aumento de quatro vezes (Bio-Art Equip. Odont. Ltda. São Carlos, SP - Brasil) para identificação da presença de fratura. Os espécimes foram classificados com relação à fratura em quatro tipos ilustrados na Tabela 2 e descritos a seguir:

a) Fratura Ausente, quando o espécime sofreu uma deformação permanente sem se fraturar;

b) Fratura Parcial, quando houve uma fratura que se estendeu à interface reforço-resina, ou às suas proximidades;

c) Fratura Total Não Separada, quando a fratura se propagou para além do reforço e partiu o espécime em duas metades, porém foram mantidas unidas pelo reforço que não foi fraturado; e 
d) Fratura Total Separada, quando o espécime foi fraturado e completamente separado em duas metades, sendo que nas amostras reforçadas o material utilizado como reforço também sofreu fratura.

TABELA 2 - Classificação das fraturas sofridas pelos espécimes

\begin{tabular}{l|l|l|}
\hline \multicolumn{1}{c|}{ Classificação da fratura } & Ilustração \\
\hline Ausente & Ou \\
\hline Parcial & & \\
\hline Total Não Separada & OLal Separada & \\
\hline
\end{tabular}

\section{Análise estatística}

Os resultados da resistência flexional e do módulo de elasticidade consistiram em 80 (oitenta) valores numéricos, cada um, resultante do intercruzamento de 8 (oito) grupos de corpos-de-prova e 10 (dez) repetições. Esses dados foram submetidos ao teste de Análise de Variância (ANOVA) para conhecimento da 
existência de diferença significante estatística entre os grupos, quanto à resistência flexional e ao módulo de elasticidade. Efetuourse então o Teste de Tukey, com significância de 5\%, para se esclarecer quais os grupos apresentaram médias significantemente diferentes entre si.

A análise das fraturas dos espécimes foi apresentada em porcentagem, representando a ocorrência de cada tipo de fratura em cada grupo. 


\section{5 - RESULTADOS}

\section{Resistência Flexional}

Os valores individuais, desvio padrão e as médias da resistência flexional de cada grupo se encontram na Tabela 3. A Análise de Variância (ANOVA) dos resultados da resistência flexional de cada espécime é ilustrada na Tabela 4, enquanto que as comparações individuais obtidas com o Teste de Tukey, com significância de 5,0\%, estão exibidas na Tabela 5.

O gráfico representado pela Figura 23 ilustra de maneira mais clara os resultados da resistência flexional de cada grupo.

TABELA 3 - Valores individuais de cada espécime, desvio padrão (D.P.) e médias da Resistência Flexional, em $\mathrm{MPa}$, de cada grupo

\begin{tabular}{l|c|c|c|c|c|c|c|c} 
Grup. & & & & & & \\
Esp. & CONTROLE & FIO 0,7 & AMARRILHO & CONNECT & GLASSPAN & SPLINT-IT & INTERLIG & FIBRANTE \\
\hline 1 & 90,07 & 162,5 & 92,66 & 111,41 & 100,01 & 97,80 & 112,16 & 88,98 \\
\hline 2 & 87,86 & 158,13 & 93,03 & 148,57 & 102,93 & 87,86 & 108,82 & 88,98 \\
\hline 3 & 92,66 & 154,80 & 134,21 & 154,42 & 108,82 & 110,32 & 173,21 & 96,33 \\
\hline 4 & 100,76 & 154,08 & 98,55 & 137,51 & 117,67 & 101,85 & 168,41 & 116,92 \\
\hline 5 & 93,03 & 156,26 & 89,70 & 145,61 & 115,46 & 129,07 & 136,42 & 114,00 \\
\hline 6 & 90,07 & 163,27 & 92,28 & 122,51 & 74,62 & 100,38 & 134,58 & 115,46 \\
\hline 7 & 82,35 & 161,43 & 113,25 & 104,06 & 107,73 & 98,92 & 104,77 & 99,26 \\
\hline 8 & 94,12 & 133,46 & 92,66 & 100,76 & 94,12 & 114,71 & 141,93 & 103,31 \\
\hline 9 & 73,16 & 125,73 & 60,67 & 122,81 & 120,60 & 104,06 & 131,28 & 90,07 \\
\hline 10 & 87,52 & 164,73 & 93,75 & 83,47 & 119,51 & 113,25 & 106,98 & 109,57 \\
\hline$D . P$. & 7,41 & 13,20 & 18,56 & 23,36 & 14,15 & 11,44 & 24,60 & 11,19 \\
\hline Média & $\mathbf{8 9 , 1 6}$ & $\mathbf{1 5 3 , 4 4}$ & $\mathbf{9 6 , 0 7}$ & $\mathbf{1 2 3 , 1 1}$ & $\mathbf{1 0 6 , 1 4}$ & $\mathbf{1 0 5 , 8 2}$ & $\mathbf{1 3 1 , 8 5}$ & $\mathbf{1 0 2 , 2 8}$ \\
& & & & & & & &
\end{tabular}


TABELA 4 - Análise de variância (ANOVA) dos resultados da Resistência Flexional dos espécimes

\begin{tabular}{llllll}
\hline $\begin{array}{l}\text { Fonte de } \\
\text { variação }\end{array}$ & $\begin{array}{l}\text { Soma de } \\
\text { quadrados }\end{array}$ & $\begin{array}{l}\text { Graus de } \\
\text { liberdade }\end{array}$ & $\begin{array}{l}\text { Quadrado } \\
\text { médio }\end{array}$ & "F" & Probabilidade \\
\hline Entre grupos & 31593,9342 & 7 & 4513,4192 & 16,5501 & $P<0,00000001$ \\
Resíduo & 19635,2987 & 72 & 272,7125 & & \\
\hline Total & 51229,2329 & 79 & & &
\end{tabular}

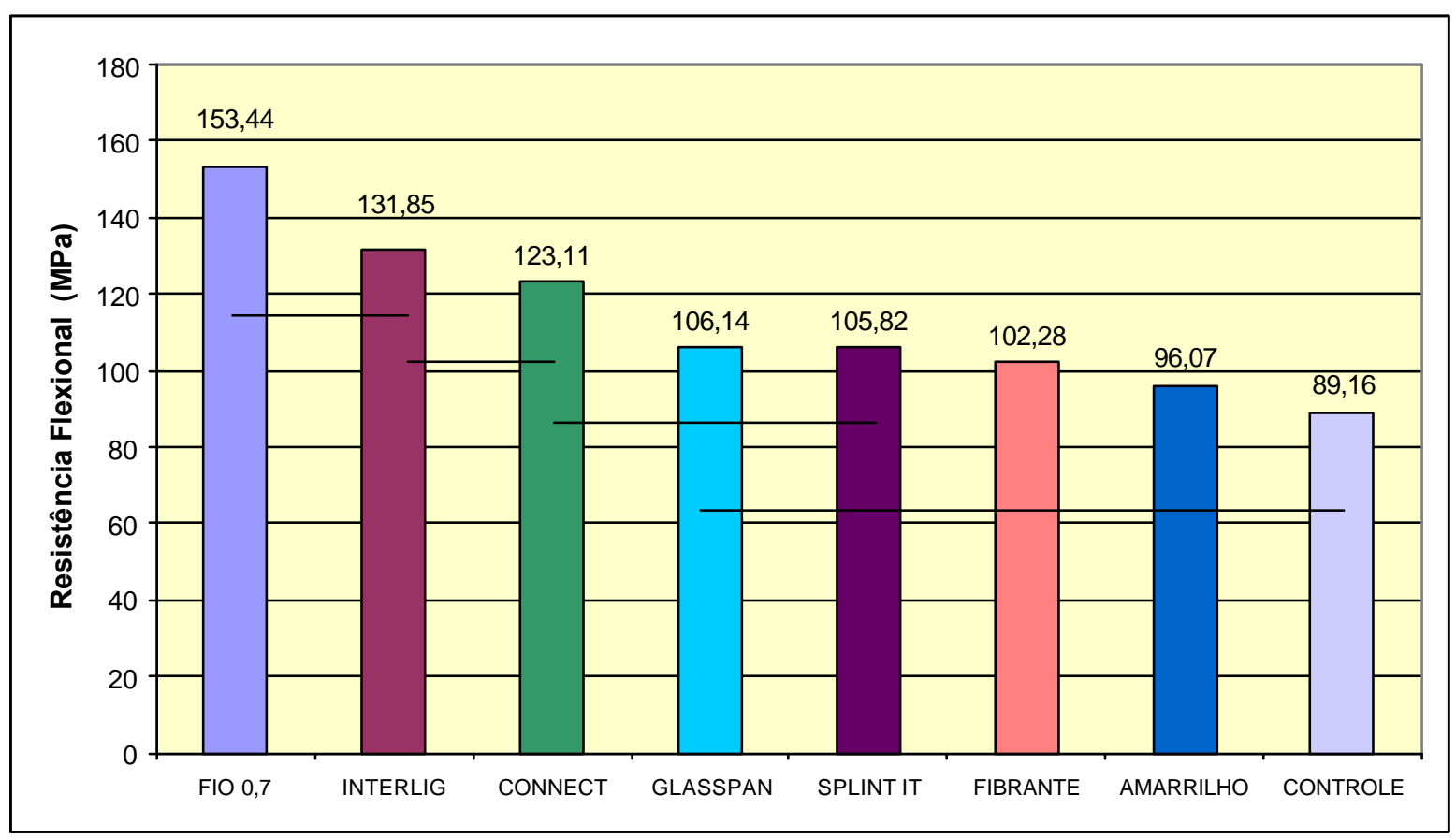

Figura 23 - Representação gráfica dos valores médios, em MPa, da Resistência Flexional para cada grupo. Grupos unidos por barras horizontais não apresentam diferenças estatisticamente significantes 
TABELA 5 - Comparações individuais obtidas através do Teste de Tukey, com nível de significância de 5,0 \%

\begin{tabular}{|c|c|c|c|}
\hline Comparação & Diferença & Valor crítico & Interpretação \\
\hline AMARRILHO X CONNECT & $-27,037$ & 23,058 & SIGNIFICANTE \\
\hline AMARRILHO X CONTROLE & 6,916 & 23,058 & Não significante \\
\hline AMARRILHO X FIBRANTE & 6,212 & 23,058 & Não significante \\
\hline AMARRILHO X FIO 0,7 & $-57,365$ & 23,058 & SIGNIFICANTE \\
\hline AMARRILHO X GLASSPAN & $-10,071$ & 23,058 & Não significante \\
\hline AMARRILHO X INTERLIG & $-35,780$ & 23,058 & SIGNIFICANTE \\
\hline AMARRILHO X SPLINT-IT & $-9,746$ & 23,058 & Não significante \\
\hline CONNECT X CONTROLE & 33,953 & 23,058 & SIGNIFICANTE \\
\hline CONNECT X FIBRANTE & 20,825 & 23,058 & Não significante \\
\hline CONNECT X FIO 0,7 & $-30,328$ & 23,058 & SIGNIFICANTE \\
\hline CONNECT X GLASSPAN & 16,966 & 23,058 & Não significante \\
\hline CONNECT X INTERLIG & $-8,743$ & 23,058 & Não significante \\
\hline CONNECT X SPLINT-IT & 17,291 & 23,058 & Não significante \\
\hline CONTROLE X FIBRANTE & $-13,128$ & 23,058 & Não significante \\
\hline CONTROLE X FIO 0,7 & $-64,281$ & 23,058 & SIGNIFICANTE \\
\hline CONTROLE X GLASSPAN & $-16,987$ & 23,058 & Não significante \\
\hline CONTROLE X INTERLIG & $-42,696$ & 23,058 & SIGNIFICANTE \\
\hline CONTROLE X SPLINT-IT & $-16,662$ & 23,058 & Não significante \\
\hline FIBRANTE X FIO 0,7 & $-51,153$ & 23,058 & SIGNIFICANTE \\
\hline FIBRANTE X GLASSPAN & $-3,859$ & 23,058 & Não significante \\
\hline FIBRANTE X INTERLIG & $-29,568$ & 23,058 & SIGNIFICANTE \\
\hline FIBRANTE X SPLINT IT & $-3,534$ & 23,058 & Não significante \\
\hline FIO 0,7 X GASSPAN & 47,294 & 23,058 & SIGNIFICANTE \\
\hline FIO 0,7 X INTERLIG & 21,585 & 23,058 & Não significante \\
\hline FIO 0,7 X SPLINT-IT & 47,619 & 23,058 & SIGNIFICANTE \\
\hline GLASSPAN X INTERLIG & $-25,709$ & 23,058 & SIGNIFICANTE \\
\hline GLASSPAN X SPLINT IT & 0,325 & 23,058 & Não significante \\
\hline INTERLIG X SPLINT IT & 26,034 & 23,058 & SIGNIFICANTE \\
\hline
\end{tabular}




\section{Módulo de elasticidade}

Os valores individuais, desvio padrão e as médias do módulo de elasticidade de cada grupo se encontram na tabela 6. A Análise de Variância (ANOVA) dos resultados do módulo de elasticidade de cada espécime é lustrada na tabela 7 , enquanto que as comparações individuais obtidas com o Teste de Tukey, com significância de 5,0 \%, estão exibidas na tabela 8 .

Para melhor visualização dos resultados de cada grupo desta propriedade, ilustramo-los através de um gráfico representado pela Figura 24.

TABELA 6 - Valores individuais de cada espécime (Esp.), desvio padrão D.P.) e médias do módulo de elasticidade (Méd.), em MPa, de cada grupo (Grup.)

\begin{tabular}{l|c|c|c|c|c|c|c|c}
\hline Grup & CONTROLE & FIO 0,7 & AMARRILHO & CONNECT & GLASSPAN & SPLINT -IT & INTERLIG & FIBRANTE \\
Esp. & & & & & & & & \\
\hline 1 & $2.060,29$ & $3.453,16$ & $1.885,96$ & $2.427,47$ & $2.380,33$ & $2.580,78$ & $2.754,77$ & $2.228,86$ \\
\hline 2 & $1.816,11$ & $3.358,56$ & $2.208,78$ & $2.818,10$ & $2.208,78$ & $2.077,75$ & $2.451,75$ & $1.925,96$ \\
\hline 3 & $1.945,83$ & $3.659,32$ & $3.453,16$ & $2.664,94$ & $2.451,75$ & $2.698,86$ & $4.019,26$ & $2.228,86$ \\
\hline 4 & $2.169,69$ & $3.269,00$ & $2.208,78$ & $2.636,29$ & $2.553,90$ & $2.786,07$ & $3.891,66$ & $2.357,45$ \\
\hline 5 & $1.726,58$ & $3.269,00$ & $1.802,75$ & $2.850,87$ & $2.608,24$ & $2.989,93$ & $3.064,68$ & $2.357,45$ \\
\hline 6 & $1.915,42$ & $3.394,89$ & $1.829,66$ & $2.580,78$ & $1.829,66$ & $2.359,57$ & $3.225,98$ & $2.527,57$ \\
\hline 7 & $1.581,77$ & $3.502,50$ & $2.451,75$ & $2.527,57$ & $2.754,77$ & $2.451,75$ & $2.580,78$ & $2.077,75$ \\
\hline 8 & $2.169,69$ & $2.818,10$ & $1.993,29$ & $2.095,51$ & $1.915,42$ & $2.636,29$ & $3.225,98$ & $2.249,31$ \\
\hline 9 & $1.977,15$ & $3.269,00$ & $1.777,50$ & $2.553,90$ & $2.818,10$ & $2.553,90$ & $3.269,00$ & $2.427,47$ \\
\hline 10 & $1.738,82$ & $3.184,09$ & $2.169,69$ & $2.009,63$ & $2.608,24$ & $2.527,53$ & $2.694,23$ & $2.357,45$ \\
\hline$D . P$. & 195,15 & 223,95 & 499,43 & 276,26 & 334,85 & 246,45 & 527,44 & 174,18 \\
\hline Méd. & $\mathbf{1 . 9 1 0 , 1 3}$ & $\mathbf{3 . 3 1 7 , 7 6}$ & $\mathbf{2 . 1 7 8 , 1 3}$ & $\mathbf{2 . 5 1 6 , 5 0}$ & $\mathbf{2 . 4 1 2 , 9 1}$ & $\mathbf{2 . 5 6 6 , 2 4}$ & $\mathbf{3 . 1 1 7 , 8 0}$ & $\mathbf{2 . 2 7 3 , 8 1}$ \\
\hline & & & & & & & & \\
\hline
\end{tabular}


TABELA 7 - Análise de variância (ANOVA) dos resultados do Módulo de Elasticidade dos espécimes

\begin{tabular}{llllll}
\hline $\begin{array}{l}\text { Fonte de } \\
\text { variação }\end{array}$ & $\begin{array}{l}\text { Soma de } \\
\text { quadrados }\end{array}$ & $\begin{array}{l}\text { Graus de } \\
\text { liberdade }\end{array}$ & $\begin{array}{l}\text { Quadrado } \\
\text { médio }\end{array}$ & "F" & Probabilidade \\
\hline Entre grupos & 15546121,1 & 7 & 2220874,45 & 19,8425 & $P<0,00000001$ \\
Resíduo & 8058610,07 & 72 & 111925,140 & & \\
\hline Total & 23604731,2 & 79 & & &
\end{tabular}

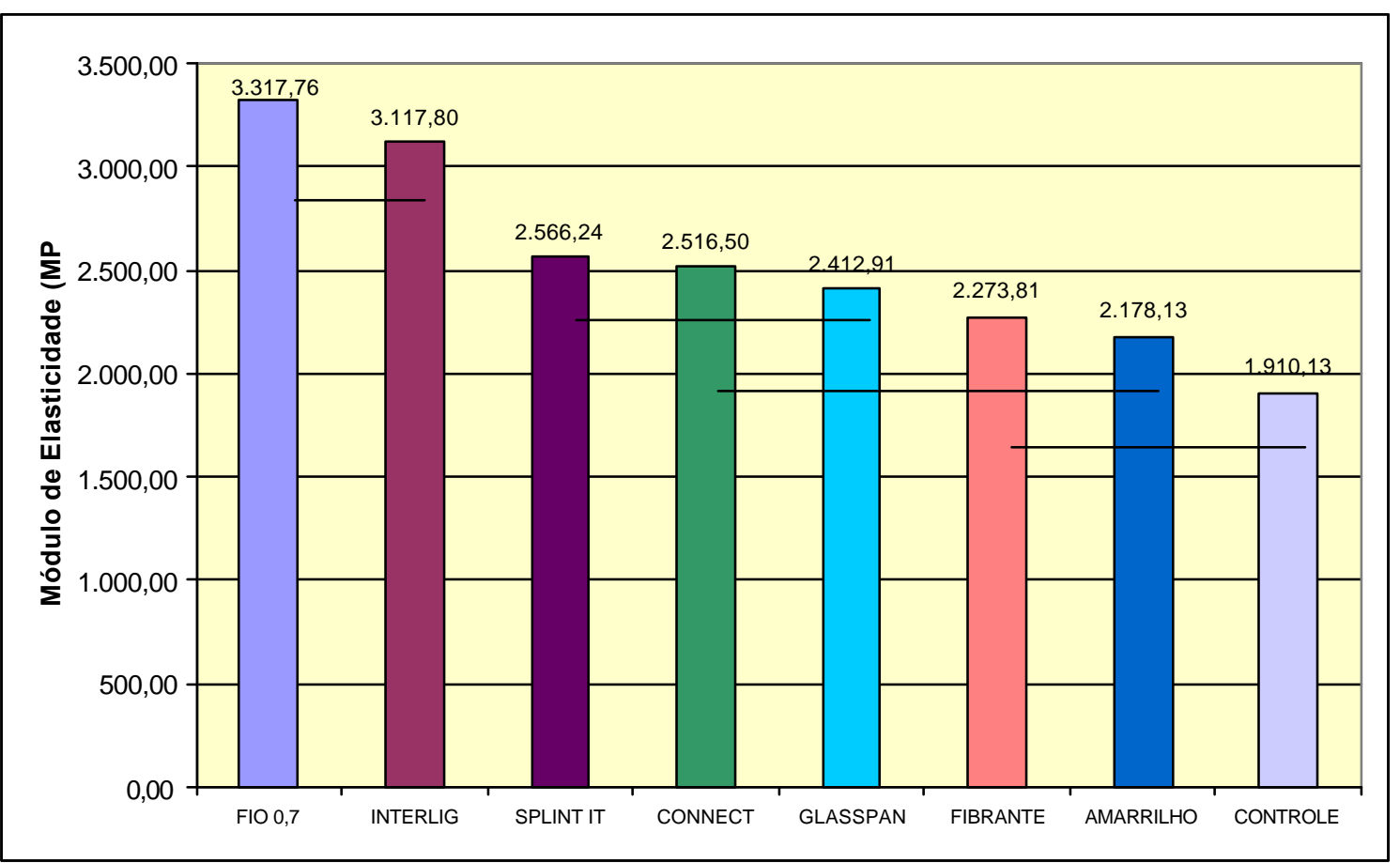

Figura 24 - Representação gráfica dos valores médios, em MPa, do Módulo de Elasticidade para cada grupo. Grupos unidos por barras horizontais não apresentam diferenças estatisticamente significantes. 
TABELA 8 - Comparações individuais obtidas através do Teste de Tukey, com nível de significância de 5,0 \%

\begin{tabular}{|c|c|c|c|}
\hline Comparação & Diferença & Valor crítico & Interpretação \\
\hline AMARRILHO X CONNECT & $-338,374$ & 467,136 & Não significante \\
\hline AMARRILHO X CONTROLE & 267,997 & 467,136 & Não significante \\
\hline AMARRILHO X FIBRANTE & $-95,681$ & 467,136 & Não significante \\
\hline AMARRILHO X FIO 0,7 & $-1.139,630$ & 467,136 & SIGNIFICANTE \\
\hline AMARRILHO X GLASSPAN & $-234,787$ & 467,136 & Não significante \\
\hline AMARRILHO X INTERLIG & - 939,677 & 467,136 & SIGNIFICANTE \\
\hline AMARRILHO X SPLINT-IT & $-388,111$ & 467,136 & Não significante \\
\hline CONNECT X CONTROLE & 606,371 & 467,136 & SIGNIFICANTE \\
\hline CONNECT X FIBRANTE & 242,693 & 467,136 & Não significante \\
\hline CONNECT X FIO 0,7 & $-801,256$ & 467,136 & SIGNIFICANTE \\
\hline CONNECT X GLASSPAN & 103,587 & 467,136 & Não significante \\
\hline CONNECT X INTERLIG & $-601,303$ & 467,136 & SIGNIFICANTE \\
\hline CONNECT X SPLINT-IT & $-49,737$ & 467,136 & Não significante \\
\hline CONTROLE X FIBRANTE & $-363,678$ & 467,136 & Não significante \\
\hline CONTROLE X FIO 0,7 & $-1.407,627$ & 467,136 & SIGNIFICANTE \\
\hline CONTROLE X GLASSPAN & $-502,784$ & 467,136 & SIGNIFICANTE \\
\hline CONTROLE X INTERLIG & $-1.207,674$ & 467,136 & SIGNIFICANTE \\
\hline CONTROLE X SPLINT-IT & $-656,108$ & 467,136 & SIGNIFICANTE \\
\hline FIBRANTE X FIO 0,7 & $-1.043,949$ & 467,136 & SIGNIFICANTE \\
\hline FIBRANTE X GLASSPAN & $-139,106$ & 467,136 & Não significante \\
\hline FIBRANTE X INTERLIG & $-843,996$ & 467,136 & SIGNIFICANTE \\
\hline FIBRANTE X SPLINT IT & $-292,430$ & 467,136 & Não significante \\
\hline FIO 0,7 X GASSPAN & 904,843 & 467,136 & SIGNIFICANTE \\
\hline FIO 0,7 X INTERLIG & 199,953 & 467,136 & Não significante \\
\hline FIO 0,7 X SPLINT-IT & 751,519 & 467,136 & SIGNIFICANTE \\
\hline GLASSPAN X INTERLIG & - 704,890 & 467,136 & SIGNIFICANTE \\
\hline GLASSPAN X SPLINT IT & $-153,324$ & 467,136 & Não significante \\
\hline INTERLIG X SPLINT IT & 551,566 & 467,136 & SIGNIFICANTE \\
\hline
\end{tabular}




\section{Classificação das fraturas}

As fraturas apresentadas pelos espécimes seguiram um padrão que nos possibilitou elaborar um sistema de classificação que consistiu de quatro diferentes tipos bem definidos, ilustrados a seguir pelas Figuras 25 a 28 :

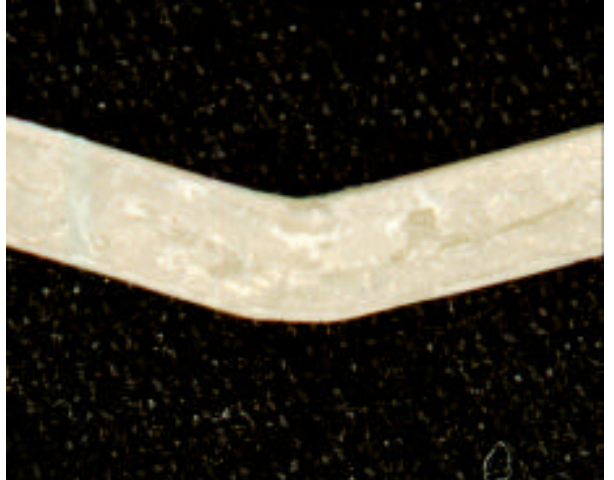

Figura 25 - Fratura Ausente



Figura 27 - Fratura Total Não Separada

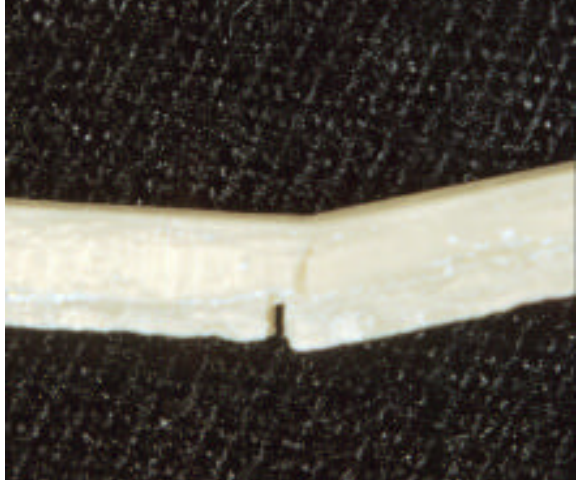

Figura 26 - Fratura Parcial



Figura 28 - Fratura Total Separada 
A Tabela 9, desta maneira, exibe a ocorrência dos quatro tipos de fratura dentro de cada grupo.

TABELA 9. Ocorrência, em porcentagem (\%), dos tipos de fratura em cada grupo

\begin{tabular}{c|c|c|c|c|c|c|c|c}
\hline $\begin{array}{c}\text { Grupo } \\
\text { Tipo }\end{array}$ & CONTROLE & FIO 0,7 & AMARRILHO & CONNECT & GLASSPAN & $\begin{array}{c}\text { SPLINT } \\
\text {-IT }\end{array}$ & INTERLIG & FIBRANTE \\
\hline Ausente & $0 \%$ & $80 \%$ & $30 \%$ & $70 \%$ & $20 \%$ & $10 \%$ & $30 \%$ & $0 \%$ \\
\hline Parcial & $0 \%$ & $20 \%$ & $60 \%$ & $30 \%$ & $50 \%$ & $20 \%$ & $50 \%$ & $40 \%$ \\
\hline $\begin{array}{c}\text { Total Não } \\
\text { Separada }\end{array}$ & $0 \%$ & $0 \%$ & $0 \%$ & $0 \%$ & $0 \%$ & $30 \%$ & $0 \%$ & $0 \%$ \\
\hline Total & $100 \%$ & $0 \%$ & $10 \%$ & $0 \%$ & $30 \%$ & $40 \%$ & $20 \%$ & $60 \%$ \\
Separada & & & & & & & & \\
\hline Total & $100 \%$ & $100 \%$ & $100 \%$ & $100 \%$ & $100 \%$ & $100 \%$ & $100 \%$ & $100 \%$ \\
\hline
\end{tabular}




\section{6 - DISCUSSÃO}

A confecção e os ensaios dos espécimes foram realizados seguindo os parâmetros determinados pela International Organization for Standardization (ISO), norma número 10477:1992/Amd.1:1998²7. Essa norma internacional abrange as especificações que regem os materiais poliméricos de uso laboratorial para facetas, coroas e pontes permanentes, restritos aos dentes anteriores, que podem ou não ser aplicados sobre uma estrutura metálica. Excluem-se os materiais utilizados clinicamente de forma direta para confecção ou reparo de coroas e facetas, além daqueles empregados em restaurações submetidas às cargas oclusais. Essa norma, além disso, não cita ou faz qualquer referência sobre a avaliação desses polímeros quando são adicionadas fibras em seu interior.

A princípio não se justificaria o uso da norma referida para a análise do efeito da inclusão de fibras sobre as propriedades mecânicas da resina acrílica PMMA que utilizamos em nosso estudo, já que este material é usualmente utilizado na confecção de forma direta ou indireta de próteses parciais fixas provisórias localizadas em regiões posteriores, submetidas às forças oclusais. A norma ISO 10477 foi escolhida, entretanto, pelas seguintes razões: a) é a que regulamenta as resinas acrílicas classificadas como tipo 2, isto é, auto-polimerizáveis, incluindo o PMMA que fez parte do nosso trabalho; b) sugere o registro e o cálculo da resistência flexional e do módulo de elasticidade através de um teste de carga de três pontos, o qual tenta simular uma condição clínica da ação de forças 
mastigatórias sobre o pôntico e conectores ${ }^{5,19,24,28,42,43,47}$ e c) alguns autores, VALLITTU (1999) ${ }^{66}$, OGAWA; TANAKA; KOYANO $(2000)^{42}$ e HASELTON; DIAZARNOLD; VARGAS $(2002)^{24}$, recentemente, realizaram pesquisas com a resina PMMA auto-polimerizável para provisórios respeitando parâmetros semelhantes aos regidos por esta norma. VALLITTU $(1999)^{66}$ o fez, inclusive, adicionando fibras e testando o seu efeito nas propriedades da resina PMMA.

O resultado médio da resistência flexional $(23,77 \mathrm{~N}$ ou 89,16 MPa) encontrado no nosso trabalho, quando utilizamos espécimes em resinas sem a presença de qualquer reforço, foi semelhante aos demonstrados por alguns autores. GRANT; GREENER $(1967)^{20}$ encontraram 28,40 N, KOUMJIAN; NIMMO $(1990)^{31}, 76,81$ MPa, PARANHOS et al $(1992)^{44}, 80,60$ MPa, VALLITTU $(1997)^{60}, 91,20$ MPa, VALLITTU; RUYTER; EKSTRAND (1998) ${ }^{70}$, 89,00 MPa, OGAWA; TANAKA; KOYANO (2000) ${ }^{42}$, 73,00 MPa, BRADEN et al $(1988)^{8}, 111,00 \mathrm{MPa}$ e HASELTON; DIAZ-ARNOLD; VARGAS $(2002)^{24}, 97,90$ MPa. Nosso resultado, entretanto, demonstrou superioridade aos obtidos por outros pesquisadores. CAUL; STANFORD; SERIO $(1949)^{11}$ observaram 58,35 MPa, WANG et al $(1989)^{72}, 55,41$ MPa e VALLITTU $(1999)^{66}, 58,00 \mathrm{MPa}$.

Evidenciamos também em nossa pesquisa, valor médio do módulo de elasticidade (1.910,13 MPa) dos espécimes confeccionados somente em resina, semelhante aos encontrados em outros estudos. GRANT; GREENER $(1967)^{20}$, registraram 1.930,53 $\mathrm{MPa}, \mathrm{BRADEN}$ et al $(1988)^{8}, 2.390,00 \mathrm{MPa}$, VALLITTU $(1999)^{66}, 1.710,00$ MPa e OGAWA; TANAKA; KOYANO $(2000)^{42}, 1.800,00$ MPa. 
Nosso resultado, entretanto, apresentourse menor que o encontrado por VALLITTU; RUYTER; EKSTRAND (1998) ${ }^{70}(2.600,00 \mathrm{MPa})$.

Algumas diferenças encontradas entre os nossos resultados e os registrados por outros autores, de ambas as propriedades, quando se utilizou a resina PMMA sem reforço, podem ser justificadas por diversos fatores. De fato, algumas diferenças na composição entre os sistemas de resinas PMMA disponíveis na Odontologia, tanto no mercado nacional quanto em outros países, além de diferentes técnicas de processamento, desde a proporção pó:líquido até a sua polimerização e armazenamento podem causar uma variação entre os resultados ${ }^{4,5,18,24}$.

A maioria dos sistemas de resinas PMMA auto-polimerizáveis consiste, no pó, de esferas pré-polimerizadas de PMMA e uma pequena quantidade de peróxido de benzoíla (iniciador) e, no líquido, um monômero de MMA contendo pequenas

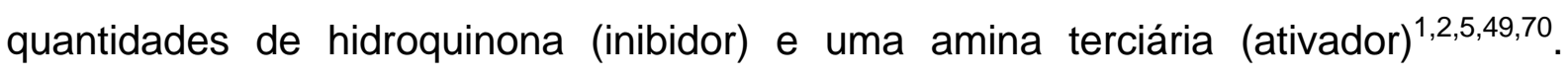
Somado a esses componentes, pode estar presente um agente de ligação cruzada, normalmente, o glicoldimetacrilato ${ }^{5,70}$. O glicoldimetacrilato possui duas duplas uniões por molécula, ao contrário das somente duas uniões permitidas pelo MMA. Uma única molécula de glicoldimetacrilato pode servir como "ponte" unindo duas cadeias do polímero PMMA permitindo uma estrutura em forma de rede ${ }^{5}$. O número de interconexões na rede polimérica vai depender, portanto, da quantidade apresentada de agente de ligação cruzada na mistura ${ }^{5}$. A presença do agente de ligação cruzada nas resinas PMMA está intimamente relacionada com a melhora de suas propriedades mecânicas incluindo a resistência flexiona ${ }^{\beta 6,52,73}$ e o módulo de 
elasticidade ${ }^{36,52,73}$. A quantidade dessa substância no líquido do sistema de resina, quando presente, pode variar em volume entre $1 \%$ e $2 \%$, porém a sua quantidade precisa não é informada pelos fabricantes ${ }^{5}$. Na resina que nós utilizamos, por exemplo, a presença ou quantidade desse agente não é informada.

A proporção da mistura pó:líquido pode ter sido, da mesma forma, um fator que contribuiu com a discrepância dos resultados, pois freqüentemente os fabricantes não informam esta proporção exata. GEGAUFF; PRYOR $(1987)^{18}$ testaram diversas concentrações de uma resina PMMA até que determinassem uma mistura com proporção ótima e tempo de trabalho adequado. No nosso trabalho, pesamos o pó $(1,50 \mathrm{~g})$ e medimos o líquido $(0,7 \mathrm{ml})$, equivalentes a proporção em torno de 3:1, em volume, indicada pelo fabricante. Desta forma conseguimos manter uma maior precisão na œnfecção dos espécimes, descartando erros inerentes ao método de se usar a proporção em volume, uma vez que, mesmo os fabricantes que sugerem alguma relação de mistura, não disponibilizam artefatos para medida dessa resina na quantidade utilizada em restaurações provisórias.

A importância da proporção pó:líquido está no seu efeito direto sobre a quantidade de monômero residual formado na massa polimérica final ${ }^{5}$. Uma maior porção de monômero residual, por sua vez, vai interferir negativamente na resistência à flexão da resina, pela formação de porosidades internas que concentram tensões quando esta resina é submetida a uma carga qualquer ${ }^{5,14}$.

A resistência flexional e o módulo de elasticidade da resina são influenciados pelo grau de conversão alcançado com a sua técnica de polimerização ${ }^{5,14}$. Quanto maior o grau de conversão ou de polimerização, maior a resistência da resina ${ }^{5}$. 
Inúmeras técnicas de polimerização das resinas PMMA têm sido sugeridas. Espécimes em resina acrílica PMMA auto-polimerizáveis são mais resistentes à flexão e apresentam maior módulo de elasticidade quando polimerizados imersos em água com temperaturas maiores que a temperatura ambiente $\left(23^{\circ} \mathrm{C}\right)^{42}$. Submeter a resina às maiores pressões contribui, da mesma forma, com o aumento dessas propriedades $^{14,28}$. O ambiente, a temperatura e o tempo em que a resina é armazenada imediatamente após a sua polimerização, entretanto, tem um efeito menor nas suas características mecânicas. KOUMJIAN; NIMMO (1990) ${ }^{31}$ não encontraram diferenças na resistência flexional de amostras em PMMA após o armazenamento em água a $3^{\circ}{ }^{\circ} \mathrm{C}$ durante sete dias, quando comparado com $\mathrm{o}$ armazenamento em ambiente seco a $23^{\circ} \mathrm{C}$ durante o mesmo tempo. IRELAND et al $(1998)^{28}$ não observaram diferença significante na resistência flexional e no módulo de elasticidade quando as resinas foram armazenadas em água a $37^{\circ} \mathrm{C}$ durante 24 horas ou 60 dias. $\mathrm{O}$ armazenamento de nossos espécimes em água a $37^{\circ} \mathrm{C}$ por 48 horas, por isso, foi somente relevante por ser um período de tempo mínimo, necessário à polimerização completa da resina.

Em nosso trabalho procuramos simular uma condição clínica em que a resina é polimerizada diretamente na boca à temperatura corpórea de $37^{\circ} \mathrm{C}$, sob mínima pressão. Os resultados da resistência à flexão e do módulo de elasticidade encontrados no nosso trabalho podem, portanto, estar menores que naqueles em que a polimerização da resina foi obtida sob maiores pressões. IRELAND et al $(1998)^{28}$ concorda que as restaurações provisórias realizadas diretamente na cavidade oral são polimerizadas sob uma mínima pressão e, por isso, geram piores 
resultados mecânicos devido à incorporação de bolhas de ar que àquelas confeccionadas indiretamente através de maiores pressões.

Outras técnicas como a polimerização em condições ambientais normais $\left(23^{\circ} \mathrm{C}\right)^{42}$, a imersão da resina em água ou saliva artificial com diferentes temperaturas $^{14,24,42}$, o uso de maior ou menor pressão ${ }^{14,28}$ e a associação destas variáveis $^{14,25}$ têm sido propostas e entendemos que podem influenciar de maneira notável as propriedades mecânicas da resina estudada.

As diferenças entre os resultados das propriedades pesquisadas podem ter sido conseqüência também do método de avaliação, isto é, das dimensões dos corpos de prova e da configuração do ensaio.

A resistência flexional, variavelmente denominada de resistência transversa ou módulo de ruptura, é uma propriedade mecânica comumente avaliada através de um teste de carga de três pontos. Esse teste mensura simultaneamente a tensão, isto é, força sobre unidade de área, de tração, de compressão e de cisalhamento de um corpo de prova em forma de barra quando submetido a uma carga. A deformação resultante na barra é representada por uma deformação compressiva na região superior e uma deformação de tração (alongamento) na região inferior. Em corpos finos o suficiente como o que utilizamos, há um predomínio de tensões de tração ao longo da superfície inferior ${ }^{3}$.

De acordo com a fórmula matemática que calcula a resistência flexional, descrita no "Material e Métodos" desta dissertação, a carga suportada por uma barra em resina, em um teste de flexão, é diretamente proporcional ao quadrado da altura do corpo de prova e inversamente proporcional à distância entre os suportes em que 
a barra é apoiada (vão) ${ }^{3,27}$. Corpos de prova confeccionados com a mesma resina, mas tendo maiores diferenças em relação à sua altura ou, ainda, testes que utilizem distâncias distintas entre os suportes, podem resultar em valores muito diferentes de resistência flexional.

Com relação ao módulo de elasticidade, observamos desigualdades relativamente menores que podem ter sido influenciadas muito mais pela composição da resina, técnica de polimerização e armazenamento do que pelas medidas do corpo de prova e distância entre os suportes das barras (vão).

O módulo de elasticidade descreve a relativa rigidez do material que é medida pela curva da porção elástica de um gráfico tensão/deformação $3,8,20,33,42,56$. Se a carga suportada pela barra em resina, dentro do seu limite elástico, for dividida pelo valor correspondente de deformação, uma constante de proporcionalidade será obtida sendo conhecida como o módulo de elasticidade, módulo flexional, módulo elástico ou módulo de Young. O módulo de elasticidade de um material é uma constante e, ao contrário da resistência flexional, não constitui uma medida de resistência. Segundo ANUSAVICE $(1999)^{3}$, quanto menor for a deformação para um determinado valor de tensão, maior será o valor do módulo de elasticidade. É importante elucidar que o módulo de elasticidade nem sempre está diretamente relacionado com as outras propriedades mecânicas. Dois materiais, por exemplo, podem possuir valores de resistência flexional semelhantes, porém, módulos de elasticidade que se diferem consideravelmente ${ }^{3,23}$.

Diante destas informações entendemos que a resistência flexional indica a carga suportada pelas regiões mais finas de um determinado material submetido à 
flexão até a sua deformação permanente, no caso de materiais mais dúcteis ou até a sua fratura, no caso de materiais mais friáveis, ou mesmo até a sua fratura após uma deformação permanente, como observado nos materiais que apresentam um certo equilíbrio entre a ductibilidade e a friabilidade ${ }^{3}$. Isto significa também que materiais com maior módulo de elasticidade necessitam de uma maior carga para induzir a sua deformação ${ }^{42,56}$.

Clinicamente, compreendemos que a resistência flexional é útil em notar a resistência à fratura da prótese, principalmente nas regiões do pôntico e conexões, quando submetidos aos esforços mastigatórios. O módulo de elasticidade significa a rigidez necessária para fornecer conforto ao paciente durante a mastigação e que evita maiores deflexões na prótese que podem levar ao deslocamento indesejável nos retentores, com conseqüente desadaptação marginal, além de permitir que dentes com comprometimento periodontal e que apresentem mobilidade exagerada possam ser contidos e prevenidos de trauma de oclusão.

As resinas utilizadas para a confecção de coroas e pontes devem ser resistentes e rígidas, mas não friáveis ${ }^{5,14,17,18,28,72}$. O equilíbrio entre a rigidez e a resistência flexional é requerida pela norma ISO $10477^{27}$ através de uma fórmula que, por fim, relaciona os valores, em $\mathrm{MPa}$, da resistência flexional e do módulo de elasticidade. Segundo a norma citada, o valor de resistência fexional mínima para as resinas acrílicas utilizadas em coroas e pontes é $50 \mathrm{MPa}$. Um valor "N" também requerido, é obtido através da seguinte fórmula: $N=$ (módulo de elasticidade $\mathrm{x}$ 0,0025) + 40 MPa. O material preenche os requisitos mecânicos, conforme a norma, se a resistência flexional for maior que $N$. Por exemplo, a resina que utilizamos 
alcançou um valor médio de resistência flexional (89,16 MPa) acima do requerido pela norma (50 MPa). O valor do módulo de elasticidade foi $1.910,13 \mathrm{MPa}$. Ao utilizarmos a fórmula para a obtenção do valor de $N$, tivemos:

$$
\begin{aligned}
& N=(1.910,13 \times 0,0025)+40 \mathrm{MPa} \\
& N=4,77+40 \mathrm{MPa} \\
& N=44,77 \mathrm{MPa}
\end{aligned}
$$

Como a resistência flexional, $89,16 \mathrm{MPa}$, foi maior que o valor ' $N$ ', 44,77 $\mathrm{MPa}$, a resina se encontra dentro dos requisitos da norma.

Diversos autores defendem que os polímeros à base de PMMA, ao contrário, exibem baixa rigidez, além de uma resistência diminuída sob a influência de cargas oclusais. Muitos deles propõem a inclusão nesses polímeros de reforços tais como as fibras de carbono ${ }^{15,36,73}$, fibras de aramida $^{7,26,46}$, fibras de poli(etileno) ${ }^{8,12,13,21,32-}$ $35,47,50,54,56,60$, fibras de vidro $26,38,39,40,41,45,52,53,57-59,61-71$, fibras de sílica ${ }^{70}$, fibras de alumínio $^{20}$, bandas ortodônticas ${ }^{25}$ e fios metálicos ${ }^{9,25,40,45,46,47,67,71}$, com a finalidade de aumentar a sua resistência flexional e/ou seu módulo de elasticidade.

Procuramos utilizar fios metálicos e fibras à base de materiais já descritos por outros pesquisadores, mas que, no entanto, não tinham sido avaliados conjuntamente em um estudo tão amplo.

Dentre todos os grupos reforçados, aqueles que alcançaram maior média de resistência flexional, foram os que utilizaram o fio metálico 0,7 mm (153,44 MPa) e a fibra de vidro trançada Interlig ${ }^{\circledR}(131,85 \mathrm{MPa})$, aumentando em $72,09 \%$ e $47,88 \%$, respectivamente, esta resistência em relação ao grupo controle $(89,16 \mathrm{MPa})$, não havendo diferença estatística significante entre eles. O grupo reforçado com fibras 
de poli(etileno) Connect $^{\circledR}(123,11 \mathrm{MPa})$ apareceu em seguida com uma resistência $38,07 \%$ maior e significantemente diferente ao encontrado pelo grupo controle. Os grupos reforçados com as fibras cerâmicas flexíveis GlasSpan ${ }^{\circledR}(106,14$ MPa), fibras de vidro trançada Splint-It $!^{\circledR}(105,82 \mathrm{MPa})$, fibras de vidro unidirecionais Fibrante ${ }^{\circledR}$ (102,28 MPa) e o fio de amarrilho $(96,07 \mathrm{MPa})$, não resultaram em diferenças significantes no que diz respeito à resistência flexional, comparados ao grupo controle.

Analisando aos valores de módulo de elasticidade, vimos que o fio $0,7 \mathrm{~mm}$ (3.317,76 MPa) proporcionou o maior aumento desta propriedade, acompanhado sem diferença estatística do grupo reforçado com Interlig $^{\circledR}(3.117,80 \mathrm{MPa})$, com um acréscimo de $73,69 \%$ e 63,22\%, respectivamente, em relação ao grupo controle $(1.910,13 \mathrm{MPa})$. Os grupos reforçados com Splint-It! ${ }^{\circledR}(2.566,24 \mathrm{MPa})$, Connect ${ }^{\circledR}$ $(2.516,50 \mathrm{MPa})$ e GlasSpan ${ }^{\circledR}(2.412,91 \mathrm{MPa})$, sem diferenças significantes entre si, aumentaram sua rigidez em 34,34\%, 31,74\% e 26,32\%, respectivamente. Os grupos em que a resina foi reforçada com Fibrante ${ }^{\circledR}(2.273,81 \mathrm{MPa})$ e com o fio de amarrilho (2.178,13 MPa) não apresentaram diferenças estatísticas no módulo de elasticidade comparados ao grupo controle.

Um resumo dos resultados da resistência flexional e do módulo de elasticidade, em função do tipo da resina e do reforço utilizado, obtido por diversos autores, é ilustrado na Tabela 10. 
TABELA 10 - Resumo dos resultados da resistência flexional e do módulo de elasticidade, em função do tipo da resina e do reforço utilizado, obtido por diversos autores

\begin{tabular}{|c|c|c|c|c|}
\hline AUTOR - ANO & MATERIAL & REFORÇO & $\begin{array}{l}\text { RESISTENCIA } \\
\text { FLEXIONAL }\end{array}$ & $\begin{array}{c}\text { MODULO DE } \\
\text { ELASTICIDADE }\end{array}$ \\
\hline HARMAN $(1949)^{22}$ & PMMA termo & - & $56,19-67,96 \mathrm{~N}$ & - \\
\hline $\begin{array}{l}\text { CAUL; } \\
(1949)^{10}\end{array}$ & PMMA termo & - & $58,83-68,64 N$ & $\begin{array}{l}- \\
-\end{array}$ \\
\hline $\begin{array}{l}\text { CAUL; STANFORD; } \\
\text { SERIO }(1952)^{11}\end{array}$ & $\begin{array}{l}\text { PMMA auto } \\
\text { PMMA termo }\end{array}$ & - & $\begin{array}{c}48,05-69,62 \mathrm{~N} \\
66,68 \mathrm{~N}\end{array}$ & $\begin{array}{l}- \\
-\end{array}$ \\
\hline $\begin{array}{c}\text { STANFORD; BURNS; } \\
\text { PAFFENBARGER } \\
(1955)^{51}\end{array}$ & $\begin{array}{l}\text { PMMA auto } \\
\text { PMMA termo }\end{array}$ & - & $\begin{array}{l}39,22-49,03 \mathrm{~N} \\
63,74-65,70 \mathrm{~N}\end{array}$ & $\overline{-}$ \\
\hline $\begin{array}{c}\text { McCRORIE; } \\
\text { ANDERSON }(1960)^{37}\end{array}$ & $\begin{array}{l}\text { PMMA termo } \\
\text { PMMA auto }\end{array}$ & - & $\begin{array}{l}73,5 \mathrm{~N} \\
60,4 \mathrm{~N}\end{array}$ & $\begin{array}{l}- \\
-\end{array}$ \\
\hline $\begin{array}{l}\text { GRANT; GREENER } \\
(1967)^{20}\end{array}$ & $\begin{array}{l}\text { PMMA termo } \\
\text { PMMA auto } \\
\text { PMMA termo } \\
\text { PMMA auto }\end{array}$ & $\begin{array}{l}\text { Controle } \\
\text { Controle } \\
\text { Alumínio } \\
\text { Alumínio }\end{array}$ & $\begin{array}{c}35,1 \mathrm{~N} \\
28,4 \mathrm{~N} \\
46,7 \mathrm{~N}-73,8 \mathrm{~N} \\
38,6 \mathrm{~N}-44,4 \mathrm{~N}\end{array}$ & $\begin{array}{c}\text { 2.344,22 MPa } \\
1.930,53 \mathrm{MPa} \\
2.344,22-3.102,64 \mathrm{MPa} \\
1.792,64-3.033,69 \mathrm{MPa}\end{array}$ \\
\hline $\begin{array}{l}\text { HARRISON; HUGGETT; } \\
\text { HANDLEY }(1979)^{23}\end{array}$ & $\begin{array}{l}\text { PMMA auto } \\
\text { PMMA termo }\end{array}$ & - & - & $\begin{array}{l}1.766,00-2.532,00 \mathrm{MPa} \\
2.000,00-2.733,00 \mathrm{MPa}\end{array}$ \\
\hline $\begin{array}{c}\text { CARROLL; VON } \\
\text { FRAUNHOFER }(1984)^{9}\end{array}$ & PMMA auto & $\begin{array}{c}\text { Controle } \\
\text { Fios metálicos } \\
\text { de vários } \\
\text { diâmetros } \\
0,41-1,30 \mathrm{~mm}\end{array}$ & $\begin{array}{c}58,35 \mathrm{MPa} \\
63,25-107,87 \mathrm{MPa}\end{array}$ & $\begin{array}{l}- \\
-\end{array}$ \\
\hline $\begin{array}{l}\text { YAZDANIE; MAHOOD } \\
(1985)^{73}\end{array}$ & PMMA termo & $\begin{array}{l}\text { Controle } \\
\text { Carbono }\end{array}$ & $\begin{array}{c}98,00 \mathrm{MPa} \\
76,5-186,00 \mathrm{MPa}\end{array}$ & $\begin{array}{c}3.521,00 \mathrm{MPa} \\
1.818,00-21.709,00 \mathrm{MPa}\end{array}$ \\
\hline $\begin{array}{l}\text { EKSTRAND; RUYTER; } \\
\text { WELLENDORF }(1987)^{15}\end{array}$ & PMMA auto & $\begin{array}{l}\text { Carbono } \\
\text { Carbono c/ } \\
\text { resina epóxi }\end{array}$ & $\begin{array}{r}95,23-268,00 \mathrm{MPa} \\
114,4-241,60 \mathrm{MPa}\end{array}$ & $\begin{array}{l}12.340,0-22.050,00 \mathrm{MPa} \\
12.700,0-19.500,00 \mathrm{MPa}\end{array}$ \\
\hline BRADEN et al (1988) & PMMA auto & $\begin{array}{l}\text { Controle } \\
\text { Poli(etileno) } \\
\text { Carbono }\end{array}$ & $\begin{array}{c}111,00 \mathrm{MPa} \\
100,90-132,5 \mathrm{MPa} \\
171,55 \mathrm{MPa}\end{array}$ & $\begin{array}{c}2.390,00 \mathrm{MPa} \\
2.880,00-3.430,00 \mathrm{MPa} \\
4.650,00 \mathrm{MPa}\end{array}$ \\
\hline WANG et al $(1989)^{72}$ & $\begin{array}{c}\text { PMMA auto } \\
\text { Bis-GMA auto } \\
\text { Bis-GMA foto }\end{array}$ & $\begin{array}{l}- \\
- \\
-\end{array}$ & $\begin{array}{c}55,41-59,33 \mathrm{MPa} \\
59,82 \mathrm{MPa} \\
59,33 \mathrm{MPa}\end{array}$ & $\begin{array}{l}- \\
- \\
-\end{array}$ \\
\hline $\begin{array}{l}\text { HENRY; BISHOP; PURT } \\
(1990)^{26}\end{array}$ & Isosit $\mathrm{N}$ & $\begin{array}{c}\text { Controle } \\
\text { Poli(etileno) } \\
\text { Aramida }\end{array}$ & $\begin{array}{c}87,6 \mathrm{MPa} \\
77,0-119,0 \mathrm{MPa} \\
85,0 \mathrm{MPa}\end{array}$ & $\begin{array}{l}- \\
- \\
-\end{array}$ \\
\hline $\begin{array}{l}\text { KOUMJIAN; NIMMO } \\
(1990)^{31}\end{array}$ & $\begin{array}{c}\text { PMMA auto } \\
\text { PMMA auto } \\
\text { UDMA foto } \\
\text { Bis-GMA auto } \\
\text { PEMA } \\
\text { PVEMA }\end{array}$ & $\begin{array}{l}- \\
- \\
- \\
-\end{array}$ & $\begin{array}{l}70,24-76,81 \mathrm{MPa} \\
56,88-69,06 \mathrm{MPa} \\
51,24-80,06 \mathrm{MPa} \\
47,27-66,27 \mathrm{MPa} \\
35,24-50,57 \mathrm{MPa} \\
29,10-37,03 \mathrm{MPa}\end{array}$ & $\begin{array}{l}- \\
- \\
- \\
- \\
- \\
-\end{array}$ \\
\hline $\begin{array}{l}\text { PARANHOS et al } \\
(1992)^{44}\end{array}$ & $\begin{array}{l}\text { PMMA termo } \\
\text { PMMA auto }\end{array}$ & $\begin{array}{l}- \\
-\end{array}$ & $\begin{array}{l}85,4 \mathrm{MPa} \\
80,6 \mathrm{Mpa}\end{array}$ & $\begin{array}{l}- \\
-\end{array}$ \\
\hline LADIZESKY et al (1993) & PMMA termo & $\begin{array}{c}\text { Controle } \\
\text { Poli(etileno) }\end{array}$ & $\begin{array}{l}96,0-105,0 \mathrm{MPa} \\
82,0-115,0 \mathrm{MPa}\end{array}$ & $\begin{array}{l}2.900,0-3.200,0 \mathrm{MPa} \\
3.100,0-3.700,0 \mathrm{MPa}\end{array}$ \\
\hline LADIZESKY et al (1993) $^{35}$ & PMMA termo & Poli(etileno) & $72,0-89,13 \mathrm{MPa}$ & $6.200,0-9.700,0 \mathrm{MPa}$ \\
\hline VALLITTU $(1993)^{5 /}$ & PMMA auto & $\begin{array}{c}\text { Controle } \\
\text { Fibra de vidro } \\
\text { Carbono } \\
\text { Aramida }\end{array}$ & $\begin{array}{c}76,49 \mathrm{~N} \\
93,16-107,87 \mathrm{~N} \\
91,20-99,05 \mathrm{~N} \\
85,32-101,01 \mathrm{~N}\end{array}$ & $\begin{array}{l}- \\
- \\
- \\
-\end{array}$ \\
\hline OSMAN; OWEN (1993) & $\begin{array}{l}\text { PMMA auto } \\
\text { Bis-GMA auto } \\
\text { Epimina } \\
\text { PEMA }\end{array}$ & $\begin{array}{l}- \\
- \\
- \\
-\end{array}$ & $\begin{array}{l}230,0 \mathrm{~N} \\
170,0 \mathrm{~N} \\
140,0 \mathrm{~N} \\
460,0 \mathrm{~N}\end{array}$ & $\begin{array}{l}- \\
- \\
- \\
-\end{array}$ \\
\hline $\begin{array}{l}\text { POWELL; NICHOLLS; } \\
\text { YUODELIS (1994) }\end{array}$ & PMMA auto & $\begin{array}{l}\text { Controle } \\
\text { Fio } 0,9 \\
\text { Aramida }\end{array}$ & $\begin{array}{c}167,07 \mathrm{~N} \\
175,18-201,16 \mathrm{~N} \\
191,36-216,12 \mathrm{~N}\end{array}$ & $\begin{array}{l}- \\
- \\
-\end{array}$ \\
\hline
\end{tabular}




\begin{tabular}{|c|c|c|c|c|}
\hline AUTOR - ANO & MATERIAL & REFORÇO & $\begin{array}{l}\text { RESISTÊNCIA } \\
\text { FLEXIONAL } \\
\end{array}$ & $\begin{array}{c}\text { MÓDULO DE } \\
\text { ELASTICIDADE }\end{array}$ \\
\hline $\begin{array}{c}\text { VALLITTU; LASSILA; } \\
\text { LAPPALAINEN }(1994)^{68}\end{array}$ & PMMA termo & $\begin{array}{c}\text { Controle } \\
\text { Fibra de vidro } \\
\text { Carbono } \\
\text { Aramida }\end{array}$ & $\begin{array}{c}83,36 \mathrm{~N} \\
109,83-125,53 \mathrm{~N} \\
98,07-112,78 \mathrm{~N} \\
107,87-117,78 \mathrm{~N} \\
\end{array}$ & $\begin{array}{l}- \\
- \\
- \\
-\end{array}$ \\
\hline VALLITTU $(1994)^{58}$ & PMMA termo & Fibra de vidro & $101,01-132,39 \mathrm{~N}$ & - \\
\hline $\begin{array}{l}\text { LADIZESKY; CHOW; } \\
\text { CHENG }(1994)^{33}\end{array}$ & PMMA termo & $\begin{array}{c}\text { Controle Fibras } \\
\text { Poli(etileno) }\end{array}$ & $\begin{array}{l}96,0-104,0 \mathrm{MPa} \\
98,0-124,0 \mathrm{MPa}\end{array}$ & $\begin{array}{l}2.900,0-3.200,0 \mathrm{MPa} \\
3.200,0-6.500,0 \mathrm{MPa}\end{array}$ \\
\hline VALLITTU $(1995)^{59}$ & PMMA termo & $\begin{array}{c}\text { Controle } \\
\text { Fibras de vidro }\end{array}$ & $\begin{array}{r}80,41-84,34 N \\
98,26-109,83 N\end{array}$ & $\begin{array}{l}- \\
-\end{array}$ \\
\hline HAZELTON et al $(1995)^{25}$ & PMMA auto & $\begin{array}{l}\text { Controle } \\
\text { Fio } 0,9 \\
\text { Banda } \\
\text { ortodôntica } \\
\end{array}$ & $\begin{array}{l}714,0 \mathrm{~N} \\
658,0 \mathrm{~N} \\
688,0 \mathrm{~N}\end{array}$ & $\begin{array}{l}- \\
- \\
-\end{array}$ \\
\hline $\begin{array}{c}\text { SAMADZADEH et al } \\
(1997)^{50}\end{array}$ & $\begin{array}{l}\text { PMMA auto } \\
\text { PMMA auto }\end{array}$ & $\begin{array}{c}\text { Controle } \\
\text { Poli(etileno) }\end{array}$ & $\begin{array}{l}488,96 \mathrm{~N} \\
524,26 \mathrm{~N}\end{array}$ & $\begin{array}{l}- \\
-\end{array}$ \\
\hline VALLITTU (1997) & PMMA auto & $\begin{array}{c}\text { Controle } \\
\text { Poli(etileno) }\end{array}$ & $\begin{array}{c}91,2 \mathrm{MPa} \\
118,1-124,7 \mathrm{MPa}\end{array}$ & $\begin{array}{l}- \\
-\end{array}$ \\
\hline $\begin{array}{c}\text { RAMOS; RUNYAN; } \\
\text { CHRISTENSEN (1996) }\end{array}$ & PMMA auto & $\begin{array}{c}\text { Controle } \\
\text { Poli(etileno) }\end{array}$ & $\begin{array}{l}247,13 \mathrm{~N} \\
313,52 \mathrm{~N}\end{array}$ & $\begin{array}{l}- \\
-\end{array}$ \\
\hline VALLITTU $(1998)^{62}$ & $\begin{array}{c}\text { PMMA }+\mathrm{n}- \\
\text { butilmetacrilato }\end{array}$ & $\begin{array}{c}\text { Controle } \\
\text { Fibra de vidro }\end{array}$ & $\begin{array}{c}614,0 \mathrm{~N} \\
659,0-973,0 \mathrm{~N}\end{array}$ & $\begin{array}{l}- \\
-\end{array}$ \\
\hline STIPHO $(1998)^{52,53}$ & PMMA termo & $\begin{array}{c}\text { Controle } \\
\text { Fibra de vidro }\end{array}$ & $\begin{array}{c}76,49 \mathrm{MPa} \\
65,90-90,68 \mathrm{MPa}\end{array}$ & $\begin{array}{c}10.240,0 \mathrm{MPa} \\
9.890,0-11.130,0 \mathrm{MPa}\end{array}$ \\
\hline IRELAND et al $(1998)^{28}$ & $\begin{array}{l}\text { PMMA auto } \\
\text { PMMA auto } \\
\text { UDMA }\end{array}$ & $\begin{array}{l}- \\
- \\
- \\
\end{array}$ & $\begin{array}{l}49,95-55,90 \mathrm{MPa} \\
49,26-58,51 \mathrm{MPa} \\
73,92-77,90 \mathrm{MPa}\end{array}$ & $\begin{array}{l}1.958,38-2.245,79 \mathrm{MPa} \\
1.832,88-2.033,00 \mathrm{MPa} \\
1815,09-2.214,57 \mathrm{MPa}\end{array}$ \\
\hline $\begin{array}{l}\text { VALLITU; RUYTER; } \\
\text { EKSTRAND (1998) }\end{array}$ & $\begin{array}{l}\text { PMMA auto } \\
\text { PMMA auto } \\
\text { PMMA auto } \\
\text { PMMA termo } \\
\text { PMMA termo } \\
\text { PMMA termo }\end{array}$ & $\begin{array}{l}\text { Controle } \\
\text { Fibras de vidro } \\
\text { Fibras de sílica } \\
\text { Controle } \\
\text { Fibras de vidro } \\
\text { Fibras de sílica } \\
\end{array}$ & $\begin{array}{c}65,0-89,0 \mathrm{MPa} \\
256,0-299,0 \mathrm{MPa} \\
186,0-290,0 \mathrm{MPa} \\
81,0-98,0 \mathrm{MPa} \\
150,0-196,0 \mathrm{MPa} \\
127,0-189,0 \mathrm{MPa} \\
\end{array}$ & $\begin{array}{c}2.600,0-2.800,0 \mathrm{MPa} \\
10.800,0-11.200,0 \mathrm{MPa} \\
10.000,0-10.900,0 \mathrm{MPa} \\
2.600,0-2.900,0 \mathrm{MPa} \\
8.500,0-9.300,0 \mathrm{MPa} \\
6.300,0-8.500,0 \mathrm{MPa}\end{array}$ \\
\hline VALLITTU $(1999)^{66}$ & $\begin{array}{l}\text { PMMA auto } \\
\text { PMMA auto } \\
\text { PMMA termo } \\
\text { PMMA termo }\end{array}$ & $\begin{array}{c}\text { Controle } \\
\text { Fibra de vidro } \\
\text { Controle } \\
\text { Fibra de vidro } \\
\end{array}$ & $\begin{array}{c}58,0 \mathrm{MPa} \\
96,2-466,4 \mathrm{MPa} \\
71,4 \mathrm{MPa} \\
98,6-341,2 \mathrm{MPa}\end{array}$ & $\begin{array}{c}1.710,0 \mathrm{MPa} \\
2.418,0-16.749,0 \mathrm{MPa} \\
2.550,0 \mathrm{MPa} \\
3.530,0-19.086,0 \mathrm{MPa}\end{array}$ \\
\hline $\begin{array}{l}\text { UZUN; HERSEK; } \\
\text { TINÇER }(1999)^{56}\end{array}$ & PMMA termo & $\begin{array}{c}\text { Controle } \\
\text { Fibras de vidro } \\
\text { Carbono } \\
\text { Aramida } \\
\text { Poli(etileno) } \\
\end{array}$ & $\begin{array}{c}400,51 \mathrm{MPa} \\
406,50 \mathrm{MPa} \\
406,50 \mathrm{MPa} \\
411,98-442,71 \mathrm{MPa} \\
380,22 \mathrm{MPa} \\
\end{array}$ & $\begin{array}{c}1.790,0 \mathrm{MPa} \\
1.900,0 \mathrm{MPa} \\
1.350,0 \mathrm{MPa} \\
1.880,0-1.930,0 \mathrm{MPa} \\
2.760,0 \mathrm{MPa} \\
\end{array}$ \\
\hline $\begin{array}{c}\text { NOHRSTROM; } \\
\text { VALLITTU; } \\
\text { YLI-URPO }(2000)^{41}\end{array}$ & $\begin{array}{c}\text { PEMA }+n- \\
\text { butilmetacrilato }\end{array}$ & $\begin{array}{c}\text { Controle } \\
\text { Fibras de vidro }\end{array}$ & $\begin{array}{c}1.061,0 \mathrm{~N} \\
515,0-1.297,0 \mathrm{~N}\end{array}$ & $\begin{array}{l}- \\
-\end{array}$ \\
\hline $\begin{array}{l}\text { OGAWA; TANAKA; } \\
\text { KOYANO }(2000)^{42}\end{array}$ & PMMA auto & - & $19,0-73,0 \mathrm{MPa}$ & $195,0-1.800,0 \mathrm{MPa}$ \\
\hline NAGAl et al $(2001)^{40}$ & PMMA termo & $\begin{array}{c}\text { Controle } \\
\text { Fibras de vidro } \\
\text { Fios metálicos }\end{array}$ & $\begin{array}{l}\text { 87,2 MPa } \\
96,8 \mathrm{MPa} \\
70,0 \mathrm{MPa}\end{array}$ & $\begin{array}{l}2.683,7 \mathrm{MPa} \\
4.189,3 \mathrm{MPa} \\
3.750,0 \mathrm{MPa}\end{array}$ \\
\hline POLYZOIS et al $(2001)^{45}$ & PMMA termo & $\begin{array}{c}\text { Controle } \\
\text { Fibras de vidro } \\
\text { Fio } 1,5 \mathrm{~mm} \\
\text { Fio achatado } \\
\end{array}$ & $\begin{array}{l}85,0 \mathrm{~N} \\
57,5 \mathrm{~N} \\
105,0 \mathrm{~N} \\
64,0 \mathrm{~N} \\
\end{array}$ & $\begin{array}{l}- \\
- \\
-\end{array}$ \\
\hline $\begin{array}{c}\text { HASELTON; DIAZ- } \\
\text { ARNOLD; VARGAS } \\
(2002)^{24}\end{array}$ & $\begin{array}{l}\text { Bis -GMA } \\
\text { PMMA auto }\end{array}$ & - & $\begin{array}{c}59,7-123,6 \mathrm{MPa} \\
56,2-97,9 \mathrm{MPa}\end{array}$ & $\begin{array}{l}- \\
-\end{array}$ \\
\hline
\end{tabular}

Trabalhos que comparam o efeito de fios metálicos com fibras em suas diversas composições, nas propriedades mecânicas da resina PMMA, são escassos 
e ilustram resultados divergentes. CARROLL; VON FRAUNHOFER $(1984)^{9}$ checaram a resistência flexional de uma resina quando reforçada com fios metálicos de diversos diâmetros. Encontraram que o fio de aço com aproximadamente $0,7 \mathrm{~mm}$ de diâmetro aumentou esta resistência em apenas 13\%, porém estatisticamente significante comparado ao grupo sem reforço. POWELL et al $(1994)^{46}$, em um estudo simulando próteses parciais fixas de três elementos, não observaram uma influência significante na resistência à fratura quando se utilizou um fio metálico 0,9 e uma fibra de aramida, em relação ao grupo não reforçado. VALLITTU; LASSILA ${ }^{67}$, em 1992, compararam reforços metálicos, tais como, fios semicirculares, fios cilíndricos com $1,0 \mathrm{~mm}$ de diâmetro, fios achatados trançados e malhas, com diversos tipos de fibras, incluindo a fibra de vidro. Concluíram que nenhuma das fibras estudada em sua pesquisa teve um efeito tão favorável quanto o fornecido pelos fios metálicos.

Algumas variáveis presentes nesses estudos contam a favor dos resultados discrepantes, quando comparados entre eles e com os nossos. CARROLL; VON FRAUNHOFER $(1984)^{9}$, por exemplo, utilizaram uma técnica de manipulação da resina pela técnica da saturação com o auxílio de um pincel ("salt-and-pepper"), sendo que o fio foi utilizado tendo sua superfície lisa. POWELL et al $(1994)^{46}$, da mesma forma, fez uso de fios metálicos lisos, porém polimerizaram a resina sob pressão e calor.

Escolhemos tornar áspero a superfície do fio de aço $0,7 \mathrm{~mm}$ através da abrasão mecânica com uma ponta abrasiva cilíndrica de carborundum, sob baixa rotação, para que pudesse evitar o seu micro-deslizamento no interior do espécime diminuindo seu efeito sobre a resistência e a rigidez da resina ${ }^{46}$. Essa técnica foi 
eleita após um teste piloto em que notamos os melhores resultados com o fio tratado superficialmente por essa técnica. Uma melhor interação mecânica entre a superfície do fio de aço 0,7 e a resina pode ter aumentado a resistência flexional dos espécimes, aumentando a resistência ao alongamento de partes da resina e evitando posterior falha por tensões de tração. A rigidez destes fios de aço 0,7 , de outra maneira, faz com que eles funcionem, provavelmente, como um reforço estrutural suportando parte da resina sobre si e aumentando a rigidez, representada pelo aumento do módulo de elasticidade de todo o conjunto. Seguindo esse mesmo raciocínio, explicamos o fato do fio de amarrilho, devido à sua baixa rigidez e incapacidade de se unir efetivamente com a resina, não ter resultado em um aumento significante de ambas as propriedades mecânicas estudadas.

Ao contrário da quantidade reduzida de estudos comparativos entre fios e fibras, os que avaliam o efeito de um ou mais tipos de fibras sobre o módulo de elasticidade e, principalmente, sobre a resistência flexional de resinas à base de PMMA, são em grande número.

O aumento da resistência flexional e do módulo de elasticidade encontrado no nosso trabalho, em decorrência do uso de fibras de vidro inseridas em espécimes de resina PMMA, está semelhante aos obtidos em alguns estudos. VALLITTU; LASSILA $(1992)^{67}$, VALLITTU (1993) ${ }^{57}$, VALLITTU; LASSILA; LAPPALAINEN $(1994)^{68}$, VALLITTU $(1995)^{59}$, STIPHO (1998) ${ }^{52}$, VALLITTU $(1998)^{62}$; VALLITTU $(1999)^{66}$, NOHRSTRÖM; VALLITTU; YLI-URPO $(2000)^{41}$, encontraram em seus trabalhos um aumento significante da resistência flexional entre $18 \%$ e $315 \%$, e no módulo de elasticidade, entre $47 \%$ e $322 \%$, em relação a espécimes em resina PMMA não 
reforçados. UZUM; HERSEK; TINÇER $(2000)^{56}$ não encontraram efeito relevante na resistência flexional de espécimes em PMMA reforçados com fibras de vidro.

Resultados da mesma maneira discrepantes foram encontrados sobre o efeito das fibras de poli(etileno) nas propriedades mecânicas de resinas PMMA. BRADEN et al $(1988)^{8}$, LADIZESKY; CHOW (1992) ${ }^{32}$, LADIZESKY et al (1993) ${ }^{35}$, LADIZESKY; CHOW, CHENG (1994) ${ }^{33}$, RAMOS; RUNYAN; CHRISTENSEN (1996) ${ }^{47}$ e VALLITTU $(1997)^{60}$ relataram um aumento relevante da resistência flexional de espécimes em PMMA utilizando as fibras de poli(etileno) entre $18 \%$ e $79 \%$, e do módulo de elasticidade entre $23 \%$ e 203\%. DIXON; BREEDING (1992) ${ }^{13}$, LADIZESKY et al $(1993)^{35}$, LADIZESKY; CHOW, CHENG $(1994)^{33}$ e SAMADZADEH $(1997)^{50}$, por sua vez, não encontraram efeito significante dessa fibra sobre a resistência flexional de amostras em resina PMMA.

O modo como as fibras agem aumentando as propriedades mecânicas da resina PMMA é, de certa forma, diferente do mecanismo de ação dos reforços metálicos mais espessos e rígidos, como por exemplo, o fio de aço com diâmetro 0,7 mm utilizado em um dos nossos grupos experimentais.

As fibras, sejam elas de vidro ou de poli(etileno), agem sobre a resistência flexional de resinas como o PMMA aumentando a resistência à tração das regiões mais inferiores do espécime e evitando a sua fratura através da interrupção da propagação de trincas ${ }^{46}$. A localização das fibras no interior do espécime é, por isso, de suma importância. Como dito anteriormente, um corpo de prova em forma de barra sendo submetido a um teste de flexão sofre deformação compressiva na superfície superior e deformação de tração na superfície inferior ${ }^{3,33}$. As tensões que 
provocam estas deformações mudam de direção dentro do corpo de prova no trajeto entre as superfícies superior e inferior, com ambas tensão e deformação sendo iguais a zero na região de transição. Esta região de mudança, onde o corpo não muda de dimensão e as tensões se anulam, é denominada eixo neutro ${ }^{3,7,33,46}$. As tensões de compressão ou tração aumentam à medida que se distanciam desse eixo. Seguindo esta teoria, a melhor localização para se inserir as fibras seria o mais inferiormente possível no interior do corpo de prova, onde se acumulam as tensões de tração ${ }^{41,46,47,60,61,62}$. A inserção as fibras no centro do espécime, isto é, no seu eixo neutro, tem sido realizada em alguns trabalhos ${ }^{7,33,34,56,58,68}$. Desses, entretanto, poucos associaram esta circunstância com a diminuição do seu efeito sobre a resistência flexiona ${ }^{\beta 4}$. No nosso trabalho preferimos posicionar os reforços, incluindo as fibras, no eixo neutro dos espécimes baseado em diversos trabalhos que assim o fizeram e, além disso, nossa intenção foi representar a condição mais adversa possível. Deste modo, compreendemos que localizando estas fibras no terço inferior dos espécimes, os resultados poderiam ser ainda melhores. O aumento da resistência flexional conseguido com alguns tipos de fibras posicionados no eixo neutro do espécime foi, de certa forma, surpreendente. Mesmo inserindo esses reforços em uma posição desfavorável, eles podem ter conseguido pela própria espessura mínima do espécime, influenciar positivamente camadas mais inferiores de resina aumentando a sua resistência à tração.

As fibras de vidro e as de poli(etileno) têm módulo de elasticidade cerca de 3 a 40 vezes maior que a resina acrílica $\mathrm{PMMA}^{29,33,35}$. Se considerarmos que essas fibras unem-se efetivamente com a resina acrílica PMMA, podemos utilizar a "Lei 
das Misturas", originada da área da Engenharia dos Materiais. ISAAC $(1998)^{29}$ afirmou que essa lei é utilizada em materiais compostos, como por exemplo, um espécime em resina PMMA reforçado com uma determinada fibra, e relaciona os valores do módulo de elasticidade de todos os materiais que o compõem juntamente com a fração, em volume, de cada um. Com base nisso, como o módulo de elasticidade da fibra é consideravelmente maior que a da resina, é de se esperar que todo o conjunto tenha sua rigidez aumentada, em função da concentração desta fibra. Para a resistência flexional, esta mesma lei pode ser empregada, porém, com uma complexidade maior, já que esta propriedade envolve o tipo de falha sofrida pelo espécime. Uma deformação permanente ou uma fratura de qualquer um dos componentes, desta maneira, deve ser considerada.

Diversos autores defendem que quanto melhor a união entre as fibras de vidro e a resina, maior a resistência flexional e o módulo de elasticidade dos espécimes $^{15,32,40,56,57,67,68,70}$.

O silano tem sido descrito como o material que promove esta união efetiva entre o PMMA e a fibra de vidro ${ }^{57,61,67,68,70}$. Justificando a sua importância, há pelo menos um estudo que compara dois compostos de silano aplicados sobre uma fibra de vidro e o seu efeito na resistência flexional de uma resina PMMA ${ }^{57}$. Fibras de vidro não silanizadas, assim sendo, parecem não exercer qualquer influência na resistência e rigidez de polímeros $\mathrm{PMMA}^{26,57,67}$. Fato que pode explicar o resultado pouco importante na resistência flexional conseguidos com as fibras cerâmicas flexíveis GlasSpan ${ }^{\circledR}$. De acordo com o fabricante, estas fibras são cerâmicas e, por isso, entendemos conter sílica em sua composição, porém, elas são comercializadas 
sem qualquer tipo de tratamento químico em sua superfície, o que pode ter contribuído com a sua baixa eficiência sobre a resistência dos espécimes.

Experimentamos além da GlasSpan ${ }^{\circledR}$, mais três tipos de fibras compostas de sílica, isto é, de vidro. Duas impregnadas com resina composta e uma impregnada com glicoldimetacrilato. Muitos detalhes da composição destas fibras, como por exemplo, a concentração de sílica, composição da matriz resinosa que envolve a sílica, tipo de silano utilizado na superfície das fibras e composição da resina composta que impregna as fibras, não são disponíveis pelos fabricantes e, provavelmente, são segredos industriais. Este fato contribuiu com a dificuldade de se discutir nossos resultados e compará-los com os de outros autores. Analisando somente os resultados do nosso estudo, as fibras de vidro trançadas impregnadas com resina composta foram as que provocaram uma maior resistência flexional e módulo de elasticidade da resina PMMA.

As fibras de poli(etileno), de outra maneira, têm como base um material obtido da polimerização do etileno, um gás proveniente da refinação do petróleo ${ }^{48}$. Estas fibras são polímeros orgânicos sem qualquer conteúdo de sílica e, portanto, não são beneficiadas com a aplicação de qualquer composto de silano. As fibras de poli(etileno), entretanto, sofrem um condicionamento superficial denominado tratamento com plasma, que consiste na inclusão destas fibras em um reator onde são tratadas com um fluxo de gás carreador, geralmente o oxigênio ou hélio, a uma potência de $120 \mathrm{~W}$ por dois minutos ${ }^{8,32}$. Segundo RAMOS; RUNYAN, CHRISTENSEN (1996) ${ }^{47}$, o gás carreador, quando sob efeito de um campo elétrico, promove a formação de radicais livres, íons e átomos que interagem com superfícies 
sólidas modificando-as, como por exemplo a fibra de poli(etileno). Há, então, um aumento da energia de superfície responsável pela maior reatividade química e compatibilidade com outros materiais. O tratamento com plasma é, por isso, realizado com a finalidade de melhorar a sua adesão com outros polímeros odontológicos, tais como, o PMMA ${ }^{32,35,47}$. Alguns autores, porém, discutem a sua real validade sobre as propriedades mecânicas de polímeros reforçados com estas fibras $^{33,54,60}$. A fibra de poli(etileno) utilizada por nós sofreu um tratamento superficial com plasma pelo fabricante. Isto foi considerado, certamente, como um fator relevante sobre o aumento considerável das propriedades mecânicas estudadas com os espécimes reforçados com estas fibras.

A forma como as fibras de vidro ou de poli(etileno) são tratadas imediatamente antes de sua inclusão no interior do espécime em PMMA é, igualmente, uma variável relevante ${ }^{68}$. A imersão destas fibras em monômero MMA é vista por alguns autores como causa da presença de bolhas de ar na interface fibraresina em decorrência da maior contração de polimerização do monômero MMA (21\%) comparado ao polímero PMMA $(7 \%)^{62,68}$. Eles associaram esta diferença na contração de polimerização com um menor aumento da resistência flexional e, por isso, propuseram a adição de uma mistura fluida de PMMA-MMA, preferencialmente, à imersão desta fibra em monômero $M M A^{58,68}$. O aumento de monômero líquido MMA ao redor das fibras antes de sua incorporação à mistura final da resina PMMA, entretanto, parece contribuir com um melhor molhamento das fibras e menor incorporação de bolhas de $\operatorname{ar}^{59}$. VALLITTU ${ }^{70}$, em 1998, além disso, observou que o uso de uma mistura fluida de PMMA-MMA não resulta em uma impregnação ótima 
das fibras pela resina PMMA. Escolhemos, por isso, imergir todos os reforços utilizados em nosso trabalho, pois é relatado em vários estudos como sendo um método de se melhorar a união entre reforços de qualquer natureza e a resina ${ }^{13,21,32,34,35,47,50,59,60,61,62,71,73}$.

Uma maior concentração em peso das fibras de vidro e de poli(etileno) deve ser considerada, também, como fator favorável ao aumento na resistência flexional e no módulo de elasticidade de resinas $\mathrm{PMMA}^{68}$. Concentrações em peso tão altas como $21 \%$ a $45,4 \%$ para as fibras de vidro e $37 \%$ para as de poli(etileno), têm sido associadas com o aumento da resistência e da rigidez destes polímeros quando reforçados com estas fibras ${ }^{35,66,68,70}$. Este fato pode explicar o aumento insignificante na resistência flexional quando utilizamos a fibra unidirecional Fibrante ${ }^{\circledR}$. Esta fibra é comercializada na forma de um longo e, relativamente, espesso feixe que pode ser cortado e/ou desfeito a depender da situação clínica-laboratorial, entretanto não é mencionado pelo fabricante qual a concentração mínima desta fibra, em peso ou em volume, que deve ser usada. Elegemos utilizar uma concentração em peso de 3,5\% desta fibra, já que esta quantidade era suficiente para preencher, em largura e comprimento, o espécime de resina. O uso nesta baixa concentração pode ter contribuído pelo seu fraco desempenho durante o teste de flexão.

$\mathrm{Na}$ investigação das fraturas, com auxílio de uma lupa com aumento de 4 vezes, percebemos a presença de fraturas restritas a quatro tipos com características bem definidas. A partir desta observação propusemos, com o intuito de facilitar a análise e comparação, classificar estas fraturas em quatro tipos 
distintos: Ausente; Parcial; Total Não Separada e Total Separada, já descritos detalhadamente no Capítulo "Material e Métodos" deste texto.

Analisando as fraturas, observamos que nos espécimes reforçados, estas foram originadas na superfície inferior do corpo de prova onde se concentram durante a deflexão, as tensões de tração. A capacidade dos reforços estudados em conter a propagação desta fratura é que vai ditar o modo de fratura do espécime em resina. A fratura, uma vez gerada, ao se propagar no interior do espécime e encontrar o reforço em uma direção perpendicular, pode levar a uma falha na interface adesiva entre a fibras e a resina que pode ser estabilizada (Fratura Parcial) ou continuar até a fratura total do polímero, porém, sem fraturar a fibra, que permanecendo íntegra, mantêm as duas partes fraturadas da resina unidas (Fratura Total Não Separada). Se a adesão entre as fibras e a resina, entretanto, for maior que a resistência coesiva da fibra, isto pode levar a fratura completa da fibra (Fratura Total Separada). Esta resistência à propagação da fratura pode ser atribuída a uma real união química ou a retenção mecânica da fibra à resina, ou ainda, a ambos $20,26,32,33,34,69$.

Avaliando as fraturas dos espécimes encontramos que o grupo controle obteve $100 \%$ de fraturas do tipo Total Separada, evidenciando a incapacidade da resina PMMA, em um certo momento, dissipar as tensões induzidas sobre ela quando submetida à uma carga que tende a flexioná-la. Com relação aos grupos reforçados que efetivamente aumentaram a resistência flexional dos espécimes em resina, no entanto, a prevalência deste tipo de fratura foi de $0 \%$ quando se utilizou o fio $0,7 \mathrm{~mm}$ e a fibra de poli(etileno) Connect $^{\circledR}$, e $20 \%$ quando se utilizou a fibra de 
vidro Interlig ${ }^{\circledR}$. As fraturas parciais foram observadas em cerca de $34 \%$ dos espécimes reforçados que tiveram aumento relevante na resistência flexional, $20 \%$ para o fio $0,7 \mathrm{~mm}, 30 \%$ para a fibra Connect ${ }^{\circledR}$ e $50 \%$ para a fibra Interlig ${ }^{\circledR}$. As fraturas totais separadas somente estiveram presentes no grupo da fibra Interlig ${ }^{\circledR}$, com uma ocorrência de $20 \%$. Estes resultados estão de acordo com o estudo de SAMADZADEH $(1997)^{50}$, em que, submetendo próteses parciais fixas confeccionadas em PMMA reforçadas com uma fibra de poli(etileno) à uma carga axial não observou fraturas totais com separação da prótese em dois segmentos, ao contrário, as conexões permaneceram intactas e somente uma porção do pôntico foi perdida em função da falha coesiva do PMMA. Em condições clínicas, a ausência da fratura ou a fratura parcial azem parte, certamente, de um comportamento ideal esperado de uma prótese provisória, visto que fraturas do tipo total separada acarretam em um maior tempo clínico na confecção de novas restaurações ${ }^{7,50,62}$.

Estudos simulando próteses parciais fixas com extensões de vão variadas têm mostrado aumento da resistência à fratura destas próteses com a inclusão de fibras em seu interior ${ }^{62}$. NOHRSTRÖM; VALLITTU; YLrURPO $(2000)^{41}$, demonstraram ainda que a efetividade das fibras está associada com as condições mais críticas, como por exemplo, vãos mais longos, onde as tensões sob os pônticos e sobre os conectores são maiores. Nestes estudos, a força suportada por estas próteses reforçadas com fibras equivale às maiores cargas registradas nas regiões de molares, entre $600 \mathrm{~N}$ a $1200 \mathrm{~N}^{16,41,46,50,62}$.

Compreendemos que a resistência flexional somado a um valor suficiente de módulo de elasticidade é somente um dos muitos fatores que devem ser seguidos 
na escolha de um material ou técnica com a finalidade de se reabilitar espaços desdentados com próteses provisórias. HASELTON; DIAZ-ARNOLD; VARGAS $(2002)^{24}$ declaram que apesar dos valores das propriedades mecânicas serem obtidos em laboratórios sobre uma carga estática e, por isso, não refletirem as condições encontradas no meio oral, são úteis para comparar materiais e/ou técnicas testadas em uma situação controlada.

Outros trabalhos têm sido desenvolvidos com a proposta de se mostrar o quanto é benéfico o emprego de fibras, principalmente, baseadas em vidro ou poli(etileno), na resistência e rigidez, enfim, na longevidade de próteses confeccionadas em PMMA. GUTTERIDGE (1988) ${ }^{21}$, VALLITTU; VOJTKOVA; LASSILA (1995) ${ }^{71}$, VALLITTU; NARVA (1997) ${ }^{69}$, UZUN; HERSEK; TINÇER (1999) ${ }^{56}$ demonstraram aumento da resistência ao impacto de espécimes em PMMA reforçados por ambos os tipos de fibras. VALLITTU $(1997)^{61}$, STIPHO $(1998)^{53}$, POLYZOIS et al $(2001)^{45}$, NAGAI et al $(2001)^{40}$, por sua vez, mostraram a utilidade destas fibras no reparo de próteses em PMMA fraturadas. TANNER $(2001)^{55}$ provou que a adesão bacteriana nestas fibras acontece de forma semelhante à própria resina PMMA.

Toda esta demonstração do bom proveito das fibras de reforços à base de vidro e de poli(etileno) discutida no nosso trabalho, somada aos resultados favoráveis de nosso estudo, enfim, torna o uso destas fibras parte de uma técnica de reforçar próteses provisórias, para nós autores, bastante promissora e fadada ao sucesso clínico. 


\section{7 - CONCLUSÃO}

Segundo o método empregado e com base nos resultados obtidos nas condições laboratoriais deste estudo, podemos concluir que:

a) Sobre as propriedades mecânicas:

a.1) Com relação a resistência flexional, somente os espécimes reforçados com fio $0,7 \mathrm{~mm}$, com a fibra de vidro $\operatorname{Interlig}^{\circledR}$ e com a fibra de poli(etileno) Connect $^{\circledR}$ foram significantemente mais resistentes, com valores médios $72,09 \%, 47,88 \%$ e $38,07 \%$, respectivamente, acima dos encontrados com os espécimes não reforçados. Em ordem decrescente, os valores médios, em MPa, para cada grupo foram: FIO $0,7 \quad(153,44 \quad \mathrm{MPa}) ; \quad$ INTERLIG $(131,85) ;$ CONNECT $(123,11) ;$ GLASSPAN (106,14); SPLINT IT (105,82); FIBRANTE $(102,28)$; AMARRILHO $(96,07)$ e CONTROLE $(89,16)$.

a.2) No que diz respeito ao módulo de elasticidade, os espécimes reforçados com fio $0,7 \mathrm{~mm}$, com a fibra de vidro $\operatorname{Interlig}^{\circledR}$, com a fibra de vidro Splint It!, com a fibra de poli(etileno) Connect $^{\circledR}$ e com a fibra cerâmica flexível GlasSpan ${ }^{\circledR}$ foram significantemente mais rígidos , com valores médios $73,69 \% ; \quad 63,22 \% ; 34,34 \% ; 31,74 \%$ e $26,32 \%$, respectivamente, acima dos obtidos com os espécimes não reforçados. Em ordem decrescente, os valores médios, em MPa, para cada grupo 
foram: FIO 0,7 (3.317,76); INTERLIG (3.117,80); SPLINT IT $(2.566,24)$; CONNECT $(2.516,50)$ e GLASSPAN $(2.412,91)$.

b) Os espécimes apresentaram, de acordo com a nova classificação, fraturas dos tipos: Ausente, Parcial, Total Não Separada e Total Separada. Todos os espécimes não reforçados sofreram fraturas do tipo Total Separada, enquanto que os espécimes reforçados apresentaram, predominantemente, fraturas dos tipos Ausente e Parcial, com a ocorrência de $34,28 \%$ e $38,57 \%$ dos espécimes, respectivamente. 


\section{ODONTO USP - BAURÚ}

EESAIO: 00000063

NORMA: REIVANILDO

IDENTIFTCAÇÃO: FTO 07 ASPERO

CÉLULA DE CARGA: $100 \mathrm{kgf}$

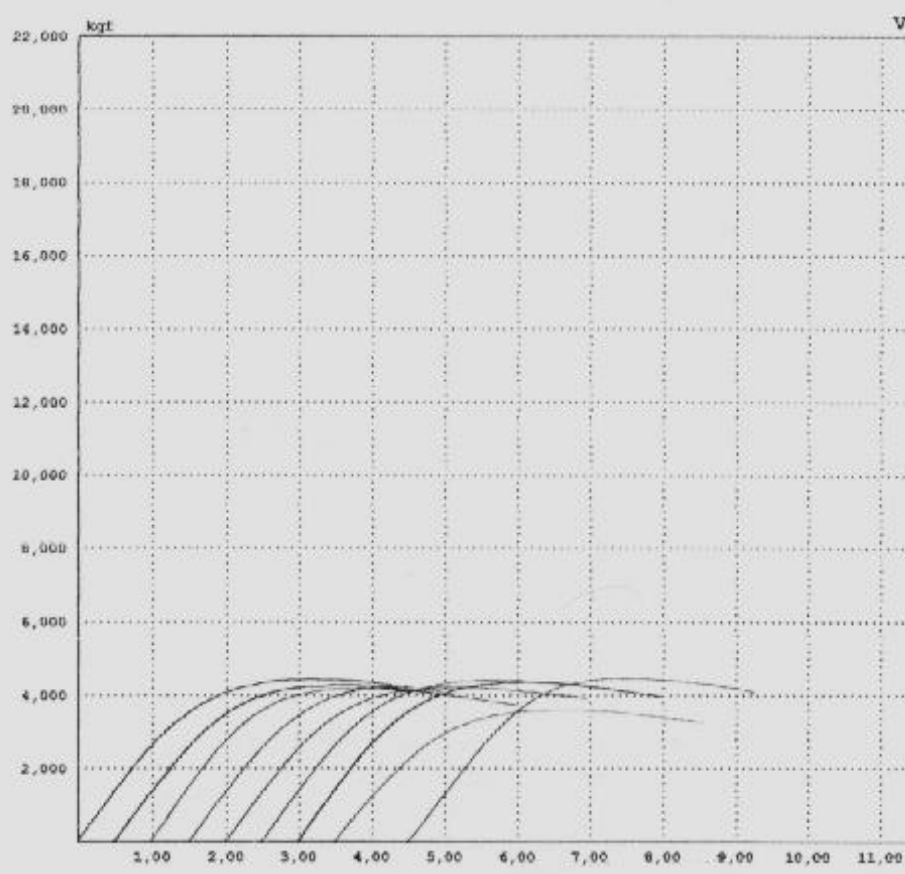

\section{$\triangleq \mathrm{KRATOS}$}

Equipamerkos Industriais Ltda

DATA: $18 / 10 / 2002$ HORA: $15: 02: 45$

ALTURA DO C.P.: 2,00 mm

OBSERVACุÃO:

VEL. DESLOC. : $1,00 \mathrm{~mm} / \mathrm{min}$

\begin{tabular}{|c|c|c|c|}
\hline$\frac{\operatorname{coses} 2 \pi}{\text { no. }}$ & $\begin{array}{l}\text { rakcin } \\
\text { redxina } \\
\text { kggt }\end{array}$ & 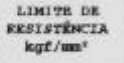 & 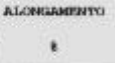 \\
\hline 물 & $-4,420$ & $-1,105$ & $26 \mathrm{ta}, 00$ \\
\hline $\mathbf{E}$ & 4,300 & $-1,025$ & 248 ; 50 \\
\hline 害 & $-6,210$ & $-1,053$ & $249,5 a$ \\
\hline E & $-6,190$ & $-1,048$ & 112,00 \\
\hline 물 & $-4,250$ & $-2,063$ & 207,30 \\
\hline 를 & $-1,440$ & -1.210 & 248,50 \\
\hline 国 & $-4,396$ & $-1,098$ & 249,50 \\
\hline E & -3.630 & -0.208 & 254.00 \\
\hline - & $-3,420$ & $=0,855$ & 248,00 \\
\hline 톨 & $-4,480$ & $-1,120$ & 239,00 \\
\hline Yhlor vosimo & $-3,120$ & $=0,855$ & 129,00 \\
\hline valor bescian & -4.480 & $-1,280$ & 254.00 \\
\hline$V_{\text {nalor }}$ tholio & $-4,173$ & -1.0 .43 & 235,15 \\
\hline Desvio Dodr ato & 0,959 & 0,090 & 40,96 \\
\hline
\end{tabular}

(mens6) 


\section{ODONTO USP - BAURÚ}

EESATO: 00000031

MOFEA: RETVANILDO

IOENTITICAÇĀO: TNTERLIG

CÉLULA DE CAPGA: $100 \mathrm{kgf}$

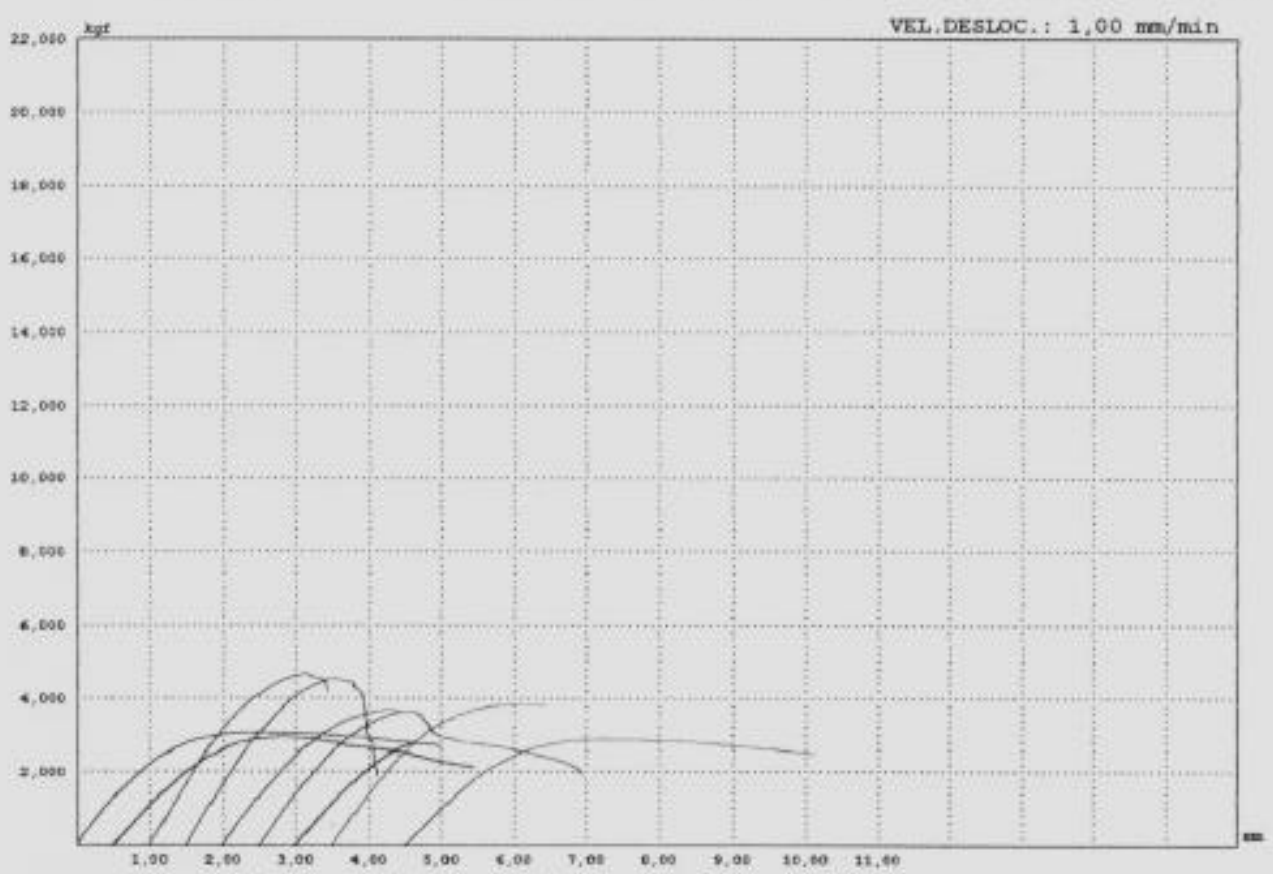

\section{DKRATOS}

Equamenks Industiais Lide

DATA: 20/09/2002 HORA: 14:56:37 ALTURA DO C.P.: 2,00 mm OBSEFVMÇÃO:

TRAB, REALYZADO: COEPRESSĂO

PRÉ CARGA (1a. Amost.) 1 $0,050 \mathrm{kgf}$ pré. CarGa (Demals Amost., $)=0,050 \mathrm{kgf}$ VEL,DESLOC : : 1,00 ma/min

\begin{tabular}{|c|c|c|c|}
\hline Nostak & $\begin{array}{l}\text { roves } \\
\text { wixinen } \\
\text { kgof }\end{array}$ & 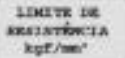 & Alawinewerto \\
\hline 로 & $-3,056$ & $-0,76$ & $2 x a, 00$ \\
\hline 묘 & $-2,260$ & $-0,26$ & 201,00 \\
\hline 물 & $\rightarrow, 710$ & $-1,170$ & anz,oe \\
\hline [ & $-4,500$ & $-1,145$ & 231,50 \\
\hline E & $-3,720$ & $-0,027$ & 230,50 \\
\hline E & $-3,0+0$ & $-0,915$ & 223,00 \\
\hline a & $-2,636$ & $-0,713$ & 63,00 \\
\hline E & -3.260 & -0.949 & 207,00 \\
\hline * & $-3,500$ & $-0,4 \times 3$ & 270,90 \\
\hline$E$ & $-2,610$ & $-0,7 z$ & 202,00 \\
\hline vatar mase & $-2,258$ & $-0,713$ & $\mathbf{n}, 00$ \\
\hline majar narisos & $\rightarrow, n e$ & $-1,17 t$ & $2 x=0 e$ \\
\hline vasar mosilis & -3.906 & $-0,-\infty n$ & 389. 10 \\
\hline pesvise radist: & $0.66 \%$ & 0.16 & 60.45 \\
\hline
\end{tabular}




\section{ODONTO USP - BAURÚ}

ENSATO: 00000057

NCHAM: REIVANIIDO



CÉLULA DE CARGA: $100 \mathrm{kgr}$



ㅌKRATOS

Equipanentos ind striais Lid

DATA: $11 / 10 / 2002$ BORA: $14: 29: 05$

ALTUEA DO C.P,: 2,00 m

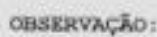

PRÉ CAraA (Demais Amost.) :0,050 kgf VEL.DESLOC, : 1,00 min/min

\begin{tabular}{|c|c|c|c|}
\hline nessus & $\begin{array}{l}\text { roses } \\
\text { nowion } \\
\text { sot }\end{array}$ & 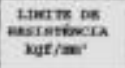 & ayconsoesmo \\
\hline E & $-3,400$ & $-0,754$ & $24 s, 50$ \\
\hline ㅁ & $-4,040$ & $-1,010$ & 264,50 \\
\hline E & -4.200 & -1.050 & 276,00 \\
\hline 国 & $-3,760$ & $-0,233$ & 265.00 \\
\hline ‥ & $-2,560$ & $-0,900$ & 260,00 \\
\hline $\mathbf{E}$ & $-3,930$ & $-0,859$ & 258.90 \\
\hline 봉 & $-2,930$ & -0, Tee & 248.50 \\
\hline 国 & $-2,740$ & $-0,645$ & 159,50 \\
\hline 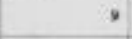 & -3.340 & $-0,035$ & 269,00 \\
\hline 틈 & -2.290 & $-4,960$ & 206,50 \\
\hline vator veasmo & $-2,270$ & $-6,568$ & 135,86 \\
\hline valor mariaso & $-4,200$ & $-1,020$ & 276,06 \\
\hline vilar Notio & $-3,34 t$ & $\rightarrow, 831$ & 246.90 \\
\hline pesvio valtas & 0,639 & $0,15 s$ & 15,34 \\
\hline
\end{tabular}

tmomet 
สรม10 กเหมด : 1233

10RMI : MBSIS TUELIONLL-LOLA

PIE CAHGL : $\quad 0.05 \mathrm{kgI}$

RLOLL DI CAYGA : $5 \mathrm{rgt}$

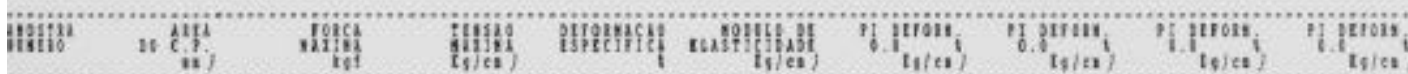

\begin{tabular}{|c|c|c|c|c|c|c|c|c|c|}
\hline 101 & 4.00 & 2.13. & 68.25 & 9.04 & $0.008+08$ & 0.00 & 0.00 & 0.10 & 1.00 \\
\hline 012 & 4.00 & 2.69 & 67.31 & 13.21 & $0.488+00$ & $0 . w$ & 0.00 & 0.00 & 0.00 \\
\hline 103 & 4.00 & $3.12^{t}$ & 78.00 & 9.36 & $0.001+08$ & 0.00 & 0.00 & 0.60 & 0.10 \\
\hline out & 4.00 & $2.83^{-17}$ & 70.81 & 12.21 & $0.00 \mathrm{E}+00$ & 0.61 & 0.00 & 0.00 & 0.00 \\
\hline WS & 4.00 & $3.0 B=$ & 71.00 & 11.68 & $0.008+00$ & 0.00 & 0.00 & 0.60 & 0.00 \\
\hline fal.Mioles & 4.00 & 2.69 & 67.31 & 9.04 & $0.003+00$ & 0.00 & 0.00 & 0.00 & 0.10 \\
\hline Val. Kaxieo & 4.00 & 3.12 & 38.00 & 13.20 & $0.018+00$ & 0.00 & 0.6 & 0.00 & 0.00 \\
\hline hil. Hedio & 4.00 & 2.89 & 12.28 & 11.10 & $0.008+00$ & 0.01 & 0.00 & 0.00 & 1.00 \\
\hline Des.Fadrac & 0.00 & 0.20 & 4.95 & $1, B 2$ & 0.00 & 0.00 & 0.00 & 0.00 & 0.00 \\
\hline
\end{tabular}

1 chab $\rightarrow 1 \mathrm{WA}=-5 \mathrm{kgf}$

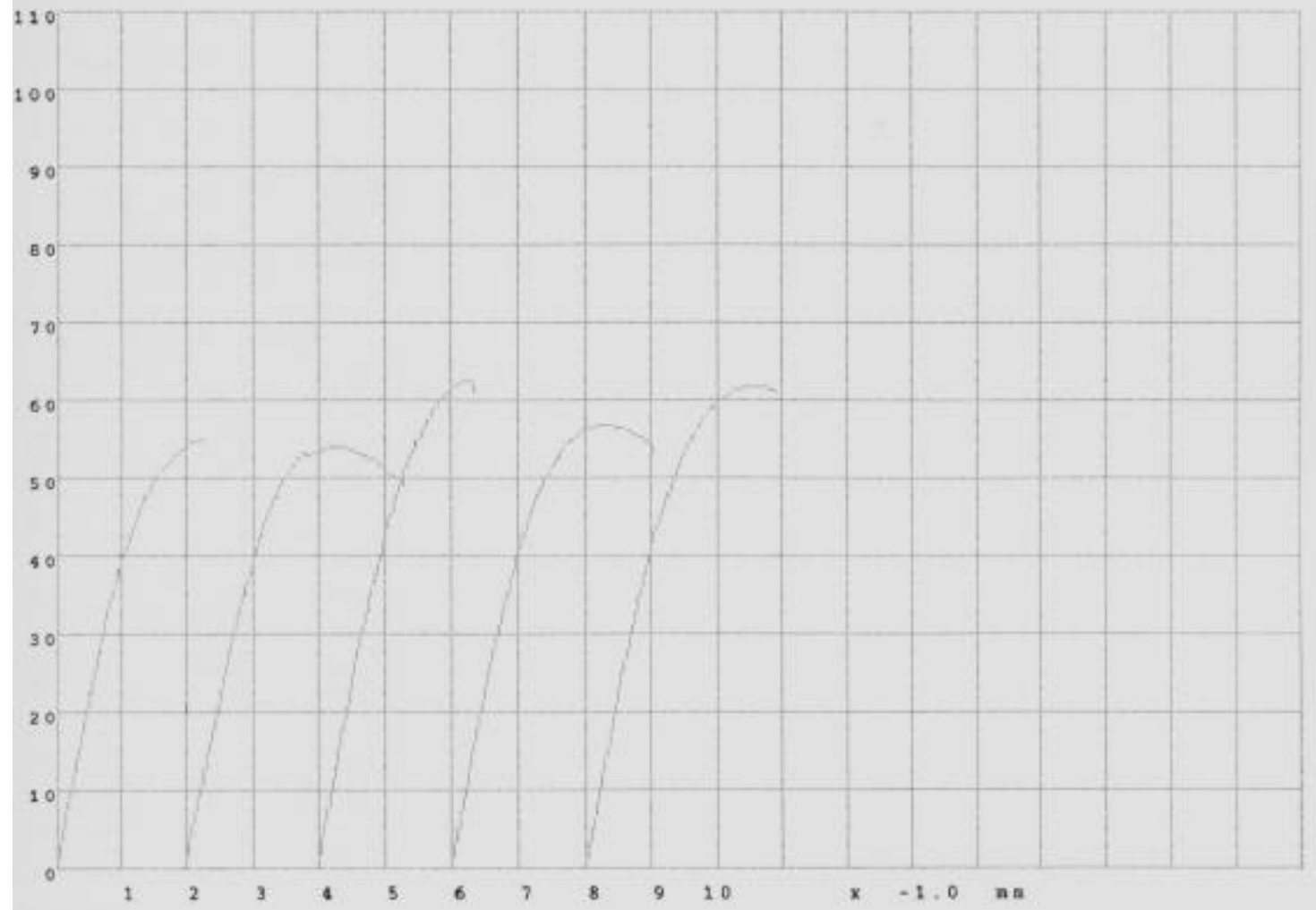

B271 : 05-10-01 HORA : 15:41:53

OBS:- $\quad$ IBSIKA ICILICB C/ SPLI?

RELOCTDADB IS EKSAIO : $\quad 1.1 \mathrm{~m} / \mathbf{v i t}$

COEPRIMEsTO UTL : 25.00 u

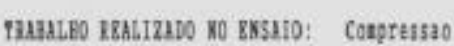




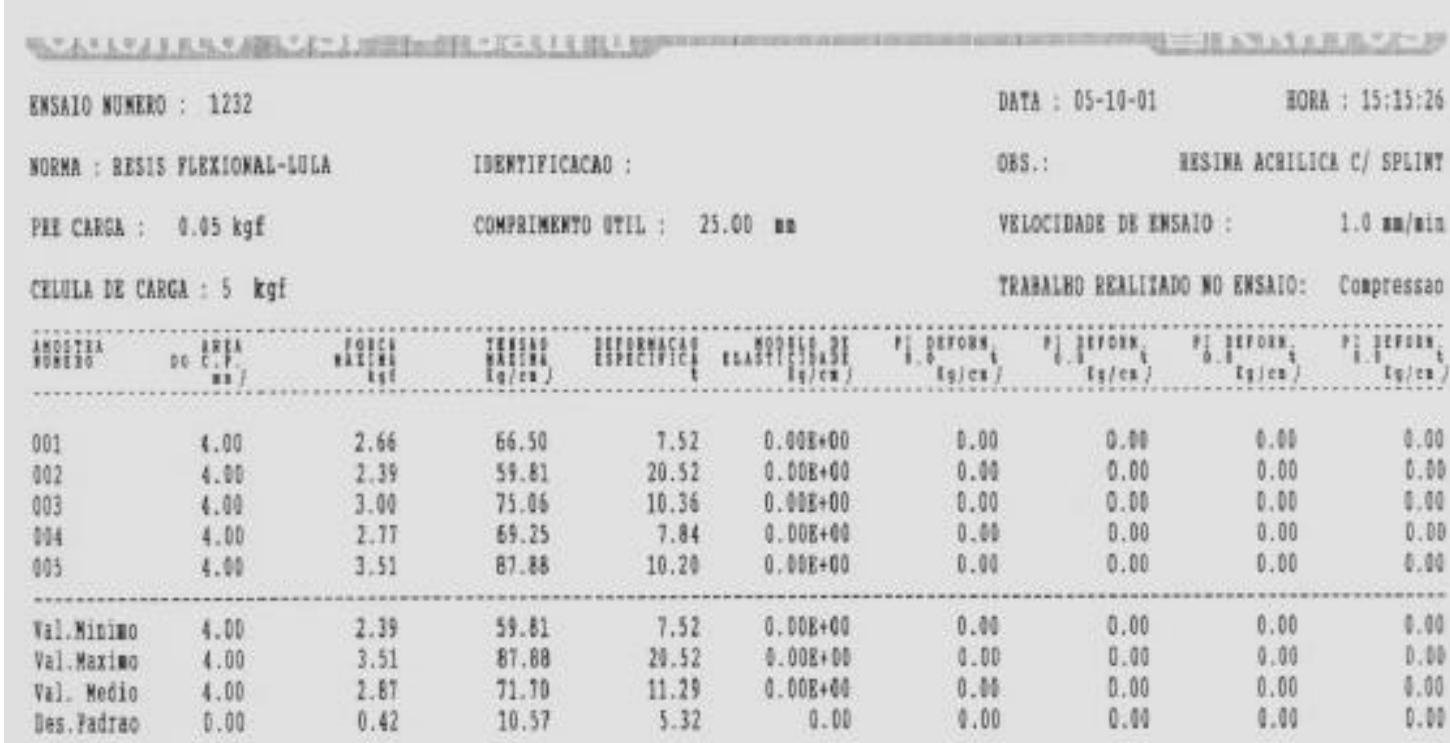

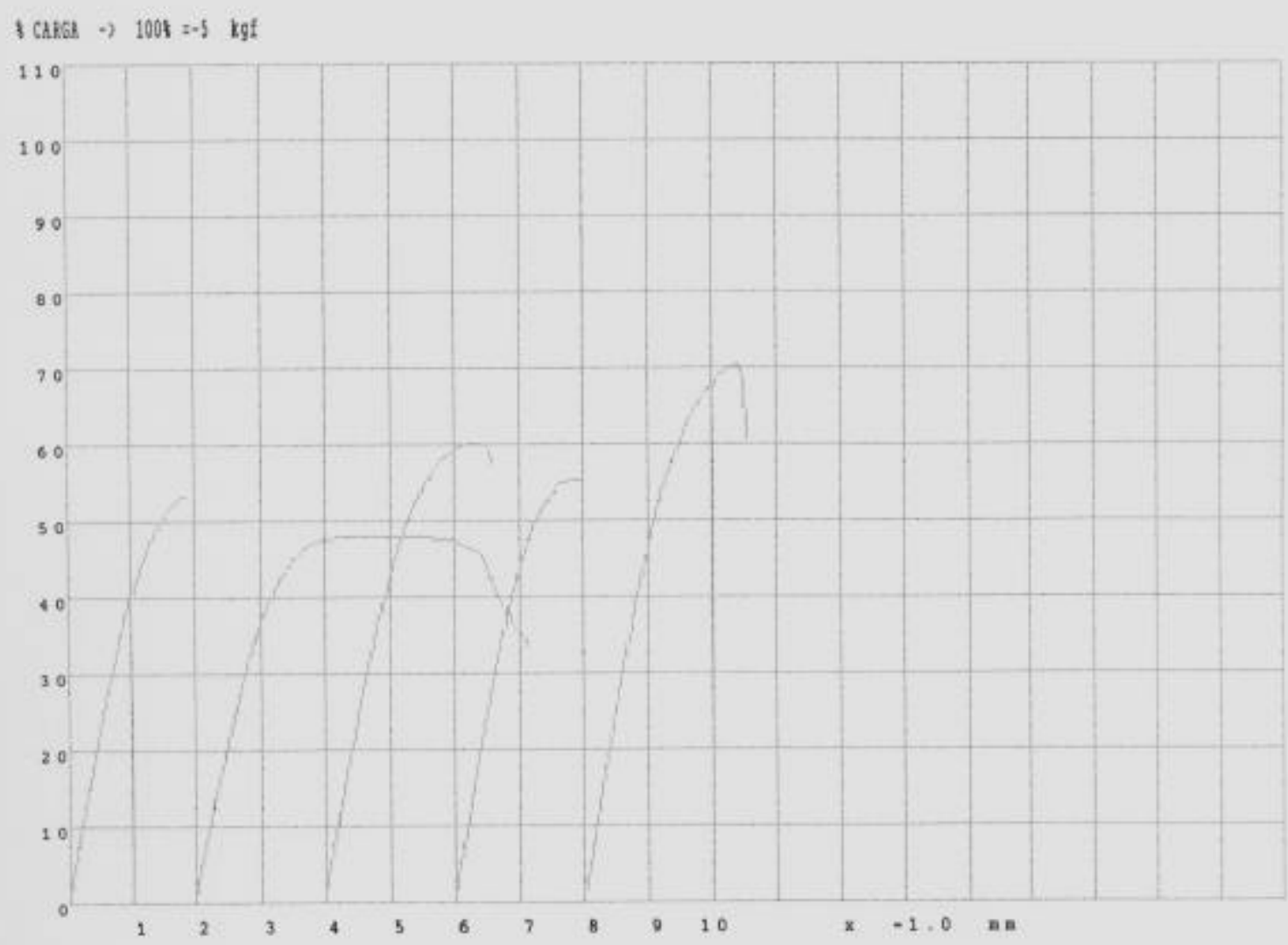




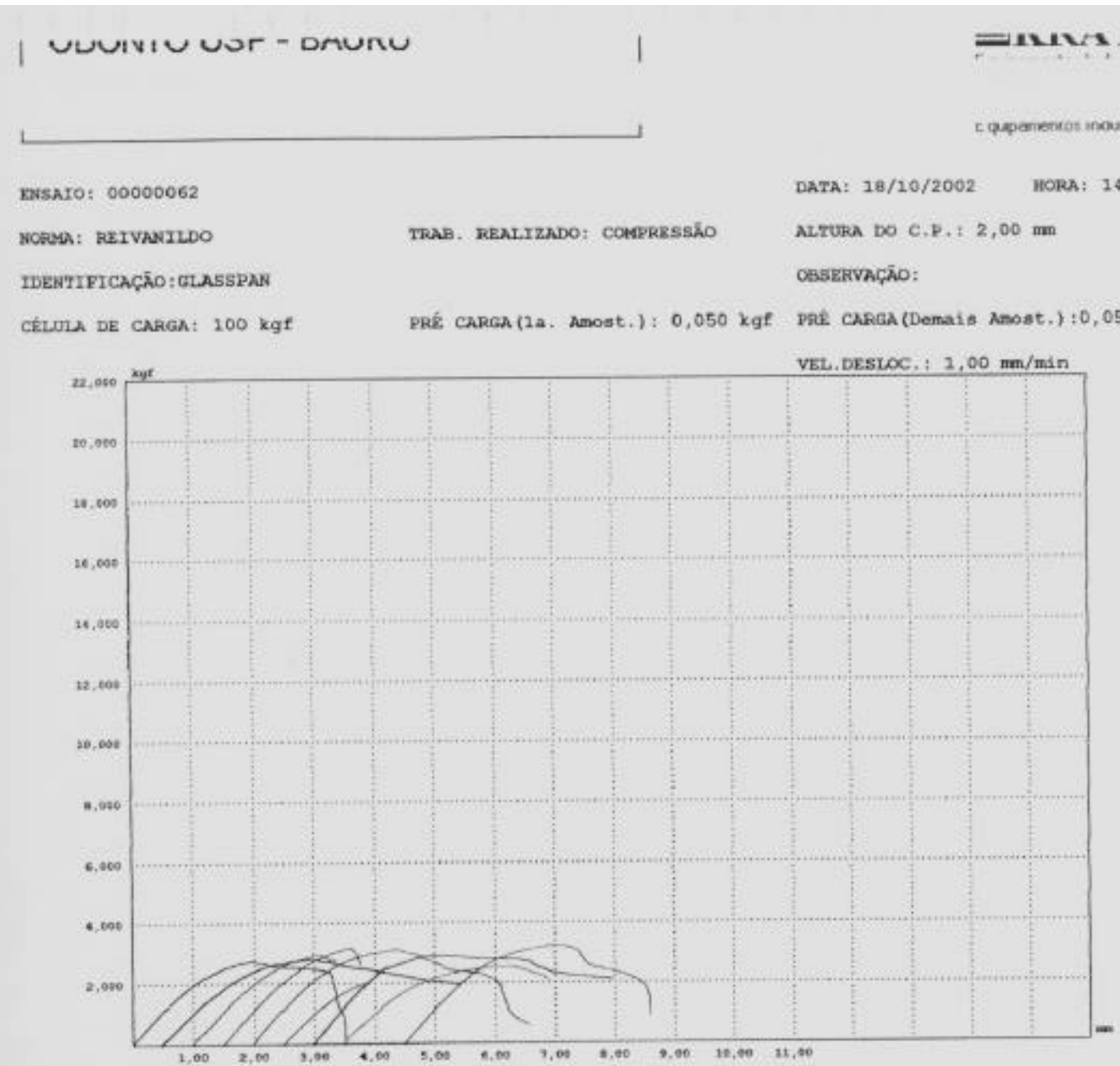

\begin{tabular}{|c|c|c|c|}
\hline mosen & $\begin{array}{l}\text { poars. } \\
\text { odixinen } \\
\text { kgte }\end{array}$ & 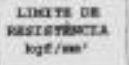 & Rtemwasto \\
\hline 톨 & -9.720 & $-0,6 e 0$ & 276,00 \\
\hline ㄹ & $-2,005$ & $-a, 700$ & 204,00 \\
\hline ㄹ & $-2,060$ & $-9,76$ & 146,50 \\
\hline E & $-3,500$ & $-4, \infty 00$ & 114,56 \\
\hline 뭄 & $-3,140$ & $-0,2 w$ & 280,00 \\
\hline ㅁ & $-2,030$ & $-0,564$ & 60,50 \\
\hline 무 & $-2,030$ & $-0,233$ & 243,50 \\
\hline 달 & $-2,585$ & -0.40 & $271, \infty 0$ \\
\hline ? & $-9,200$ & $-\infty, \infty 20$ & 106,50 \\
\hline E & $-3,296$ & $\rightarrow, E \pm 3$ & 200,50 \\
\hline rales varise & $-2,030$ & $-6,525$ & 00,06 \\
\hline vejar vertixo & $-3,3 \times 0$ & $-0,020$ & 200,00 \\
\hline value matio & $-2,057$ & $\rightarrow-382$ & 305,60 \\
\hline Deevis ratras & 0,365 & 0,596 & 63,67 \\
\hline
\end{tabular}




\section{ODONTO USP - BAURÚ}

Exsaro: 00000005

norak: Karog

IDENYIFICACAO : FIBWANYE

CĚLULA DE CARGA: $100 \mathrm{kgf}$

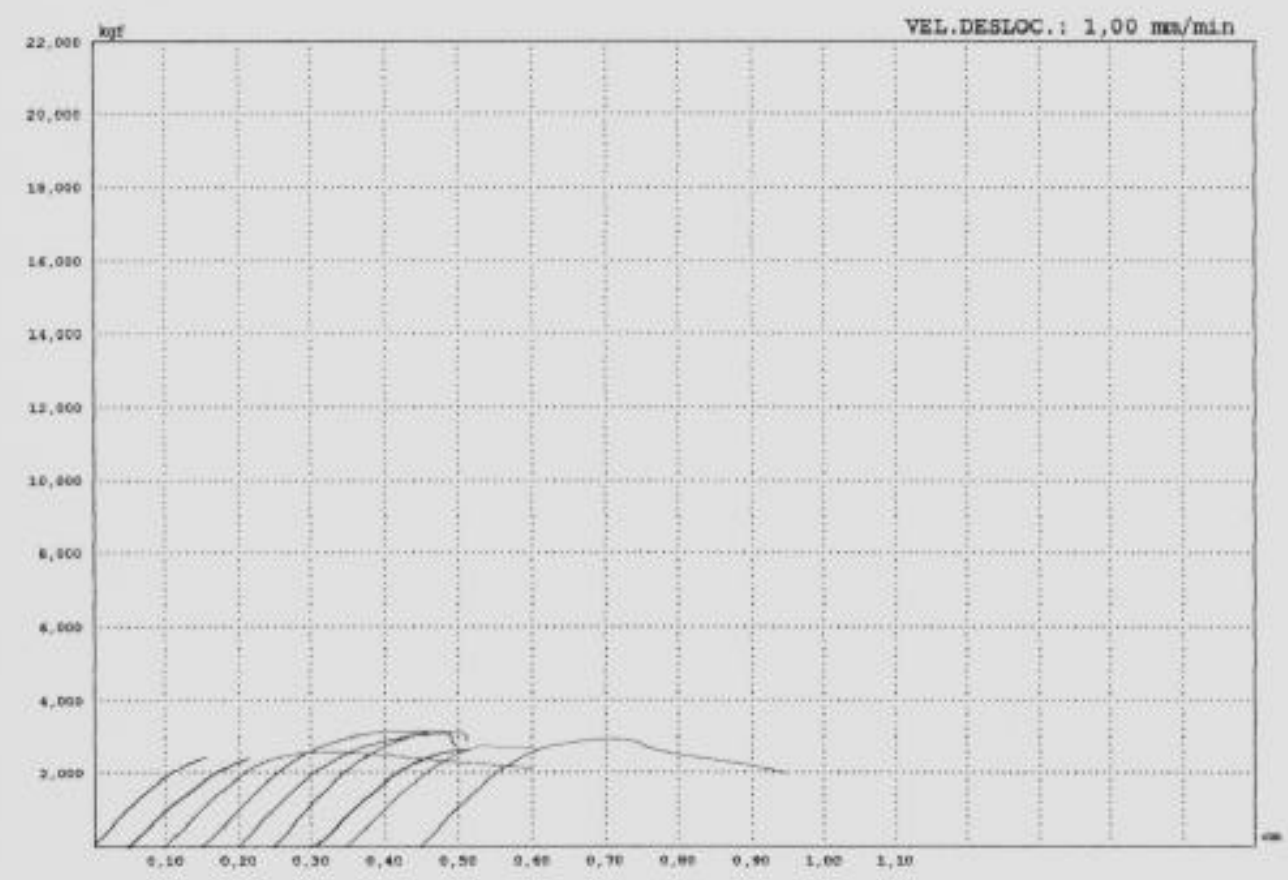

$\triangle \mathrm{KRATOS}$

Equpomertos Induatiais Lidh

DATA: $30 / 08 / 2002$ HOth: $16: 08: 53$

ALTURA DO C.P.: $0,20 \mathrm{~cm}$

OBSERVAÇ̄̄o:

TRAB, REALIZADO: COMPRESSĔO

PRE CARGA (2a. Mmost.) : $0,050 \mathrm{kgf}$ PRE CARGA (Demais Amost.) :0,050 kgf VEL.DESLOC, : $1,00 \mathrm{ma} / \mathrm{min}$

\begin{tabular}{|c|c|c|c|c|}
\hline Novessin & $\begin{array}{l}\text { moves. } \\
\text { outrine } \\
\text { kyt }\end{array}$ & 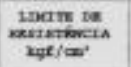 & arcwsueserso & nogen \\
\hline 㗐 & $-2,420$ & $-\infty, 500$ & $w .00$ & 0.06 \\
\hline D & $-2,420$ & $-61,500$ & $\$ 3,00$ & 4,90 \\
\hline 톨 & $-2,420$ & $-65,500$ & 251,00 & 4,00 \\
\hline E & $-3,100$ & $-73,500$ & 101,30 & 0,06 \\
\hline E & $-2,200$ & $-77,200$ & 151,00 & 8,90 \\
\hline $\mathbf{a}$ & $-3,240$ & $-70,500$ & 100,00 & 0,00 \\
\hline $\mathbf{z}$ & $-2,700$ & $-61,590$ & 107,20 & 0,00 \\
\hline 료 & $-2,010$ & $-70,250$ & 152,30 & 4,00 \\
\hline 0 & $-2,450$ & $-\infty 1,290$ & 30,50 & 5,80 \\
\hline 묘 & $-2,900$ & $-76,500$ & 249,80 & 0,80 \\
\hline valer suisos & $-2,420$ & $-e n, 5 a b$ & 10,50 & $0,000 \cdot 90$ \\
\hline Valoe marias & $-3,188$ & $-79,520$ & 251,04 & $0,025+60$ \\
\hline Walor mato & $-2,7 m 2$ & $\rightarrow 6,550$ & 210,52 & $0,008+50$ \\
\hline Dewio vatras & 0,204 & 3,636 & $\theta, 00$ & $0,000+80$ \\
\hline
\end{tabular}

(7xachs)

nqine:s 


\section{ODONTO USP - BAURÚ}

ENSAIO: 00000032

BORMA: RETVANILDO



CELULA DE CARGA: $100 \mathrm{~kg}$

22,200, knt

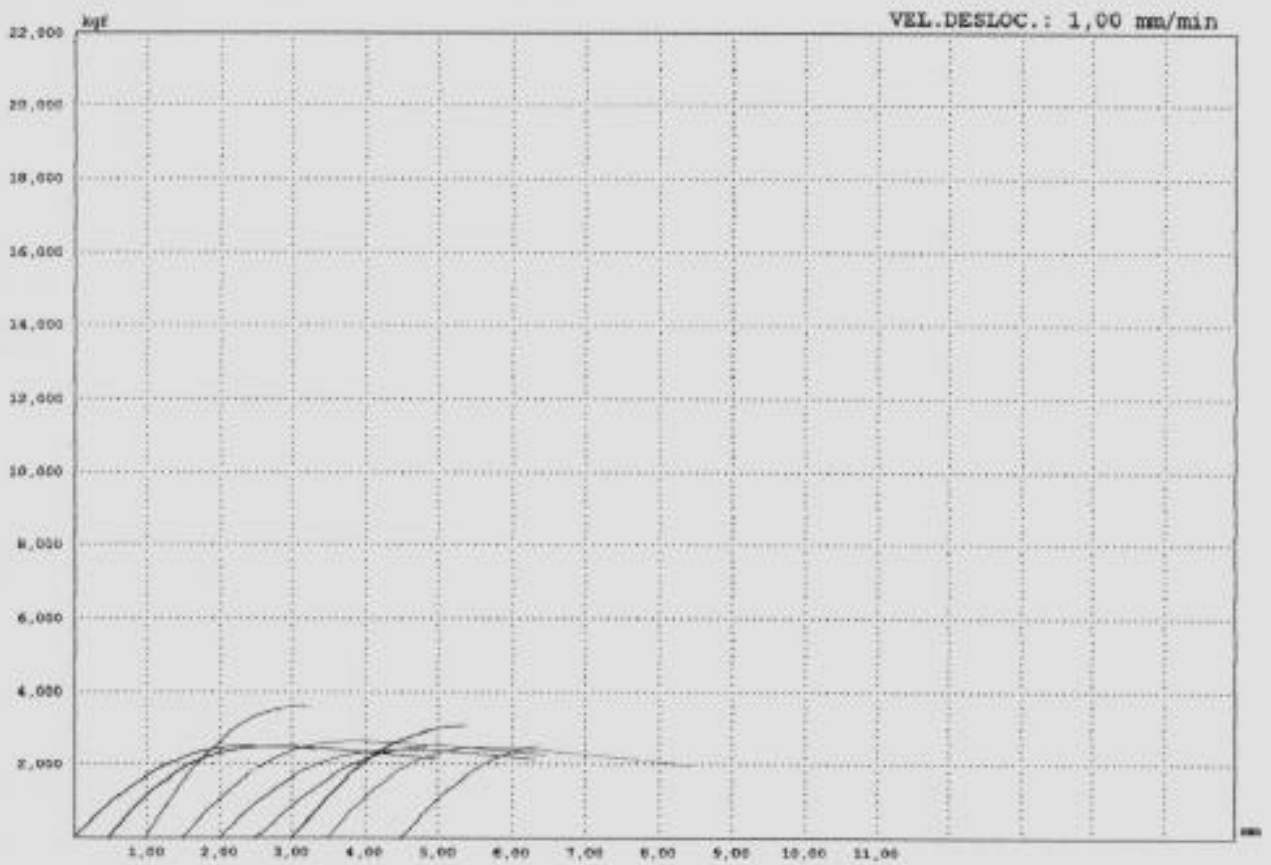

DKRATOS

Equpamerios industrisis Lida

DAZA: 20/09/2002 HONA: $15: 39: 49$

ALTURA DO C.P.: $2,00 \mathrm{~mm}$



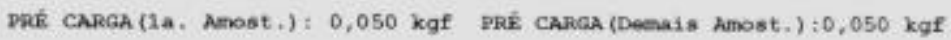
VEL.DESLOC.: $1,00 \mathrm{~mm} / \mathrm{min}$

\begin{tabular}{|c|c|c|c|}
\hline $\begin{array}{l}\sec 5 \operatorname{sen} \\
=\end{array}$ & $\begin{array}{l}\text { Foser } \\
\text { wixina } \\
\text { kgt }\end{array}$ & 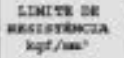 &  \\
\hline 표 & $-2,500$ & $-0,680$ & 240, s] \\
\hline E & $=2,836$ & $-6,63$ & 262,00 \\
\hline E & $-3,650$ & $-6,913$ & 133,00 \\
\hline 토 & $-2, \infty$ & $-6,670$ & $20.6,500$ \\
\hline 무 & $-2,406$ & $-6,40$ & $236, \infty 0$ \\
\hline 르 & $-9,516$ & $\rightarrow, 60$ & $13 k, \infty$ \\
\hline 를 & $-3,060$ & $-6,370$ & 149,50 \\
\hline E & $-2,420$ & $-4,60$ & $20 k, 50$ \\
\hline * & $-1,6.60$ & $\rightarrow, 413$ & $0, \infty$ \\
\hline E & $-2,550$ & $-4,698$ & ss, so \\
\hline Thior venino & $-1,650$ & $-4,013$ & 61,90 \\
\hline Thiot manes & $-3,65 \pi$ & $-4,813$ & 246,50 \\
\hline Yolor mate & $-8,613$ & $-4,453$ & 261,30 \\
\hline Denrio Padris & 0,560 & 0,128 & $\mathrm{w}, \mathrm{si}$ \\
\hline
\end{tabular}









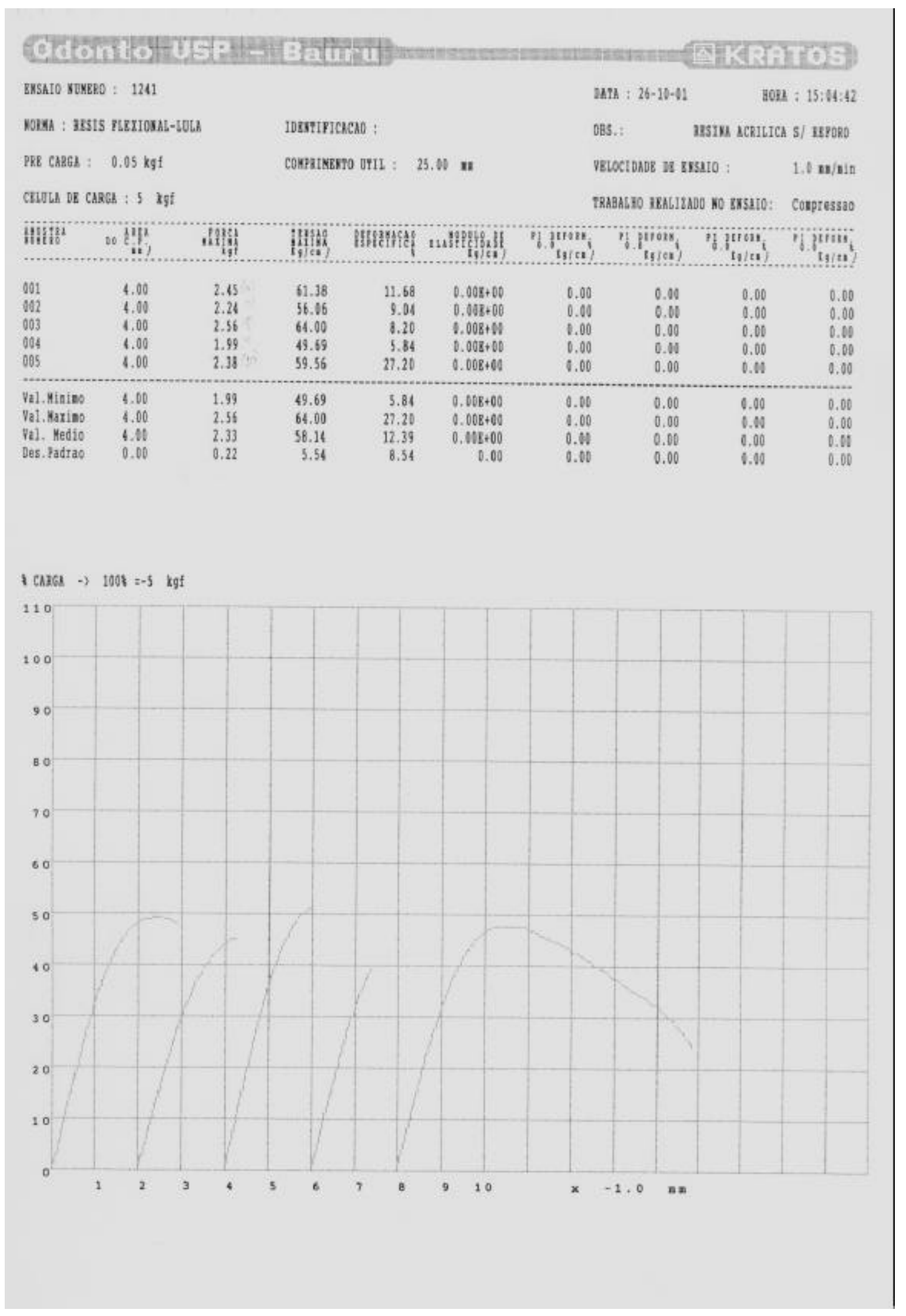




\section{REFERÊNCIAS BIBLIOGRÁFICAS*}

1. ALFREY JUNIOR, T.; SCHRENK, W.J. Multipolymer systems. Science, v.208, n.4446, p.813-18, May 1980.

2. ANDERSON, B.C.; BARTRON, L.R.; COLLETE, J.W. Trends in polymer development. Science, v.208, n.4446, p.807-12, May 1980.

3. ANUSAVICE, K.J. Propriedades mecânicas dos materiais dentários. In: Materiais Dentários - Phillips. 10.ed. São Paulo, Guanabara Koogan, 1999. p.28-43.

4. ANUSAVICE, K.J. Química das resinas sintéticas. In: Materiais

Dentários - Phillips. 10.ed. São Paulo, Guanabara Koogan, 1999. p.12539.

5. ANUSAVICE, K.J. Resina para base de dentaduras. Considerações técnicas e técnicas de processamento. In: Materiais Dentários -

Phillips. 10.ed. São Paulo, Guanabara Koogan, 1999. p.140-60.

\footnotetext{
* Normas recomendadas para uso no âmbito da Universidade de São Paulo, com base no documento "Referências Bibliográficas: exemplos", emanado do Conselho Supervisor do Sistema Integrado de Bibliotecas da USP, em reunião realizada em 20 de setembro de 1991.
} 
6. BEARDMORE, P. et al. Fiber-reinforced composites: engineered structural materials. Science, v.208, n.4446, p.833-40, May 1980.

7. BERRONG, J.M.; WEED, R.M.; YOUNG, J.M. Fracture resistance of Kevlarreinforced poly(methyl methacrylate) resin: a preliminary study. Int. J. Prosthodont., v.3, n.4, Apr. 1990.

8. BRADEN, M. et al. Denture base poly(methyl methacrylate) reinforced with ultra-high modulus polyethylene fibres. Brit. dent. J., v.164, n.20, p.10913, Feb. 1988.

9. CARROLL, C.E.; VON FRAUNHOFER, J.A. Wire reinforcement of acrylic resin prostheses. J. prosth. Dent., v.52, n.5, p.639-41, Nov. 1984

10.CAUL, H.J.; SCHOONOVER, I.C. A method for determining the extent of polymerization of acrylic resins and its applications for dentures. J. Amer. dent. Ass., v.39, n.1, p.1-9, July 1949.

11.CAUL, H.J.; STANFORD, J.W; SERIO, A.F. Properties of self-curing denture base resins. J. Amer. dent. Ass., v.44, n.3, p.295-8, Feb. 1949.

12. $\mathrm{CHOW}, \mathrm{T} . \mathrm{W}$. et al. Ultra-high-modulus polyethylene fibres in denture construction. In: VALLITTU, P.K. The first symposium on fibre reinforced plastics in dentistry. Turku, Finland, Aug. 1998. Symposium 
book of the European Prosthodontic Association (EPA), $22^{\text {nd }}$ Annual Conference, paper V, p.1-10.

13.DIXON, D.L.; BREEDING, L.C. The transverse strengths of three denture base resins reinforced with polyethylene fibers. J. prosthet. Dent., v.67, n.3, p.417-9, Mar. 1992.

14.DONOVAN, T.E.; HURST, R.G.; CAMPAGNI, W.V. Physical properties of acrylic polymerized by different techniques. J. prosthet. Dent., v.54, n.4, p.522-4, Oct. 1985.

15.EKSTRAND, K.; RUYTER, E.; WELLENDORF, H. Carbon/graphite fiber reinforced poly(methylmethacrylate): properties under dry and wet conditions. J. Biomed. Mater. Res., v. 21, n.9, p.1065-80, Sept. 1987.

16.EL-EBRASHI, M.K.; CRAIG, R.G; PEYTON, F.A. Experimental stress analysis of dental restorations. Part VII. Structural design and stress analysis of fixed partial dentures. J. prosthet. Dent., v.23, n.2, p.177-86, Feb. 1970.

17.GALINDO, D.; SOLTYS, J.L.; GRASER, G.N. Long-term reinforced fixed provisional restorations. J. prosthet. Dent., v.79, n.6, p.698-701, June 1998. 
18.GEGAUFF, A.G.; PRYOR, H.G. Fracture toughness of provisional resins for fixed prosthodontics. J. prosthet. Dent., v.58, n.1, p.23-9, July 1987.

19.GEGAUFF, A.G.; WILKERSON, J.J. Fracture toughness testing of visible light- and chemical-initiated provisional restoration resins. Int. J. Prosthodont., v.8, n.1, p.62-8, Jan. 1995.

20.GRANT, A.A.; GREENER, E.H. Whisker reinforcement of polymethyl methacrylate denture base resins. Aust. dent. J., v.12, n.2, p. 29-33, Feb. 1967.

21.GUTTERIDGE, D.L. The effect of including ultra-high-modulus polyethylene fibre on the impact strength of acrylic resin. Brit. dent. J., v.164, n.19, p.177-80, Mar. 1988.

22. HARMAN, I.M.; J. Effect of time and temperature on polymerization of a methacrylate resin denture base. J. Amer. dent. Ass., v.38, n.2, p.189203, Feb. 1949.

23. HARRISON, A.; HUGGETT, R.; HANDLEY, R.W. A correlation between abrasion resistance and other properties of some acrylic resins used in dentistry. J. Biomed. Mater. Res., v. 13, n.1, p. 23-34, Jan. 1979. 
24.HASELTON, D.R.; DIAZ-ARNOLD, A.M.; VARGAS, M.A. Flexural strength of provisional crown and fixed partial denture resins. J. prosthet. Dent., v.87, n.2, p.225-8, Feb. 2002.

25. HAZELTON, L.R. et al. Influence of reinforcement design on the loss of marginal fixed partial dentures. Int. J. Prosthodont., v.8, n.6, p.572-9, June 1995.

26. HENRY, P.J.; BISHOP, B.M.; PURT, R.M. Fiber-reinforced plastics for interim restorations. Quintessence dent. Technol. Yearbook. p.110-23. 1990/1991.

27.INTERNATIONAL ORGANIZATION FOR STANDARDIZATION. Dentistry polymer-based crown and bridge materials. no 10477: 1992/Amd.1. Geneve, Switzerland, 1998.

28. IRELAND, M.F. et al. In vitro mechanical property comparison of four resins used for fabrication of provisional fixed restorations. J. prosthet. Dent., v.80, n.2, p.158-62, Aug. 1998.

29.ISAAC, D.H. Engineering aspects of fibre reinforced composites. In: VALLITTU, P.K. The first symposium on fibre reinforced plastics in dentistry. Turku, Finland, Aug. 1998. Symposium book of the European Prosthodontic Association (EPA), $22^{\text {nd }}$ Annual Conference, paper I, p.1-22. 
30.JAGGER, D.C.; HARRISON, A.; JANDT, K.D. The reinforcement of dentures. J. oral Rehab., v.26, n.3, p.185-94, Mar. 1999.

31.KOUMJIAN, J.H.; NIMMO, A. Evaluation of fracture resistance of resins used for provisional restorations. J. prosthet. Dent., v.64, n.6, p.654-7, Dec. 1990.

32.LADIZESKY, N.H.; CHOW, T.W. The effect of interface adhesion, water immersion and anatomical notches on the mechanical properties of denture base resins reinforced with continuous high performance polyethylene fibres. Aust. dent. J., v.37, n.4, p.277-89, Apr. 1992.

33.LADIZESKY, N.H.; CHOW, T.W.; CHENG, Y.Y. Denture base reinforcement using woven polyethylene fiber. Int. J. Prosthodont., v.7, n.4, p.307-14, Mar. 1994.

34.LADIZESKY, N.H. et al. Acrylic resins reinforced with woven highly drawn linear polyethylene fibres. 3. Mechanical properties and further aspects of denture construction. Aust. dent. J., v.38, n.1, p.28-38, Jan. 1993.

35.LADIZESKY, N.H. et al. Acrylic resin reinforced with chopped high performance polyethylene fiber -properties and denture construction. Dent. Mat., v.9, n.3, p.128-35, Mar. 1993. 
36.LARSON, W.R. et al. The effect of carbon graphite fiber reinforced on the strength of provisional crown and fixed partial denture resins. J. prosthet. Dent., v.66, n.6, p.816-20, Dec. 1991.

37.McCRORIE, J.W.; ANDERSON, J.N. Transverse strength of repairs with selfcuring resins. Brit. dent. J., v.1, n.11, p.364-6, Nov. 1960.

38. MIETTINEN, V.M.; VALLITTU, P.K. Water sorption and solubility of glass fiber-reinforced denture polymethyl methacrylate resin. J. prosthet. Dent., v.76, n.5, p.531-4, May 1996.

39. MIETTINEN, V.M.; VALLITTU, P.K. Release of residual methyl methacrylate into water from glass fibre-poly(methyl methacrylate) composite used in dentures. Biomaterials, v.18, n.2, p.181-5, Feb. 1997.

40.NAGAI, E. et al. Repair of denture base resin using woven metal and glass fiber: effect of methylene chloride pretreatment. J. prosthet. Dent., v.85, n.5, p.496-500, Nov. 2001.

41.NOHRSTRÖM, T.J.; VALLITTU, P.K.; YLFURPO, A. The effect of placement and quantity of glass fibers on the fracture resistance on interim fixed partial dentures. Int. J. Prosthodont., v.13, n.1, p.72-8, Jan. 2000. 
42. OGAWA, T.; TANAKA, M., KOYANO, K. Effect of water temperature during polymerization on strength of autopolymerizing resin. J. prosthet. Dent., v.84, n.2, p.222-4, Aug. 2000.

43.OSMAN, Y.I.; OWEN, C.P. Flexural strength of provisional restorative materials. J. prosthet. Dent., v.70, n.1, p.94-6, July 1993.

44.PARANHOS, H.F.O. et al. Estudo da resistência à flexão de resinas acrílicas envelhecidas e reembasadas. Rev. Fac. Odont. Lins, v.5, n.2, p.19-27, jul./dez. 1992.

45.POLYZOIS, G.L. et al. Fracture force, deflection at fracture, and toughness of repaired denture resin subjected to microwave polymerization or reinforced with wire or glass fiber. J. prosthet. Dent., v.86, n.6, p.613-9, Dec. 2001.

46.POWELL et al. A comparison of wire- and Kevlar-reinforced provisional restorations. Int. J. Prosthodont., v.7, n.1, p.81-9, Jan. 1994.

47.RAMOS, V.; RUNYAN, D.A.; CHRISTENSEN, L.C. The effect of plasmatreated polyethylene fiber on the fracture strength of polymethyl methacrylate. J. prosthet. Dent., v.76, n.1, p.94-6, July 1996.

48.REDFARN. Tecnologia dos materiais plásticos. 2. ed. São Paulo, Polígono, 1962. p. 79-82. 
49.RUYTER, I.E. Methacrylate-based polymeric dental materials: conversion and related properties. Acta odont. scand., v.40, n.5, p.359-76, 1982.

50.SAMADZADEH, A. et al. Fracture strengths of provisional restorations reinforced with plasma-treated woven polyethylene fiber. J. prosthet. Dent., v.78, n.5, p.447-50, Nov. 1997.

51.STANFORD, J.W.; BURNS, C.L.; PAFFENBARGER, G.C. Self-curing resins for repairing dentures: some physical properties. J. Amer. dent. Ass, v.51, n.3, p.307-15, Sept. 1955.

52.STIPHO, H.D. Effect of glass fiber reinforcement on some mechanical properties of autopolymerizing polymethyl methacrylate. J. prosthet. Dent., v.79, n.5, p.580-4, May. 1998.

53.STIPHO, H.D. Repair of acrylic resin denture base reinforced with glass fiber. . J. prosthet. Dent., v.80, n.5, p.546-50, Nov. 1998.

54. TANER, B. et al. A study on impact and tensile strength of acrylic resin filled with short ultra-high molecular weight polyethylene fibers. J. oral Sci., v.41, n.1, p.15-8, Mar. 1999.

55.TANNER, J. Introduction to microbial adhesion to fiber-reinforced composites used in dentures. In: VALLITTU, P.K. The Second International 
Symposium on Fibre Reinforced Plastics in Dentistry. Nijmegen, Netherland. Oct. 2001, paper V, p.2-9.

56.UZUN, G.; HERSEK, N.; TINÇER, T. Effect of five woven fiber reinforcements on the impact and transverse strength of a denture base resin. $\mathbf{J}$. prosthet. Dent., v.81, n.5, p.616-20, May. 1999.

57.VALLITTU, P.K. Comparison of two different silane compounds used for improving adhesion between fibres and acrylic denture base material. $\mathbf{J}$. oral Rehabil., v.20, n.5, p.533-9, Sept. 1993.

58.VALLITTU, P.K. Acrylic resin-fiber composite - part II: the effect of polymerization shrinkage of polymethyl methacylate applied to fiber roving on transverse strength. J. prosthet. Dent., v.71, n.6, p.613-7, Jun. 1994.

59.VALLITTU, P.K. The effect of void space and polymerization time on transverse strength of acrylic-glass fibre composite. J. oral Rehabil., v.22, n.4, p.257-61, Apr. 1995.

60.VALLITTU, P.K. Ultra-high-modulus polyethylene ribbon as reinforcement for denture polymethyl methacrylate: a short communication. Dent. Mater., v.13, n.11, p.381-2, Nov. 1997. 
61.VALLITTU, P.K. Glass fiber reinforced in repaired acrylic resin removable dentures: preliminary results of a clinical study. Quintessence Int., v.28, n.1, p.39-44, Jan. 1997.

62.VALLITTU, P.K. The effect of glass fiber reinforcement on the fracture resistance of a provisional fixed partial denture. J. prosthet. Dent., v.79, n.2, p.125-30, Feb. 1998.

63. VALLITTU, P.K. Experience of the use of glass fibres with multiphase acrylic resin systems. Teoretical background and clinical examples. In: VALLITTU, P.K. The First Symposium on Fibre Reinforced Plastics in Dentistry. Turku, Finland, Aug. 1998. Symposium book of the European Prosthodontic Association (EPA), $22^{\text {nd }}$ Annual Conference, paper II, p.135.

64. VALLITTU, P.K. Strength and interfacial adhesion of FRC-tooth system. In: VALLITTU, P.K. The Second International Symposium on Fibre Reinforced Plastics in Dentistry. Nijmegen, Netherland. Oct. 2001, paper I, p.2-28.

65. VALLITTU, P.K. Some aspects of the tensile strength of unidirectional glass fibre-polymethyl methacrylate composite used in dentures. J. oral. Rehabil., v.25, n.2, p.100-5, Feb. 1998. 
66. VALLITTU, P.K. Flexural properties of acrylic resin polymers reinforced with unidirectional and woven glass fibers. J. prosthet. Dent., v.81, n.3, p.318-26, Mar. 1999.

67. VALLITTU, P.K.; LASSILA, V.P. Reinforcement of acrylic resin denture base material with metal or fibre strengtheners. J. oral Rehabil., v.19, p.225-30, 1992.

68.VALLITTU, P.K.; LASSILA, V.P.; LAPPALAINEN, R. Acrylic resin-fiber composite - part I: the effect of fiber concentration on fracture resistance. J. prosthet. Dent., v.71, n.6, p.607-12, Jun. 1994.

69. VALLITTU, P.K.; NARVA, K. Impact strength of a modified continuous glass fiber - Poly(methyl methacrylate). Int. J. Prosthodont, v.10, n.2, Feb. 1997.

70.VALLITTU, P.K.; RUYTER, I.E.; EKSTRAND, K. Effect of water storage on the flexural properties of eglass and silica fiber acrylic resin composite. Int. J. Prosthodont., v.11, n.4, Apr. 1998.

71.VALLITTU, P.K.; VOJTKOVA, H.; LASSILA, V.P. Impact strength of denture polymethyl methacrylate reinforced with continuous glass fibers or metal wire. Acta odont. scand., v.53, p.392-6,1995. 
72.WANG, R.L. et al. A comparison of resins for fabricating provisional fixed restorations. Int. j. Prosthodont., v.2, n.2, p.173-84, Feb. 1989.

73. YAZDANIE, N.; MAHOOD, M. Carbon fiber acrylic resin composite: an investigation of transverse strength. J. prosthet. Dent., v.54, n.4, p.543-7, Oct. 1985.

74.ZINNER, I.D.; TRACHTENBERG, D.I.; MILLER, R.D. Provisional restorations in fixed partial prosthodontics. Dent. Clin. N. Amer., v.33, n.3, July 1989. 


\section{ABSTRACT}

Provisional restorations are essential components of oral rehabilitation treatment. The strength and durability features are, however, critical when long-term treatment is needed. The aim of this work was to measure the flexural strength, the elastic modulus and the type of fracture of poly (methyl methacrylate) (PMMA) resin specimens when submitted to a three-point-bend test. Seven types of reinforcements constituted the experimental groups with ten specimens each: a $0.7 \mathrm{~mm}$ of diameter wire; an orthodontic braided wire; a braided fiberglass Interlig ${ }^{\circledR}\left(\right.$ Angelus $\left.^{\circledR}\right)$; an woven fiberglass Splint-It $!^{\circledR}$ (Jeneric-Pentron $\left.{ }^{\circledR}\right)$; a roving fiberglass Fibrante ${ }^{\circledR}$ (Angelus $\left.{ }^{\circledR}\right)$; a braided poly(ethylene) fiber Connect ${ }^{\circledR}\left(\right.$ Kerr $\left.^{\circledR}\right)$ and a flexible ceramic fiber GlasSpan ${ }^{\circledR}$ $\left(\right.$ GlasSpan $\left.^{\circledR}\right)$. The control group, also with ten samples, included not reinforced specimens. All specimens were made and test according to modified ISO specification Nb. 10477. The analysis of the results (ANOVA, $p<0.05$ ), for both properties, showed significant differences between groups. Tukey's test detected higher figures for groups reinforced with wire of $0.7 \mathrm{~mm}$ of diameter wire; Interlig ${ }^{\circledR}$ and Connect $^{\circledR}$ when flexural strength was concerned. Groups reinforced with a wire $0.7 \mathrm{~mm}$ of diameter; Interlig ${ }^{\circledR}$; Splint-It $!^{\circledR}$; Connect ${ }^{\circledR}$ and GlasSpan ${ }^{\circledR}$, increased the elastic modulus, when compared to the control group. The fractures analysis contributed with the elaboration of new index system dividing them in four types: Absent, Partial, Total Not Separated and Total Separated. It was observed that the reinforced specimens fractures were more favorable, occurring, predominantly, in the Absent and Partial types.

Keywords: acrylic resins, poly(methylmethacrylate), fiber reinforcement 